Aus der Abteilung Unfallchirurgie, Plastische und Wiederherstellungschirurgie

$$
\begin{gathered}
\text { (Prof. Dr. med. K. M. Stürmer) } \\
\text { im Zentrum Chirurgie }
\end{gathered}
$$

der Medizinischen Fakultät der Universität Göttingen

\title{
Kurzzeiteffekte von Estradiol, Raloxifen, Phytohormonen und Parathormon auf die metaphysäre Frakturheilung des manifest osteoporotischen Knochens der Ratte
}

\author{
INAUGURAL - DISSERTATION \\ zur Erlangung des Doktorgrades \\ der Medizinischen Fakultät der \\ Georg-August-Universität zu Göttingen
}

vorgelegt von

Florian Daub

aus

Witzenhausen

Göttingen 2010 
Dekan: Prof. Dr. med. C. Frömmel

I. Berichterstatterin: PD Dr. med. E.K. Stürmer

II. Berichterstatter: PD Dr. rer. nat. Thelen

Tag der mündlichen Prüfung: $\quad$ 16.06.2010 


\section{Inhaltsverzeichnis}

\begin{tabular}{ll|l}
\hline 1 & Einleitung & 1
\end{tabular}

1.1 Einleitung und Fragestellung . . . . . . . . . . . . . . . . . . . 1

1.2 Grundlagen . . . . . . . . . . . . . . . . . . . 2

1.2 .1 Knochen . . . . . . . . . . . . . . . . 2

1.2.1.1 Knochenaufbau . . . . . . . . . . . . . . 2

1.2.1.2 Zellen des Knochens . . . . . . . . . . . . . . . . . . 4

1.2.1.3 Knochenmatrix . . . . . . . . . . . . . 5

1.2.1.4 "Remodeling" und ,peak bone mass" . . . . . . . . . 5

1.2.1.5 Kalziumstoffwechsel . . . . . . . . . . . . . 6

1.2 .2 Frakturen . . . . . . . . . . . . . . . . 7

1.2.2.1 Definition . . . . . . . . . . . . . 7

1.2 .2 .2 Frakturheilung . . . . . . . . . . . . 7

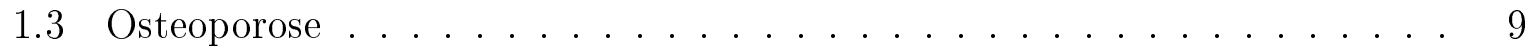

1.3 .1 Definition . . . . . . . . . . . . . . . 9

1.3 .2 Pathophysiologie der Osteoporose . . . . . . . . . . . . . . 10

$1.3 .3 \quad$ Epidemiologie und sozioökonomische Bedeutung . . . . . . . . . . . 12

1.3 .4 Einteilung . . . . . . . . . . . . . . . . . . . . . . 12

1.3.4.1 Primäre versus sekundäre Osteoporose . . . . . . . . . . . 13

1.3.4.2 High-turnover- versus Low-turnover-Osteoporose . . . . . 14

1.3.4.3 Generalisierte versus lokalisierte Osteoporose. . . . . . . . 14

1.3 .5 Risikofaktoren . . . . . . . . . . . . . . . . . 15

$1.3 .6 \quad$ Frakturen und Frakturheilung unter Osteoporose . . . . . . . . . 15

1.3 .7 Diagnostik $\ldots \ldots \ldots \ldots \ldots \ldots$

1.3.7.1 Anamnese ..................... 17

1.3.7.2 Klinische Untersuchung . . . . . . . . . . . . 17

1.3.7.3 Konventionelles Röntgen . . . . . . . . . . . . . . . 17

1.3.7.4 Osteodensitometrie . . . . . . . . . . . . . . . 18

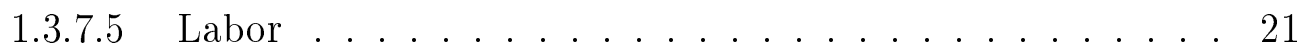

1.3 .8 Therapie . . . . . . . . . . . . . . . . . . . 22

1.3.8.1 Prävention und Basistherapie . . . . . . . . . . . 22

1.3.8.2 Spezifische medikamentöse Therapie . . . . . . . . . . 22

1.3.8.3 Hormonersatztherapie . . . . . . . . . . . . . . 23 
1.3.8.4 Selektive Östrogen-Rezeptor-Modulatoren . . . . . . . . 24

1.3.8.5 Bisphosphonate . . . . . . . . . . . . 25

1.3.8.6 Strontiumranelat . . . . . . . . . . . . . 26

1.3 .8 .7 Parathormon . . . . . . . . . . . . . 27

1.3.8.8 Phytoöstrogene . . . . . . . . . . . . . . 27

Cimicifuga racemosa . . . . . . . . . . . . 28

Equol. . . . . . . . . . . . . . . . 29

Genistein . . . . . . . . . . . . . . . 29

1.4 Die Ratte als Modelltier der postmenopausalen Osteoporose . . . . . . . . 30

2 Material und Methoden 31

2.1 Versuchsaufbau . . . . . . . . . . . . . . . . . . 31

2.2 Versuchstiere und Versuchstierhaltung $\ldots \ldots \ldots \ldots \ldots$. . . . . . . 32

2.3 Ovarektomie . . . . . . . . . . . . . . . . . . . . . 33

2.4 Osteotomie und Osteosynthese . . . . . . . . . . . . . . 33

2.5 Futter und Testsubstanzen . . . . . . . . . . . . . . . . . . 35

2.6 Obduktion . . . . . . . . . . . . . . . . . . . . 36

2.7 Röntgenbilder . . . . . . . . . . . . . . . . 36

2.8 Biomechanischer Test $\ldots \ldots \ldots \ldots \ldots \ldots$. . . . . . . . . . . . . . . . . . .

2.8 .1 Prinzip des biomechanischen Tests $\ldots \ldots \ldots$. . . . . . . 37

2.8 .2 Versuchsaufbau und -ablauf . . . . . . . . . . . . . . 37

2.8 .3 Auswertung des biomechanischen Tests . . . . . . . . . . . . . 39

2.8 .4 Messparameter . . . . . . . . . . . . . . . 40

2.8.4.1 Elastizität . . . . . . . . . . . . . . . . . 40

2.8 .4 .2 Streckgrenze . . . . . . . . . . . . . . 40

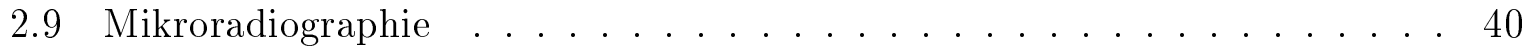

2.9.1 Histologische Aufarbeitung und Anfertigung der Mikroradiographien 40

2.9 .2 Auswertung der Mikroradiographien . . . . . . . . . . . . 41

2.9.3 Algorithmus zur digitalen morphometrischen Auswertung . . . . . . 41

2.9 .4 Messparameter . . . . . . . . . . . . . . . . 46

2.10 Polychrome Sequenzmarkierung . . . . . . . . . . . . . . 47

2.10 .1 Prinzip der Polychromen Sequenzmarkierung . . . . . . . . . . . 47

2.10 .2 Fluorochrome . . . . . . . . . . . . . . . . 47

2.10 .3 Auswertung der Polychromen Sequenzmarkierung . . . . . . . . . 48 
2.10 .4 Algorithmus zur digitalen morphometrischen Auswertung . . . . . . 48

2.10 .5 Messparameter . . . . . . . . . . . . . . 51

2.11 Benutzerspezifität und Reproduzierbarkeit der Messergebnisse . . . . . . . 52

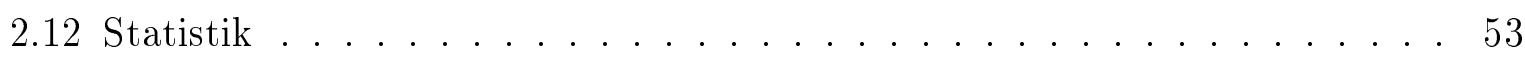

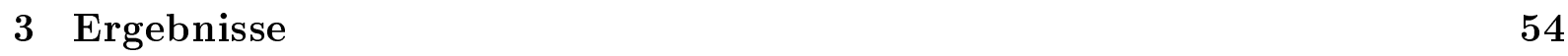

3.1 Körpergewicht . . . . . . . . . . . . . . . . 54

3.2 Röntgenbilder . . . . . . . . . . . . . . . . . . 54

3.3 Biomechanischer Test . . . . . . . . . . . . . . . . . . 56

3.3.1 Auswertung und Ergebnispräsentation des biomechanischen Tests . 56

3.3 .2 Elastizität . . . . . . . . . . . . . . . . . 57

$3.3 .3 \quad$ Streckgrenze . . . . . . . . . . . . . . . . . 58

3.4 Mikroradiographie $\ldots \ldots \ldots \ldots \ldots$

3.4.1 Auswertung und Ergebnispräsentation der Mikroradiographie. . . . 59

3.4 .2 Kortikalisdicke distal plattennah . . . . . . . . . . . . 62

3.4.3 Kortikalisdicke distal plattenfern . . . . . . . . . . . . . . 62

3.4.4 Knochendurchmesser proximal . . . . . . . . . . . . 63

3.4 .5 Knochendurchmesser distal . . . . . . . . . . . . . 63

$3.4 .6 \quad$ Kallusdicke plattennah . . . . . . . . . . . . . . 64

$3.4 .7 \quad$ Kallusdicke plattenfern . . . . . . . . . . . . . . . . 64

$3.4 .8 \quad$ Knochenflächendichte Kortikalis distal plattennah . . . . . . . . 65

3.4 .9 Knochenflächendichte Kortikalis distal plattenfern . . . . . . . . . 65

3.4.10 Knochenflächendichte Kallus plattennah . . . . . . . . . . 66

3.4.11 Knochenflächendichte Kallus plattenfern . . . . . . . . . . . 66

3.4 .12 Knochenflächendichte Kallus endostal . . . . . . . . . . . . . . 67

3.4.13 Knochenflächendichte Trabekel distal . . . . . . . . . . . . . 67

3.4.14 Anzahl Trabekelkreuzungen absolut . . . . . . . . . . . . . 68

3.4 .15 Dichte Trabekelkreuzungen . . . . . . . . . . . . . 68

3.4 .16 Mittlere Trabekeldicke . . . . . . . . . . . . . . . . 69

$3.5 \quad$ Polychrome Sequenzmarkierung . . . . . . . . . . . . . . . . 71

3.5.1 Auswertung und Ergebnispräsentation der Polychromen Sequenzmarkierung ......................... 71

3.5 .2 Gesamtfläche Kallus plattennah . . . . . . . . . . . . . . 73

3.5.3 CG-Fläche Kallus plattennah . . . . . . . . . . . . . . . 73 
$3.5 .4 \quad$ AK-Fläche Kallus plattennah . . . . . . . . . . . . . . . 74

3.5.5 TC-Fläche Kallus plattennah . . . . . . . . . . . . . 74

3.5.6 Gesamtfläche Kallus plattenfern . . . . . . . . . . . . . . . 75

3.5.7 CG-Fläche Kallus plattenfern . . . . . . . . . . . . . . 75

3.5.8 AK-Fläche Kallus plattenfern . . . . . . . . . . . . . . 76

$3.5 .9 \quad$ TC-Fläche Kallus plattenfern $\ldots \ldots \ldots$. . . . . . . . 76

3.5 .10 Gesamtfläche Kallus endostal . . . . . . . . . . . . . . . . 77

3.5.11 CG-Fläche Kallus endostal . . . . . . . . . . . . . . . . . 77

3.5 .12 AK-Fläche Kallus endostal . . . . . . . . . . . . . . . 78

3.5 .13 TC-Fläche Kallus endostal . . . . . . . . . . . . . . . . . 78

3.5.14 Additivkallus . . . . . . . . . . . . . . . . 79

3.6 Zusammenfassung der Ergebnisse $\ldots \ldots \ldots$. . . . . . . . . . 81

$\begin{array}{lll}4 & \text { Diskussion } & 82\end{array}$

4.1 Metaphysäres Frakturmodell . . . . . . . . . . . . . . . . . . . . . . . 82

4.2 Analyse der Ergebnisse . . . . . . . . . . . . . . . . . 83

$4.2 .1 \quad$ Estradiol . . . . . . . . . . . . . . . . . . 83

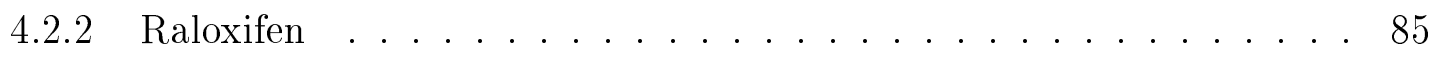

4.2 .3 Cimicifuga racemosa $\ldots \ldots \ldots \ldots$. . . . . . . . . 86

4.2 .4 Equol $\ldots \ldots \ldots \ldots \ldots \ldots$

$4.2 .5 \quad$ Genistein $\ldots \ldots \ldots \ldots \ldots$. . . . . . . . . . . . . . . 88

4.2 .6 Parathormon . . . . . . . . . . . . . . . . . . . 89

4.3 Schlussfolgerung . . . . . . . . . . . . . . . . . . . . . 92

$\begin{array}{lll}5 & \text { Zusammenfassung } & 94\end{array}$

\begin{tabular}{lll}
\hline 6 & Literaturverzeichnis & 95
\end{tabular} 


\section{Tabellenverzeichnis}

$1 \quad$ Stadieneinteilung der Osteoporose $\ldots \ldots \ldots$. . . . . . . . . . 10

2 Mögliche Ursachen sekundärer Osteoporose . . . . . . . . . . . . . . . . . 13

3 Zusammenstellung wichtiger Risikofaktoren der Osteoporose . . . . . . . 15

$4 \quad$ Empfehlung für die Durchführung einer Basisdiagnostik . . . . . . . . . . 16

5 Empfohlene Basislaborparameter . . . . . . . . . . . . . . 21

$6 \quad$ T-Werte in Abhängigkeit von Lebensalter und Geschlecht, die im Mittel mit einem 30 prozentigen Frakturrisiko für Wirbelkörper- und proximale

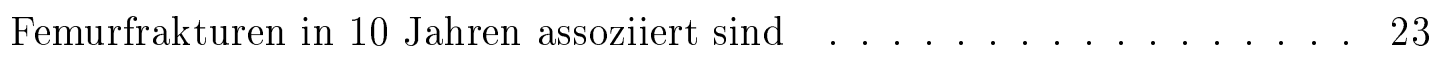

7 Testgruppen und Substanzen mit Abkürzungen . . . . . . . . . . . . 32

$8 \quad$ Gruppenzuordnung der Tiere $\ldots \ldots \ldots$. . . . . . . . . . . 32

$9 \quad$ Wirkstoffkonzentration im Futter . . . . . . . . . . . . . . . . . 35

$10 \quad$ Futter- und Wirkstoffaufnahme . . . . . . . . . . . . . . . . 36

11 Messparameter der mikroradiographischen Auswertung mit Berechnungsgrundlage . . . . . . . . . . . . . . . . . . 4 46

12 Dosierung, Applikationstag, Markierungszeitraum und Farbe in Blaufluoreszenz der verwendeten Fluorochrome . . . . . . . . . . . . . . . . . . . . 48

13 Messparameter der Fluoreszenz-mikroskopischen Untersuchung . . . . . . . 52

14 Entwicklung des durchschnittlichen Körpergewichts in den einzelnen Test-

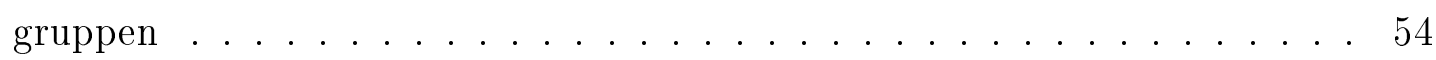

15 Ergebnisse des biomechanischen Tests . . . . . . . . . . . . . . . 59

$16 \quad$ Ergebnisse der mikroradiographischen Auswertung. . . . . . . . . . . . 70

17 Ergebnisse der Polychromen Sequenzmarkierung (plattennaher Kallus) . . 79

18 Ergebnisse der Polychromen Sequenzmarkierung (plattenferner Kallus) . . 80

19 Ergebnisse der Polychromen Sequenzmarkierung (endostaler Kallus) . . . . 80

$20 \quad$ Ergebnisse der Polychromen Sequenzmarkierung (Additivkallus) . . . . . . 80

21 Zusammenfassung der Ergebnisse $\ldots \ldots \ldots \ldots$. . . . . . . . . 81 


\section{Abbildungsverzeichnis}

$1 \quad$ Gesunder Knochen vs. osteoporotischer Knochen . . . . . . . . . . . . . . . 11

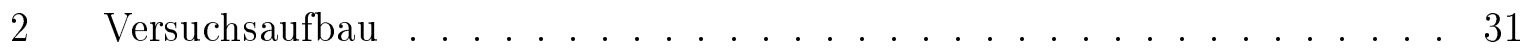

3 Osteotomie und Osteosynthese . . . . . . . . . . . . . . . . 34

$4 \quad$ Lagerung der Tibia im Gipsbett zur biomechanischen Prüfung . . . . . . . 38

5 Eingebettete Tibia in der Werkstoffprüfmaschine . . . . . . . . . . . . 38

$6 \quad$ Typisches Kraft-Weg-Diagramm . . . . . . . . . . . . . . . . . . . . 39

$7 \quad$ Mikroradiographisches Bild mit Kennzeichnung der anatomischen Ausrich-

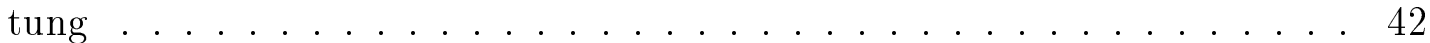

$8 \quad$ Auswertung der Mikroradiographien: Graudetektion . . . . . . . . . . . . . 42

$9 \quad$ Auswertung der Mikroradiographien: Flächendefinition . . . . . . . . . . . 44

$10 \quad$ Auswertung der Mikroradiographien: Vektoren . . . . . . . . . . . . . . 45

11 Fluoreszenz-mikroskopisches Bild mit Kennzeichnung der anatomischen Aus-

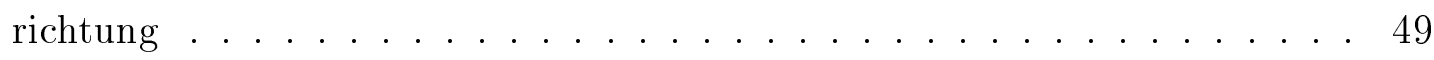

12 Fluoreszenz-mikroskopisches Bild mit Kennzeichnung der anatomischen Flächenzuordung und der Farb-Fluorochrom-Zuordnung . . . . . . . . . . . . 51

13 Röntgenbild einer Tibia mit Osteosynthesematerial . . . . . . . . . . . . 55

14 Röntgenbild einer Tibia nach Entfernung des Osteosynthesematerials . . . 56

15 Messergebnisse für den Parameter 'Elastizität' . . . . . . . . . . . . . 57

16 Messergebnisse für den Parameter 'Elastizität in Bezug auf das Körperge-

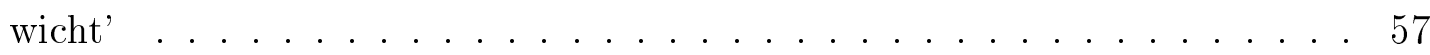

17 Messergebnisse für den Parameter 'Streckgrenze $\ldots . . . . . .58$

18 Messergebnisse für den Parameter 'Streckgrenze in Bezug auf das Körpergewicht $\ldots \ldots \ldots \ldots \ldots \ldots \ldots$. . . . . . . . . . . . . . . . . . . . . . .

19 Repräsentative mikroradiographische Bilder der Testgruppen C, E2, R und

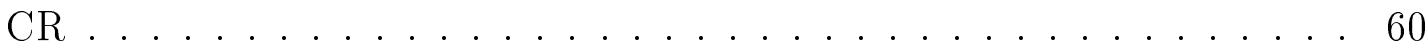

20 Repräsentative mikroradiographische Bilder der Testgruppen EQ, GEN und $\mathrm{PTH} \ldots \ldots \ldots \ldots \ldots \ldots$. . . . . . . . . . . . . . . . . . .

$21 \quad$ Messergebnisse für den Parameter 'Kortikalisdicke distal plattennah' . . . . 62

22 Messergebnisse für den Parameter 'Kortikalisdicke distal plattenfern']. . . . 62

$23 \quad$ Messergebnisse für den Parameter 'Knochendurchmesser proximal' . . . . . 63

24 Messergebnisse für den Parameter 'Knochendurchmesser distal' . . . . . . . 63

25 Messergebnisse für den Parameter 'Kallusdicke plattennah' . . . . . . . . . 64

26 Messergebnisse für den Parameter 'Kallusdicke plattenfern' . . . . . . . . . 64 
27 Messergebnisse für den Parameter 'Knochenflächendichte Kortikalis distal plattennah $\ldots \ldots \ldots \ldots \ldots \ldots \ldots \ldots$. . . . . . . . . . . . . . . . . .

28 Messergebnisse für den Parameter 'Knochenflächendichte Kortikalis distal

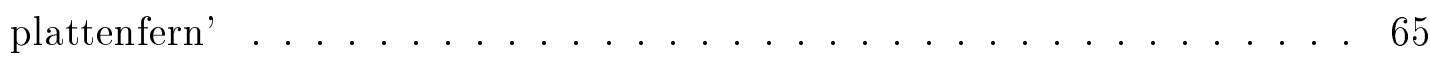

29 Messergebnisse für den Parameter 'Knochenflächendichte Kallus plattennah' 66

$30 \quad$ Messergebnisse für den Parameter 'Knochenflächendichte Kallus plattenfern' 66

31 Messergebnisse für den Parameter 'Knochenflächendichte Kallus endostal'] 67

32 Messergebnisse für den Parameter 'Knochenflächendichte Trabekel distal' . 67

33 Messergebnisse für den Parameter 'Anzahl Trabekelkreuzungen absolut' . . 68

34 Messergebnisse für den Parameter 'Dichte Trabekelkreuzungen' . . . . . . . 68

35 Messergebnisse für den Parameter 'Mittlere Trabekeldicke' . . . . . . . . . 69

36 Repräsentative Fluoreszenz-mikroskopische Bilder der Testgruppen C, E2,

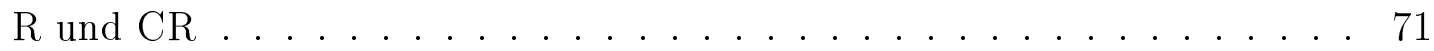

37 Repräsentative Fluoreszenz-mikroskopische Bilder der Testgruppen EQ, GEN und PTH . . . . . . . . . . . . . . . . . . 72

38 Messergebnisse für den Parameter 'Gesamtfläche Kallus plattennah' . . . . 73

39 Messergebnisse für den Parameter 'CG-Fläche Kallus plattennah' . . . . . 73

$40 \quad$ Messergebnisse für den Parameter 'AK-Fläche Kallus plattennah' . . . . . 74

41 Messergebnisse für den Parameter 'TC-Fläche Kallus plattennah' . . . . . 74

42 Messergebnisse für den Parameter 'Gesamtfläche Kallus plattenfern'] . . . . 75

$43 \quad$ Messergebnisse für den Parameter 'CG-Fläche Kallus plattenfern' . . . . . 75

44 Messergebnisse für den Parameter 'AK-Fläche Kallus plattenfern' . . . . . 76

45 Messergebnisse für den Parameter 'TC-Fläche Kallus plattenfern' . . . . . 76

$46 \quad$ Messergebnisse für den Parameter 'Gesamtfläche Kallus endostal' $\ldots$. . . . 77

47 Messergebnisse für den Parameter 'CG-Fläche Kallus endostal' . . . . . . . 77

48 Messergebnisse für den Parameter 'AK-Fläche Kallus endostal' . . . . . . . 78

49 Messergebnisse für den Parameter 'TC-Fläche Kallus endostal' . . . . . . . 78

$50 \quad$ Messergebnisse für den Parameter 'Additivkallus' $\ldots$. . . . . . . . . . . . 79 


\section{Abkürzungsverzeichnis}

$\% \quad$ Prozent

Grad

Abb. Abbildung

AK Alizarinkomplexon

AZ Aktenzeichen

BMC bone mineral content / Knochenmineralgehalt

BMD bone mineral density / Knochenmineraldichte

BMI Body Mass Index

BUA broadband ultrasound and attenuation / Breitband-Ultraschall-Abschwächung

bzw. beziehungsweise

C Kontrollgruppe

${ }^{\circ} \mathrm{C} \quad$ Grad Celsius

ca. circa

CG Calcein-Grün

$\mathrm{Cl}$ Chlor

cm Zentimeter

$\mathrm{cm}^{2} \quad$ Quadratzentimeter

$\mathrm{cm}^{3} \quad$ Kubikzentimeter

$\mathrm{CO}_{2} \quad$ Kohlendioxid

CR Cimicifuga racemosa

CT Computertomographie

d Tag

dB Dezibel

DVO Dachverband Osteologie

DXA Dual-X-Ray-Absorptiometrie

E2 Estradiol

EL Elastizität

en endostal

engl. englisch

EQ Equol

ER estrogen receptor / Östrogenrezeptor

$\mathrm{ER} \alpha \quad$ estrogen receptor alpha / Östrogenrezeptor alpha

$\operatorname{ER} \beta \quad$ estrogen receptor beta / Östrogenrezeptor beta

et al. et alii

Fa. Firma

FDA Food and Drug Administration 


\begin{tabular}{|c|c|}
\hline g & Gramm \\
\hline$\gamma-\mathrm{GT}$ & Gamma-Glutamyl-Transferase \\
\hline GEN & Genistein \\
\hline $\mathrm{GHz}$ & Gigahertz \\
\hline $\mathrm{h}$ & Stunde \\
\hline $\mathrm{H}$ & Wasserstoff \\
\hline HRT & hormone replacement therapy / Hormonersatztherapie \\
\hline IL & Interleukin \\
\hline ISCD & International Society for Clinical Densitometry \\
\hline $\mathrm{K}$ & Kelvin \\
\hline Kfd & Knochenflächendichte \\
\hline $\mathrm{kg}$ & Kilogramm \\
\hline KG & Körpergewicht \\
\hline $\mathrm{kV}$ & Kilovolt \\
\hline LWS & Lendenwirbelsäule \\
\hline $\mathrm{m}$ & Meter \\
\hline $\mathrm{mA}$ & Milliampere \\
\hline $\mathrm{mg}$ & Milligramm \\
\hline $\mathrm{MHz}$ & Megahertz \\
\hline $\min$ & Minute \\
\hline $\mathrm{ml}$ & Milliliter \\
\hline$\mu \mathrm{m}$ & Mikrometer \\
\hline $\mathrm{mm}$ & Millimeter \\
\hline $\mathrm{mm}^{2}$ & Quadratmillimeter \\
\hline MMA & Methylmethacrylsäure \\
\hline MORE & Multiple Outcomes of Raloxifene Evaluation \\
\hline $\mathrm{ms}$ & Millisekunde \\
\hline $\mathrm{N}$ & Newton \\
\hline $\mathrm{Na}$ & Natrium \\
\hline n.a. & nicht angegeben \\
\hline $\mathrm{NaCl}$ & Natriumchlorid \\
\hline $\mathrm{nm}$ & Nanometer \\
\hline Nr. & Nummer \\
\hline $\mathrm{O}$ & Sauerstoff \\
\hline $\mathrm{pf}$ & plattenfern \\
\hline pn & plattennah \\
\hline pQCT & periphere Quantitative Computertomographie \\
\hline PSM & Polychrome Sequenzmarkierung \\
\hline
\end{tabular}


PTH Parathormon

PTH(1-34) rekombinantes humanes Parathormonfragment 1-34 /

Teriparatid / $\operatorname{rhPTH}(1-34)$

PTH(1-84) vollständiges rekombinantes Parathormon 1-84

QCT Quantitative Computertomographie

QUS Quantitative Ultrasonographie

R Raloxifen

s Sekunde

S. Seite

s.c. Subkutan

SD standard deviation / Standardabweichung

SERM selektiver Östrogen-Rezeptor-Modulator

SOS speed of sound / Schallgeschwindigkeit

SOTI Spinal Osteoporosis Therapeutic Intervention

Tab. Tabelle

TC Tetracyclin-Hydrochlorid

TNF- $\alpha \quad$ Tumornekrosefaktor alpha

TROPOS Treatment of Peripheral Osteoporosis

TSH Thyreoidea stimulierendes Hormon

u.a. unter anderem

USA United States of America

UV Ultraviolett

vgl. vergleiche

vs. versus

WHI Women's Health Initiative

WHO World Health Organization / Weltgesundheitsorganisation

$\mathrm{XO} \quad$ Xylenolorange Tetranatriumsalz

z.B. zum Beispiel 


\section{Einleitung}

\subsection{Einleitung und Fragestellung}

Die Weltgesundheitsorganisation (WHO) stuft die Osteoporose als eine der zehn gravierendsten Volkskrankheiten ein [Bartl R und Bartl C 2008]. Sie geht mit einer hohen Krankheitslast einher und ist in sozioökonomischer Hinsicht von großer Bedeutung. Schätzungen gehen davon aus, dass weltweit 200 Millionen Menschen unter Osteoporose und ihren Folgen leiden [Lane 2006]. Allein in Deutschland werden die direkt durch Osteoporose verursachten jährlichen Kosten auf 5,4 Milliarden Euro geschätzt [Häussler et al. 2007]. Aufgrund steigender Lebenserwartung und veränderter Lebensgewohnheiten ist in den nächsten Jahrzehnten eine deutliche Zunahme der Inzidenz postmenopausaler und altersassoziierter Osteoporose zu erwarten.

Osteoporose ist eine systemische Skeletterkrankung, die durch eine verringerte Knochenmineraldichte und gestörte Mikroarchitektur charakterisiert ist. Diese Veränderungen führen zu einer geringeren Belastbarkeit des Knochens mit erhöhter Frakturgefahr. Osteoporoseassoziierte Frakturen treten hauptsächlich im Bereich der Wirbelsäule, des proximalen Femurs und des distalen Radius auf. Häufige Folgen sind Immobilität, lebenslange Invalidität und eine erhöhte Mortalität. Nach Schätzungen belief sich im Jahr 2000 die Anzahl osteoporotischer Frakturen auf 9 Millionen weltweit [Johnell und Kanis 2006].

Bei der Therapie osteoporotischer Frakturen besteht die Problematik, dass das Regenerationsvermögen des vorgeschädigten Knochens deutlich beeinträchtigt ist. Der Ablauf der Frakturheilung ist sowohl in qualitativer als auch in quantitativer Hinsicht verzögert. Nach dem aktuellen Stand des Wissens verläuft die Heilung um ca. $30 \%$ langsamer als beim gesunden Knochen [Lill et al. 2002 a, b].

So stellt sich im Fall einer osteoporotischen Fraktur die Frage, durch welche therapeutischen Maßnahmen sowohl der Heilungsprozess gefördert als auch ein Fortschreiten der Osteoporose verhindert werden kann. Derzeit werden verschiedenste Therapieansätze untersucht. Ein aussichtsreiches Forschungsgebiet liegt in der medikamentösen Unterstützung der Frakturheilung.

Frauen sind von Osteoporose deutlich häufiger betroffen als Männer. Der größte Anteil aller Fälle von Osteoporose bei der Frau ist auf den postmenopausalen Östrogenmangel zurückzuführen. Bis in die späten 90er Jahre galt die Hormonsubstitution als beste Möglichkeit zur Prävention und Therapie dieser Form der Osteoporose. Als sich jedoch im Rahmen der „Million Women Study“ und der „Woman's Health Iniative Study“ herausstellte, dass eine Langzeittherapie u.a. zu einer steigenden Inzidenz für Mammakarzinome, Arteriosklerose und Schlaganfälle führt, wurde die Suche nach medikamentösen Alternativen erforderlich [Anderson et al. 2004; Beral 2003; Rossouw et al. 2002]. 
Durch eine Vielzahl von Untersuchungen konnten einige Substanzgruppen ermittelt werden, die positive Effekte auf osteoporotisch veränderten Knochen zeigen. Der Einfluss dieser Wirkstoffe auf die Frakturheilung unter Osteoporose ist bislang weitgehend unbekannt.

In der vorliegenden Arbeit wurde die Auswirkung der potentiell antiosteoporotisch wirksamen Substanzen Estradiol (E2), Raloxifen (R), Parathormon (PTH) und der Phytoextrakte Cimicifuga racemosa (CR), Genistein (GEN) und Equol (EQ) auf die Frakturheilung osteoporotischen Knochens untersucht. Als Untersuchungsobjekt diente die ovarektomierte Ratte, ein anerkanntes Modelltier der postmenopausalen Osteoporose. Obwohl bekannt ist, dass sich die Osteoporose nach Ovarketomie bei Ratten im Bereich der metaphysären Tibia manifestiert, basierten bisherige Versuche fast ausnahmslos auf Frakturen im Bereich des Schaftes von Tibia oder Femur. Im Gegensatz dazu wurde in der vorliegenden Arbeit eine standardisierte Osteotomie der Tibiametaphyse durchgeführt. Somit konnte die Frakturheilung direkt am Ort der Osteoporosemanifestation untersucht werden.

Die Bewertung der Frakturheilung erfolgte anhand radiologischer, biomechanischer und histomorphometrischer Kriterien. Mit Hilfe der Polychromen Sequenzmarkierung wurde zudem der zeitliche Verlauf der Konsolidierung untersucht.

Zusammenfassend lassen sich die folgenden Fragestellungen formulieren:

In welcher Weise wird die Frakturheilung osteoporotischen Knochens durch Estradiol, Raloxifen, Parathormon bzw. die Phytoextrakte Cimicifuga racemosa, Genistein und Equol beeinflusst? Kann eine Verbesserung der Frakturheilung durch diese Substanzen erreicht werden?

\subsection{Grundlagen}

\subsubsection{Knochen}

Knochengewebe ist ein spezialisiertes Bindegewebe, das sich im Wesentlichen aus Knochenmatrix, einer kalzium- und kollagenreichen Interzellulärsubstanz, und Knochenzellen (Osteoblasten, Osteozyten und Osteoklasten) zusammensetzt. Der Knochen hat neben einer Stütz- und Schutzfunktion die Aufgabe der Speicherung von Mineralien. So dient er als größtes Mineraldepot des menschlichen Körpers, in dem $99 \%$ des Kalziums, $85 \%$ des Phosphats und $50 \%$ des Magnesiums gespeichert sind [Bartl R und Bartl C 2008].

\subsubsection{Knochenaufbau}

Histologisch lassen sich zwei Knochenarten unterscheiden: Geflechtknochen (Primärknochen) und Lamellenknochen (Sekundärknochen). Geflechtknochen tritt nur bei der Knochenneubildung auf (Knochenentwicklung, Frakturheilung). Er zeichnet sich durch eine 
zufällige Anordnung der Kollagenfibrillen aus. Im Erwachsenenalter ist der Primärknochen fast vollständig durch lamellären Knochen ersetzt.

Sekundärknochen weist eine regelmäßige Ausrichtung der Kollagenfasern auf. Diese bilden etwa 3-7 $\mu$ m dicke Lamellen, die um einen zentralen Kanal (Havers-Kanal, Zentralkanal) konzentrisch angeordnet sind. Die Einheit aus Haverskanal und umgebenden Lamellen wird als Havers-System oder Osteon bezeichnet. Innerhalb einer Lamelle verlaufen alle Fasern parallel, wohingegen die Ausrichtung der Kollagenfasern angrenzender Lamellen um ca. $90^{\circ}$ versetzt ist. Dies trägt wesentlich zur großen Festigkeit des Knochens bei. Osteone verlaufen in Längsrichtung des Knochens. Die Zentralkanäle sind untereinander durch querverlaufende Volkmann-Kanäle verbunden. Sekundärknochen weist einen höheren Mineralgehalt als Geflechtknochen auf.

Makroskopisch lassen sich am Knochen zwei Bauprinzipien unterscheiden. So wird die Außenhülle aller Knochen durch eine kompakte Knochenschicht (Substantia compacta, Compacta, Kortikalis) gebildet, die insbesondere im Schaftbereich langer Röhrenknochen gut ausgeprägt ist. Im Inneren zeigt der Knochen einen schwammartigen Aufbau (Substantia spongiosa, Spongiosa, trabekulärer Knochen) aus vielen vernetzten Knochenbälkchen (Trabekel). Trabekel sind in Richtung der größten einwirkenden Druck- und Zugspannung ausgerichtet. Diese Bauweise erlaubt bei geringem Gewicht eine hohe mechanische Belastbarkeit. Trabekulärer Knochen ist im axialen Skelett (z.B.: Wirbelsäule und Becken) besonders stark ausgebildet. Sowohl Spongiosa als auch Kortikalis bestehen aus lamellärem Knochen.

Die äußere Schicht der Knochen wird von Periost bedeckt. Die Binnenräume sind durch Endost ausgekleidet. Periost und Endost besitzen eine osteogene Aktivität und spielen bei der Frakturheilung eine wichtige Rolle (vgl. 1.2.2.2, S. 7] [Bartl R und Bartl C 2008; Junqueira und Carneiro 2005; Schiebler und Schmidt W 2002].

Nach der Form lassen sich kurze, lange und platte Knochen unterscheiden. Aufgrund ihrer Bedeutung für die vorliegende Arbeit wird im Folgenden nur die Anatomie langer Knochen (Röhrenknochen) genauer dargestellt. Zu den langen Knochen zählen u.a. Tibia, Fibula und Femur. Sie bestehen aus einem röhrenförmigen Mittelstück, der Diaphyse, und aus zwei verbreiterten Enden, den Epiphysen. Die Diaphyse zeichnet sich durch eine kräftige Kortikalis mit schmalem inneren Spongiosasaum aus. Dahingegen besteht der epiphysäre Anteil überwiegend aus spongiösem Knochen, der nach außen von einer dünnen Kompakta begrenzt wird. Zwischen Epiphyse und Diaphyse liegt bei einem im Wachstum befindlichen Knochen ein knorpeliger Abschnitt, der als Epiphysenfuge bezeichnet wird. In diesem Bereich findet das Knochenlängenwachstum statt. Nach Abschluss des Wachstums verknöchert dieser Bereich und ist nur noch als Epiphysenlinie zu erkennen. Der verbreiterte Anteil der Diaphyse, der an die Epiphysenfuge oder Epiphysenlinie grenzt, 
wird als Metaphyse bezeichnet [Junqueira und Carneiro 2005; Schiebler und Schmidt W 2002]. Hier befindet sich die Hauptlokalisation der Osteoporose.

\subsubsection{Zellen des Knochens}

\section{Osteoblasten}

Osteoblasten zählen zu den mesenchymalen Zellen. Sie haben die Aufgabe, neuen Knochen zu bilden. Ihre Aktivität wird durch eine Vielzahl von Zytokinen und Hormonen, wie beispielsweise PTH, Östrogene, Androgene oder Calcitriol, gesteuert.

Aktive Osteoblasten lagern sich an der Knochenoberfläche an. Dort synthetisieren und sezernieren sie die organischen Anteile der Knochenmatrix, wie Kollagen Typ I, Proteoglykane und Glykoproteine. Diese unverkalkte Knochensubstanz wird als Osteoid bezeichnet. Die folgende Mineralisierung durch Einlagerung von Kalziumphosphat und dessen Umwandlung zu Hydroxylapatitkristallen schließt diesen als Knochenapposition bezeichneten Vorgang ab. Osteoblasten unterstützen die Mineralisierung u.a. durch Osteocalcin, Osteopontin und die auf der Zelloberfläche verankerte alkalische Phosphatase.

Unter der fortschreitenden Apposition werden einzelne Osteoblasten in den Knochen eingebaut, reduzieren dort ihre Syntheseleistung und entwickeln sich zu Osteozyten.

Inaktive Osteoblasten bedecken 80-95\% der Knochenoberfläche. Sie werden als ,endosteal lining cells" bezeichnet. Ihnen wird eine Schutz- und Überwachungsfunktion zugeschrieben. "Endosteal lining cells" spielen eine wichtige Rolle bei der Osteoklastenaktivierung [Bartl R und Bartl C 2008; Junqueira und Carneiro 2005].

\section{Osteozyten}

Osteozyten sind von mineralisierter Knochenmatrix umgeben. Sie liegen in Lakunen und sind untereinander über dendritische Zellausläufer und Gap Junctions verbunden. Diese Zellfortsätze verlaufen in einem Netz kleiner Knochenkanäle, den Canaliculi.

Osteozyten spielen eine wichtige Rolle in der Knochenhomöostase. Sie vermitteln den Austausch organischer und anorganischer Stoffe zwischen der mineralisierten Knochenmatrix und den Blutgefäßen. Außerdem registrieren sie das Alter des Knochengewebes und können bei Bedarf dessen Umbau einleiten. In eingeschränktem Maße haben Osteozyten zudem die Fähigkeit, Knochen sowohl auf- als auch abzubauen [Bartl R und Bartl C 2008; Junqueira und Carneiro 2005].

Osteozyten zählen zu den mechanosensiblen Zellen. Es wird davon ausgegangen, dass sie eine wichtige Rolle in der belastungsabhängigen Knochenadaptation einnehmen [You et al. 2008].

Die Apoptose der Osteozyten führt zur Resorption der umgebenden Knochenmatrix. 


\section{Osteoklasten}

Osteoklasten sind große mehrkernige Zellen, die mineralisierten Knochen abbauen können. Sie leiten sich von den Monozyten des Knochenmarks ab.

Zur Resorption treten Osteoklasten in Kontakt mit der Knochenoberfläche. Im Kontaktbereich bilden sie Membraneinfaltungen („ruffled border") aus und reichern im Raum zwischen Zelle und Knochen (Resorptionslakune, Howship-Lakune) vermehrt Wasserstoffionen und proteolytische Enzyme an. Der niedrige pH-Wert führt zunächst zur Demineralisierung der Knochenmatrix. Freigelegte Kollagenfibrillen können dann durch Proteasen hydrolysiert werden. Die Knochenabbauprodukte werden abschließend phagozytiert.

Die osteoklastische Aktivität wird durch eine Vielzahl von Hormonen (Parathormon, Östrogen, Leptin, Schilddrüsenhormone) und Wachstumsfaktoren gesteuert [Bartl R und Bartl C 2008; Junqueira und Carneiro 2005].

\subsubsection{Knochenmatrix}

Die Knochenmatrix besteht aus Mineralien, Kollagen, Wasser und nichtkollagenen Proteinen. Der Anteil an Mineralien beläuft sich auf etwa $50 \%$. Es handelt sich dabei hauptsächlich um Kalzium und Phosphat, die in Form von Hydroxylapatitkristallen an Kollagenfibrillen gelagert sind.

Der organische Anteil macht 25\% der Knochenmatrix aus. Er besteht wiederum zu $95 \%$ aus Kollagen Typ I. Die restlichen $5 \%$ setzten sich aus Proteoglykanen und Glykoproteinen zusammen.

Die interzelluläre Knochenmatrix besteht etwa zu einem Viertel aus Wasser.

Der anorganische Knochenanteil ist im Wesentlichen für die Festigkeit, der kollagene Anteil für die Elastizität verantwortlich. So behält ein entkalkter Knochen seine Form, ist jedoch sehr biegsam. Ein Knochen ohne Kollagen ist spröde und zerbricht leicht [Junqueira und Carneiro 2005].

\subsubsection{4 "Remodeling" und ,peak bone mass"}

Der Knochen ist ein dynamisches Organ, das eine hohe Durchblutung und Stoffwechselakti-

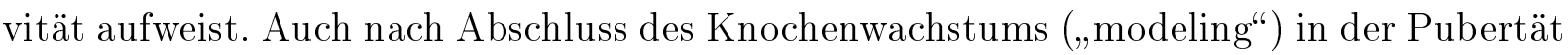
finden ständig Umbauprozesse statt. Diese werden als „remodeling“ bezeichnet. Sie dienen der Kalziumhomöostase, dem Austausch alten Knochengewebes, der Belastungsadaptation [Wolff's Gesetz, Wolff 1892] und der Reparatur. Spongiöser Knochen weist aufgrund seines hohen Oberflächen/Volumen-Verhältnisses eine größere Knochenumbaudynamik als die Kortikalis auf. So wird durch das „remodeling“ jährlich etwa $25 \%$ der Spongiosa und 2,5\% des kortikalen Knochens erneuert [Bartl R und Bartl C 2008]. 
In jungen Lebensjahren überwiegt der Knochenaufbau die Knochenresorption. Es kommt zu einem kontinuierlichen Anstieg der Knochendichte. Sie erreicht ein Maximum („peak bone mass“) zwischen dem 25. und 30. Lebensjahr. Die „peak bone mass“ wird sowohl durch endogene (hereditär, endokrin) als auch exogene (Ernährung, körperliche Aktivität) Faktoren beeinflusst [Matkovic et al. 1994]. Männer zeigen eine höhere „peak bone mass“ als Frauen.

Ab dem 30. Lebensjahr verlagert sich das Gleichgewicht zwischen Auf- und Abbauvorgängen zugunsten der Knochenresorption. Dies hat einen Knochenverlust von $1 \%$ pro Jahr zur Folge. Bei postmenopausalen Frauen steigt der jährliche Verlust aufgrund des eintretenden Östrogenmangels sogar bis auf $4 \%$ an (vgl. 1.3.2, S. 10). Durchschnittlich verliert eine Frau so zwischen dem 40. und 70. Lebensjahr $40 \%$ ihrer Knochenmasse.

Eine hohe „peak bone mass“ schützt vor Osteoporose, da die Knochendichte trotz des physiologischerweise eintretenden Knochenverlusts lange Zeit oberhalb des kritischen Schwellenwertes bleibt [Bartl R und Bartl C 2008].

\subsubsection{Kalziumstoffwechsel}

Die Stoffwechselvorgänge des Knochengewebes sind eng mit der Kalzium- und Phosphathomöostase verbunden. Der Knochen hat die wichtige Funktion eines Mineraldepots. So kann bei Bedarf Kalzium freigesetzt oder überschüssiges Kalzium eingelagert werden.

Aufgrund der eingeschränkten Löslichkeit von Kalziumphosphationen ist der Phosphatstoffwechsel nicht vom Kalziumstoffwechsel zu trennen. Änderungen der extrazellulären Kalziumkonzentration ohne Korrektur der Phosphatkonzentration kann zum Ausfallen von Kalziumphosphat führen.

Die Plasmakalziumkonzentration wird im Wesentlichen durch Parathormon (PTH), Kalzitriol und Kalzitonin reguliert. Das in den Epithelkörperchen der Nebenschilddrüsen synthetisierte PTH wird bei Hypokalzämie ausgeschüttet. Es führt über verschiedene Mechanismen zu einem Anstieg der extrazellulären Kalziumkonzentration. So fördert PTH die Osteoklastenaktivität und bewirkt einen vermehrten Knochenabbau mit Freisetzung von Kalzium und Phosphat. In der Niere hemmt PTH die Kalziumausscheidung. Zugleich wird die renale Elimination des Phosphats gesteigert.

Sowohl PTH als auch niedrige Blutkalziumspiegel stimulieren die Kalzitriolsynthese. Kalzitriol (1,25( $\left(\mathrm{OH}_{2}\right)$-Vitamin-D3) wird stufenweise durch Hydroxylierungsvorgänge in Leber und Niere aus Vitamin D3 gebildet. Vitamin D3 kann entweder diätetisch aufgenommen oder im Körper synthetisiert werden. Zur endogenen Vitamin-D3-Synthese ist die UV-Exposition der Haut erforderlich. Kalzitriol bewirkt eine vermehrte Kalzium- und Phosphatresorption im Darm. Zudem zeigt es eine direkte stimulierende Wirkung auf die Knochenresorption. Es kommt zum Anstieg der extrazellulären Kalzium- und Phos- 
phatkonzentration. Dies fördert wiederum die Mineralisierung des Knochens und führt im Rahmen einer negativen Rückkopplung zur Hemmung der PTH-Ausschüttung.

Bei einer Hyperkalzämie wird Kalzitonin aus den C-Zellen der Schilddrüse freigesetzt. Im Knochengewebe bewirkt es als Gegenspieler des PTH einen vermehrten Einbau von Kalziumionen und senkt so deren Konzentration im Blut [Löffler und Petrides 2003; Schmidt R et al. 2000].

\subsubsection{Frakturen}

\subsubsection{Definition}

Die Fraktur ist definiert als Kontinuitätsunterbrechung eines Knochens unter Bildung zweier oder mehrerer Knochenfragmente. Frakturen, die aus einer plötzlichen adäquaten Gewalteinwirkung resultieren, werden als traumatische Frakturen bezeichnet. Kommt es zu einem Knochenbruch ohne Einwirkung eines adäquaten Traumas, so handelt es sich um eine pathologische Fraktur. Ursache solcher Frakturen ist eine Vorschädigung des Knochengewebes, wie sie beispielsweise unter Osteoporose auftritt. Der Ermüdungsbruch, eine dritte Frakturform, resultiert aus der Summation vieler Mikrotraumen, die vom Körper nicht in ausreichendem Maße "repariert" werden konnten. Ermüdungsfrakturen beruhen häufig auf ungewohnter Überbeanspruchung (z.B.: Marschfraktur) [Bartl R und Bartl C 2008; Böcker et al. 2004].

\subsubsection{Frakturheilung}

Die Frakturheilung hat das Ziel der vollständigen strukturellen und funktionellen Wiederherstellung des ursprünglichen Zustands. Sie beruht auf einer komplexen Kaskade lokaler und systemischer Mechanismen, an der eine Vielzahl von Wachstumsfaktoren, verschiedene Zytokine und der Kalzium-, PTH- und Vitamin-D-Stoffwechsel beteiligt sind. Man unterscheidet zwei Formen der Frakturheilung: indirekte und direkte.

\section{Indirekte Frakturheilung}

Die indirekte (sekundäre) Knochenheilung geht mit periostaler, endostaler und interfragmentärer Kallusbildung einher. Diese wird durch Mikrobewegungen der Frakturfragmente angeregt. Der Kallus hat die wichtige biomechanische Funktion, diese Beweglichkeit so weit zu reduzieren, dass eine knöcherne Überbrückung erfolgen kann. Dies wird unter fortschreitender Heilung durch eine zunehmende Vergrößerung der Querschnittsfläche und der mechanischen Festigkeit des überbrückenden Kallusgewebes erreicht [Claes und Heigele 1998]. Ist der Frakturspalt oder die interfragmentäre Beweglichkeit zu groß, so bleibt eine Heilung aus. 
Die indirekte Frakturheilung lässt sich in vier, teilweise parallel verlaufende, Stadien unterteilen [Rüter et al. 2004; Siewert 2006]:

Durch die Kontinuitätsunterbrechung des Knochens kommt es zur Verletzung angrenzender Gefäße. Dies führt in der ersten Phase der Frakturheilung zur Ausbildung eines interfragmentären Hämatoms, in das Granulozyten, Monozyten und Mastzellen einströmen (Stadium 1: Entzündungsphase; Dauer: bis 4 Wochen). Die Einwanderung weiterer Zellen und die Versorgung vorhandener Zellen mit Nährstoffen wird durch eine gesteigerte Kapillaraussprossung und eine vermehrte periostale Durchblutung unterstützt.

In der nächsten Phase wird das Frakturhämatom durch Granulationsgewebe ersetzt (Stadium 2: Granulationsphase; Dauer: 3-8 Wochen). Osteoblasten, Chondroblasten und eingewanderte Fibroblasten synthetisieren die extrazellulären Bestandteile des Granulationsgewebes. So entsteht eine erste weiche Überbrückung des Frakturspalts. Gleichzeitig bauen Osteoklasten nekrotische Knochenanteile ab. Diese Resorptionsvorgänge sind insbesondere im Bereich der Frakturenden zu beobachten.

Im weiteren Verlauf wird das Granulationsgewebe zunehmend mineralisiert und so zu Geflechtknochen umgebaut (Stadium 3: Kallushärtung; Dauer: 6 Wochen - 4 Monate). Ausgangspunkt der Knochenneubildung ist dabei die vom Frakturspalt etwas entfernt liegende endostale und periostale Oberfläche der Kortikalis [Einhorn 1995]. Es entsteht der Fixationskallus, der die interfragmentäre Beweglichkeit einschränkt, aber noch nicht optimal auf mechanische Beanspruchung ausgerichtet ist. Unter zunehmender Belastung wird der Geflechtknochen allmählich in Lamellenknochen umstrukturiert, wobei Markraum und die ursprüngliche Knochenkontur wieder hergestellt werden (Stadium 4: Modeling und Remodeling; Dauer: 3 - 24 Monate).

Eine indirekte Frakturheilung zeigt sich beispielsweise bei Marknagelung oder konservativer Therapie mit Gipsverband [Böcker et al. 2004; Hirner und Weise 2004; Rüter et al. 2004; Siewert 2006].

\section{Direkte Frakturheilung}

Bei der direkten (primären) Knochenheilung bildet sich kein endostales oder periostales Kallusgewebe. Auch die für die indirekte Heilung charakteristische Resorption im Bereich der Frakturenden bleibt aus. Diese Form der Heilung tritt nur bei rigider Fixation der Knochenfragmente auf.

Liegen beide Knochenenden direkt aufeinander, so kommt es zur Kontaktheilung. Dabei wachsen die Havers'schen Systeme von einem Frakturfragment zum anderen vor. Die Knochenkontinuität wird durch direkte Ausbildung von Lamellenknochen wieder hergestellt. Auch bei einem Frakturspalt bis zu 0,5 mm kann eine primäre Knochenheilung erfolgen [Schenk und Willenegger 1977]. Bei diesem als Spaltheilung bezeichneten Vorgang wird 
der Raum zwischen den Knochenfragmenten ohne vorhergehende Entzündungs- und Granulationsphase direkt mit Geflechtknochen überbrückt und anschließend durch lamellären Knochen ersetzt.

Die direkte Frakturheilung wird bei stabilen Druckosteosynthesen angestrebt [Böcker et al. 2004; Hirner und Weise 2004; Rüter et al. 2004].

\subsection{Osteoporose}

\subsubsection{Definition}

"Osteoporose ist als Skeletterkrankung definiert, die durch eine unzureichende Knochenfestigkeit charakterisiert ist, welche zu einem erhöhten Frakturrisiko prädisponiert. Die Knochenfestigkeit spiegelt dabei primär das Zusammenwirken von Knochendichte und Knochenqualität wieder."

(NIH Consensus Development Panel on Osteoporosis 2001; Übersetzung aus Pfeilschifter [2006, S. 22])

Die "Consensus-Definition" gibt einen allgemeinen Überblick zum Begriff der Osteoporose. Sie legt besonderen Wert auf pathophysiologische Veränderungen und ihre Folgen. Eine einfache Grundlage zur Diagnostik und Behandlung der Osteoporose schafft sie jedoch nicht.

Eine deutlich pragmatischere Definition stammt dahingegen von der Weltgesundheitsorganisation [WHO 1994]. Hiernach liegt dann eine Osteoporose vor, wenn die Knochendichte mehr als 2,5 Standardabweichungen (SD) unterhalb des Mittelwertes der Knochendichte gesunder Menschen im Alter von 30 Jahren liegt. Diese ermittelte Standardabweichung wird als T-Score bezeichnet. Grundlage der Knochendichtemessung ist die Dual-X-RayAbsorptiometrie (DXA; siehe 1.3.7.4. S. 18) des proximalen Femurs und der Lendenwirbelsäule.

Bei der WHO-Definition ist zu beachten, dass sie allein für postmenopausale Frauen und Männer ab 50 Jahren gültig ist. Bei Kindern, jüngeren Männern und prämenopausalen Frauen empfiehlt die „International Society for Clinical Densitometrie” [ISCD 2004] den Vergleich der Knochendichte mit dem gleichaltrigen knochengesunden Referenzkollektiv. Die so ermittelte Standardabweichung wird dann als Z-Score bezeichnet.

Aufbauend auf dem T-Score und den bis zur Untersuchung aufgetretenen pathologischen Frakturen gibt die WHO eine Richtlinie zur Stadieneinteilung der Osteoporose vor. Diese wird in Tab.11 dargestellt. 
Tabelle 1: Stadieneinteilung der Osteoporose (modifiziert nach WHO [1994])

\begin{tabular}{lll}
\hline Klinisches Stadium & Kriterien \\
\hline \hline & Normalbefund & T-Score: $\geq-1 \mathrm{SD}$ \\
0 & Osteopenie & T-Score: $-1,0$ bis $-2,5 \mathrm{SD}$ \\
1 & Osteoporose & T-Score: $<-2,5 \mathrm{SD}$ \\
2 & Manifeste Osteoporose & T-Score: $<-2,5 \mathrm{SD}$ \\
& \multirow{2}{*}{ Fortgeschrittene Osteoporose } & T-Score: $<-2,5 \mathrm{SD}$ \\
& & multiple Wirbelkörperfrakturen \\
& oft auch extraspinale Frakturen \\
\hline
\end{tabular}

$\mathrm{SD}=$ Standardabweichung

\subsubsection{Pathophysiologie der Osteoporose}

Wie bereits unter 1.2.1.4 (S. 5 ) dargestellt, finden am Knochen im Rahmen des ,remodelings“ lebenslang Umbauvorgänge statt. Kommt es zu einer Verschiebung des sensiblen Gleichgewichts zwischen Knochenresorption und Knochenformation zu Gunsten der Resorption, so bildet sich eine Osteopenie bzw. Osteoporose aus. Die Osteoporose manifestiert sich zuerst an der Substantia spongiosa [Banse et al. 2001; Thomsen et al. 2002]. Diese unterliegt aufgrund ihres großen Oberflächen/Volumen-Verhältnisses im Gegensatz zur Kortikalis einem vermehrten Umbau (vgl. 1.2.1.4. S. 5) und ist somit besonders anfällig für Störungen des Knochenstoffwechsels. Unter fortschreitendem Knochenabbau kommt es in der Spongiosa zu Erosion, Perforation und partiellem Verlust der Trabekel (siehe Abb. 11). Die Anzahl, Dicke und Vernetzung der Knochenbälkchen nimmt ab [Gasser et al. 2005; Lane et al. 1995; Steiniche 1995]. Als Folge dieser Umbauvorgänge kommt es neben dem Verlust von Knochenmasse auch zu einer Störung der Mikroarchitektur. Es resultiert eine geringere Belastbarkeit des knöchernen Gewebes mit einer gesteigerten Frakturgefahr [NIH Consensus Development Panel on Osteoporosis 2001].

Der infolge einer abnehmenden endokrinen Funktion der Ovarien eintretende postmenopausale Östrogenmangel wird als wichtigster pathogenetischer Faktor für die Ausbildung einer Osteoporose angenommen. Er führt u.a. zu einer vermehrten Freisetzung verschiedener Zytokine (z.B.: IL-1, IL-6, TNF- $\alpha$ ) aus Knochenmark und Knochenzellen. Diese Zytokine bewirken eine gesteigerte Osteoklastogenese, erhöhen die Resorptionsaktivität reifer Osteoklasten und verlängern deren Lebenszeit [Manolagas 2000; Pacifici 1998]. Auch die Osteoblastogenese wird unter Östrogenmangel gefördert („high-turnover osteoporosis“; vgl. 1.3.4.2, S. 14). Gleichzeitig führt das Hormondefizit aber auch zu einer verkürzten Lebenszeit von Osteozyten und Osteoblasten [Manolagas 2000]. Aus den postmenopausa- 


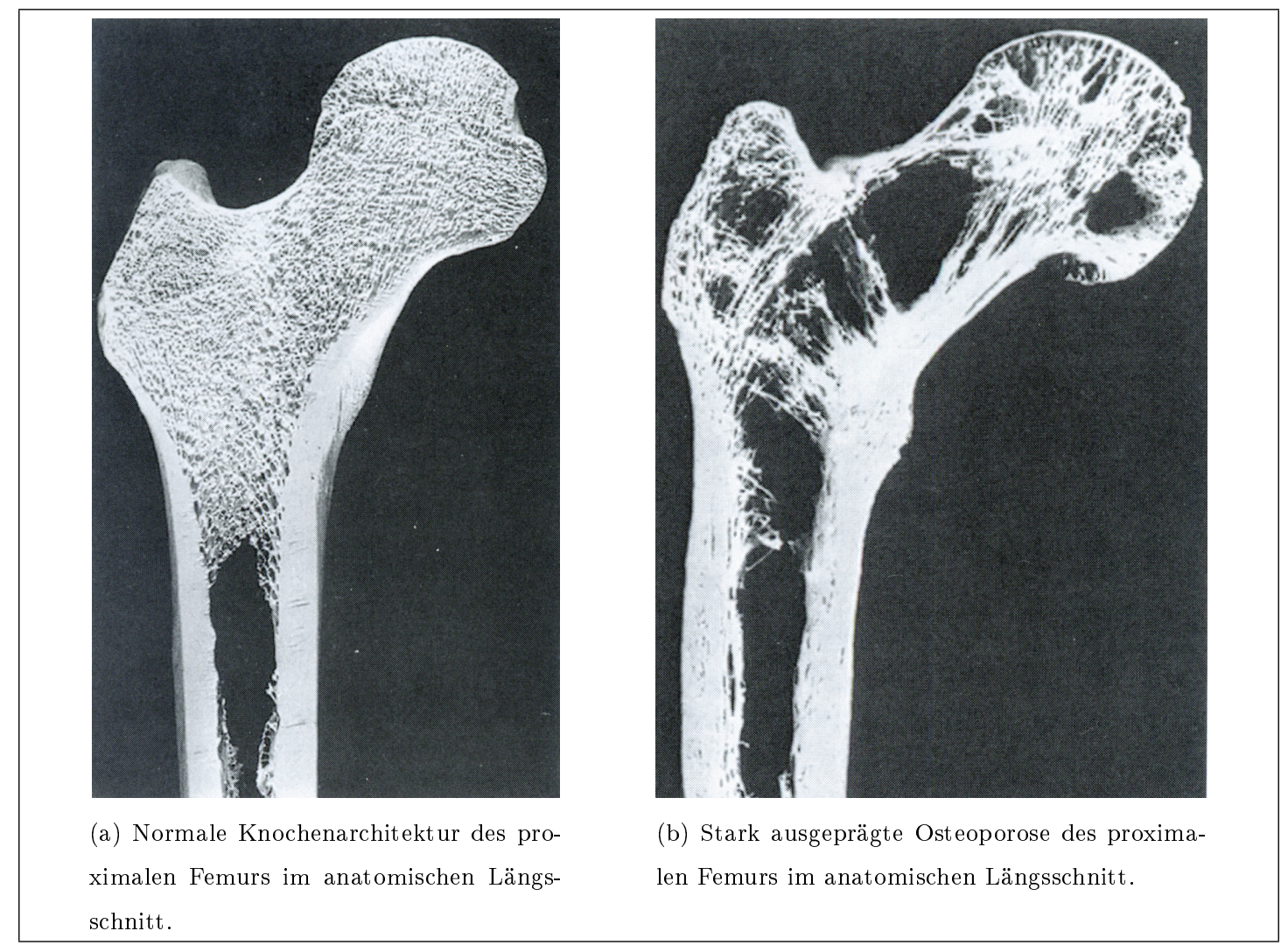

Abbildung 1: Gesunder Knochen vs. osteoporotischer Knochen (modifiziert nach Bartl R und Bartl C [2008], S. 6 und 22)

len Veränderungen resultiert in der Summe ein gesteigertes „remodeling“ mit negativer Knochenbilanz [Manolagas 2000; Seeman 2003].

Die intensivierte Knochenresorption unter Östrogenmangel führt zu einer vermehrten Freisetzung von Kalzium in den Extrazellulärraum. Dadurch wird die Ausschüttung von PTH gehemmt. Dies hat zwei wichtige Folgen. Zum einen wird die Kalziumausscheidung über die Niere gesteigert. Zum anderen hat der niedrige PTH-Spiegel eine Hemmung der Kalzitriolsynthese zur Folge. Der Kalzitriolmangel führt zu einer verminderten enteralen Kalziumresorption (vgl. 1.2.1.5. S. 6). Es resultiert somit eine negative Kalziumbilanz, die wiederum den Knochenmasseverlust unterstützt [Siegenthaler und Blum 2006].

Im hohen Alter kommt es häufig durch veränderte Ernährungsgewohnheiten und durch eine verminderte Sonnenlichtexposition zu einem Mangel an Vitamin D3. Dies führt dazu, dass der Körper nicht ausreichend Kalzitriol synthetisieren kann. Die Folge ist eine unzureichende enterale Kalziumresorption. Als Reaktion auf die niedrigen extrazellulären Kalziumspiegel kommt es zu einem leichten sekundären Hyperparathyreoidismus, der zu einer vermehrten Knochenresorption mit Freisetzung von Kalzium führt [Siegenthaler und Blum 2006]. Die so entstehende negative Knochenbilanz wird durch eine altersbedingte Abnahme der Osteoblastogenese weiter gefördert („low-turnover osteoporosis“; vgl. 1.3.4.2. S. 14) [Manolagas 2000]. 


\subsubsection{Epidemiologie und sozioökonomische Bedeutung}

Osteoporose und ihre Folgen sind weltweit in sozialer und ökonomischer Hinsicht von großer Bedeutung. Sie beeinträchtigen die Gesundheit und Lebensqualität der Betroffenen und stellen eine enorme finanzielle Belastung für die Gesundheitssysteme dar. Die WHO stuft die Osteoporose als eine der zehn gravierendsten Volkskrankheiten ein [Bartl R und Bartl C 2008].

Nach Lane [2006] sind weltweit schätzungsweise 200 Millionen Menschen von Osteoporose betroffen. 30-50\% der Frauen und 15-30\% der Männer werden in ihrem Leben eine osteoporoseassoziierte Fraktur erleiden [Randell et al. 1995]. Im Jahr 2000 kam es nach Schätzungen weltweit zu 9 Millionen osteoporotischen Knochenbrüchen, wovon die meisten $(34,8 \%)$ in Europa registriert wurden [Johnell und Kanis 2006].

Die Frakturen führen zu Immobilität und gegebenenfalls zu dauerhafter Invalidität. Bei Hüftfrakturen liegt die Einjahresmortalität zwischen 20 und 24\% [Cooper et al. 1993; Leibson et al. 2002].

In der Bundesrepublik Deutschland waren im Jahre 2003 7,8 Millionen Menschen, davon 6,5 Millionen Frauen, von Osteoporose betroffen [Häussler et al. 2007]. Die durch Osteoporose direkt entstandenen Kosten beliefen sich in diesem Jahr auf 5,4 Milliarden Euro [Häussler et al. 2007].

Aufgrund der demographischen Entwicklung in Europa wird die Inzidenz der Osteoporose in den nächsten Jahrzehnten zunehmen, was insbesondere auf die steigende Zahl postmenopausaler Frauen in der Bevölkerung zurückzuführen ist. Dies wird einen Anstieg osteoporotischer Frakturen und der damit verbundenen Kosten zur Folge haben. So schätzt ein Bericht der Europäischen Kommission (1998) die Zunahme der Inzidenz von Hüftfrakturen in Deutschland von 117.000 im Jahr 2000 auf 240.000 im Jahr 2040 [Häussler et al. 2007]. Kanis und Johnell [2005] prognostizieren ein Wachstum der europaweiten Kosten von ca. 31,7 Milliarden im Jahr 2000 auf 76,7 Milliarden Euro für das Jahr 2050. Osteoporose gilt als unterdiagnostizierte und untertherapierte Krankheit [Häussler et al. 2007]. Schätzungen gehen davon aus, dass derzeit $80 \%$ der Personen mit hohem Frakturrisiko weder identifiziert noch behandelt werden [Nguyen et al. 2004].

\subsubsection{Einteilung}

In der Literatur wird eine Vielzahl an Möglichkeiten zur Einteilung der Osteoporose aufgezeigt. Diese berücksichtigen Aspekte wie beispielsweise metabolische und histologische Charakteristika, Ätiologie und Therapiekonsequenzen in unterschiedlichem Maße.

Im Folgenden werden die gebräuchlichsten Formen der Einteilung aufgezeigt. 


\subsubsection{Primäre versus sekundäre Osteoporose}

Die Einteilung in primäre und sekundäre Formen der Osteoporose erfolgt anhand der Ätiologie.

Die primären Formen der Osteoporose sind mit einem Anteil von 95\% am häufigsten vertreten. Diese zeichnen sich definitionsgemäß dadurch aus, dass bei ihnen eine genaue Ursache für die Entwicklung der Osteoporose nicht festzustellen ist. Sie sind häufig multifaktoriell bedingt. Zu den primären Formen zählen die idiopathische juvenile, die postmenopausale und die senile Osteoporose.

Die postmenopausale Osteoporose, die auch als Typ-1-Osteoporose bezeichnet wird, manifestiert sich etwa 10 - 15 Jahre nach der Menopause. Sie betrifft ca. $30 \%$ aller Frauen [Melton et al. 1993; Jones et al. 1994]. Der postmenopausal eintretende Östrogenmangel, der durch eine nachlassende endokrine Funktion der Ovarien verusacht wird, führt zu einem gesteigerten Abbau des spongiösen Knochens. Davon sind insbesondere die Wirbelkörper und das proximale Femur betroffen.

Tabelle 2: Mögliche Ursachen sekundärer Osteoporose (modifiziert nach Bartl R und Bartl C [2008], S. 33-35)

Endokrinologische Erkrankungen
Morbus Cushing, Diabetes mellitus, Hyperparathyreoidismus
Hypogonadismus, Hyperthyreose
Medikamentös/iatrogen
Glukokortikoide, Antikoagulantzien, Antiepileptika
Genetische Erkrankungen
Osteogenesis imperfecta, Turner-Syndrom, Klinefelter-
Syndrom, Ehler-Danlos-Syndrom, Marfan-Syndrom
Gastroenterologische Erkrankungen
Chronisch entzündliche Darmerkrankungen,
Pankreasinsuffizienz, Primäre biliäre Zirrhose
Hämatologische/myelogene Erkrankungen
Plasmozytom, Polyzythämia vera, Chronische myeloische
Leukämie, Systemische Mastozytose
Onkologische Erkrankungen
Metastasierung, Paraneoplastisch bei Malignomen
Nephrologische Erkrankungen
Chronische Niereninsuffizienz
Rheumatologische/immunologische Erkrankungen
Chronische Polyarthritis
Immobilisation


Die Typ-1-Osteoporose tritt mit deutlich geringerer Häufigkeit auch bei Männern auf. Als Ursache gilt hier ein Mangel an Testosteron, der ebenfalls zu einem spongiosabetonten Knochenmasseverlust führt.

Definitionsgemäß geht die Typ-1-Osteoporose ab dem 70. Lebensjahr stufenlos in die senile Osteoporose (Typ 2) über. Spongiosa und Kortikalis werden im Rahmen einer generalisierten Knocheninvolution gleichermaßen abgebaut. Als Ursachen der senilen Osteoporose werden der physiologische Alterungsprozess, Bewegungsmangel und Kalzium- und/oder Vitamin D-Mangel angenommen. Die senile Osteoporose betrifft etwa zweimal mehr Frauen als Männer [Bartl R und Bartl C 2008].

Bei den sekundären Osteoporosen ist die Ätiologie bekannt. Sie werden beispielsweise durch eine andere Grunderkrankung oder die Einnahme bestimmter Medikamente verursacht. Die sekundären Formen machen nur 5\% aller Fälle von Osteoporose aus. Tab.2 zeigt eine Übersicht möglicher Ursachen sekundärer Osteoporose.

\subsubsection{High-turnover- versus Low-turnover-Osteoporose}

Osteoporose unter gesteigertem Knochenumbau wird als High-turnover-Osteoporose bezeichnet. Die Aktivität der Osteoklasten ist gegenüber der normalen Aktivität der Osteoblasten gesteigert. Es kommt zu einer Fast-loser-Situation, bei der der Patient jährlich mehr als 3,5\% seiner trabekulären Knochenmasse verliert. Diese Form tritt typischerweise in der frühen postmenopausalen Osteoporose (bis zehn Jahre nach der Menopause) auf [Herold 2009].

Liegt dahingegen eine Osteoporose unter generell vermindertem Knochenumbau vor, wird von einer Low-turnover-Osteoporose gesprochen. Hierbei ist die Osteoklastenaktivität normal. Allein die Knochenneubildung durch Osteoblasten ist reduziert. Der Knochenabbau erfolgt nur langsam (Slow-loser-Situation) und beträgt jährlich weniger als 3,5\% des trabekulären Knochens. Dieser langsame Knochenmasseverlust ist typisch für die späte postmenopausale (mehr als 10 Jahre nach der Menopause) und die senile Osteoporose [Herold 2009].

Das Wissen über die metabolischen Eigenschaften der zu behandelnden Osteoporose ist von Bedeutung für die Auswahl der medikamentösen Therapie. So wird eine auf gesteigertem Knochenabbau basierende Form durch ein antiresorptiv wirkendes Medikament therapiert, während zur Behandlung einer reduzierten Knochenneubildung ein osteoanaboles Präparat zu bevorzugen ist (vgl. 1.3.8, S. 22).

\subsubsection{Generalisierte versus lokalisierte Osteoporose}

In Abhängigkeit vom Befallsmuster des Skelettes wird zwischen einer generalisierten (systemischen) und einer lokalisierten (fokalen) Osteoporose unterschieden. 
$\mathrm{Zu}$ den fokalen Formen zählen beispielsweise die Osteoporose bei komplexem regionalem Schmerzsyndrom, die gelenknahe Osteoporose bei rheumatoider Arthritis und die Inaktivitätsosteoporose einer Extremität.

$\mathrm{Zu}$ einem generalisierten Befall des Skelettes kommt es unter anderem bei der bereits oben beschriebenen postmenopausalen Osteoporose (Тур 1) und der senilen Osteoporose (Тур 2).

\subsubsection{Risikofaktoren}

Tab. 3 zeigt eine Übersicht der wichtigsten Risikofaktoren für die Ausbildung einer Osteoporose.

Tabelle 3: Zusammenstellung wichtiger Risikofaktoren der Osteoporose (modifiziert nach NIH Consensus Development Panel on Osteoporosis [2001] und Bartl R und Bartl C [2008])

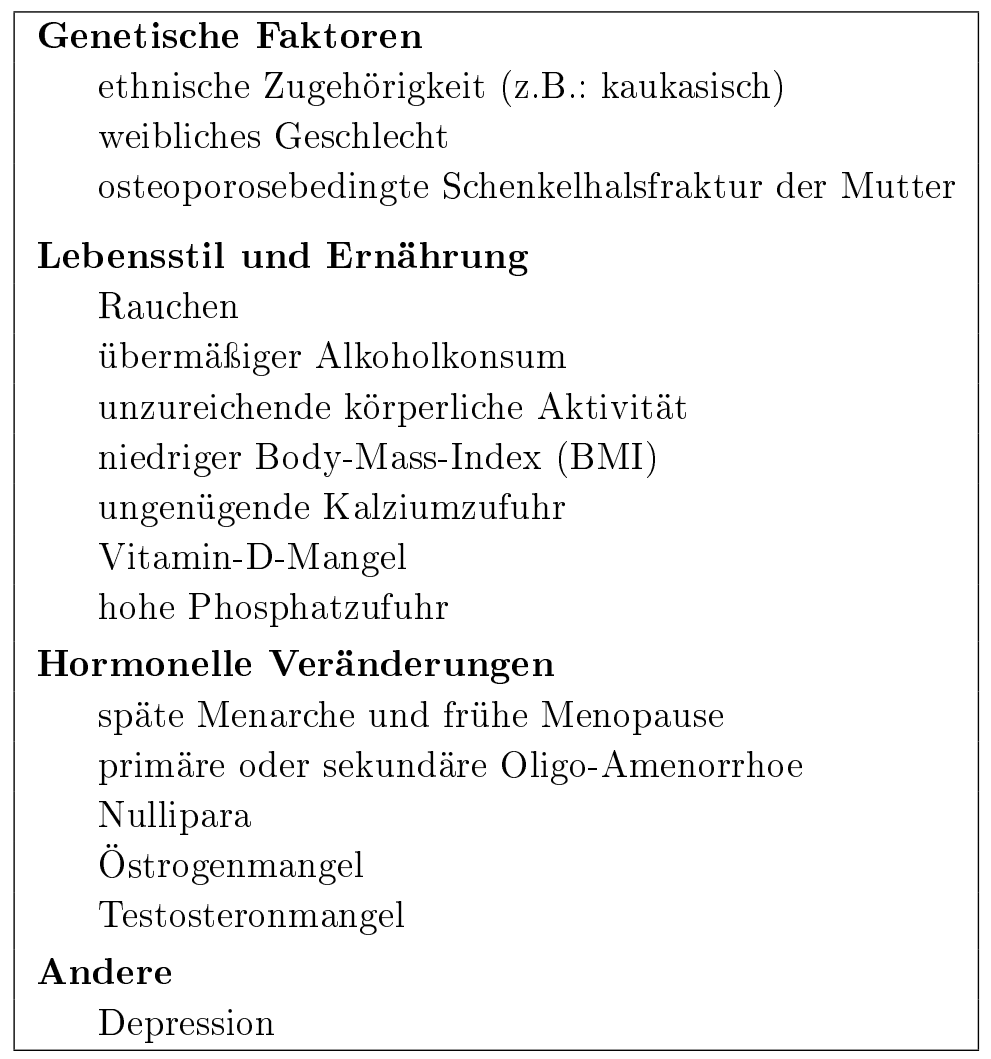

\subsubsection{Frakturen und Frakturheilung unter Osteoporose}

Frakturen stellen die wesentliche klinische Manifestation der Osteoporose dar. Ihnen geht häufig über viele Jahre ein präklinischer Knochensubstanzverlust voraus. Da dieser meist schleichend und asymptomatisch verläuft, wird die Diagnose „Osteoporose“ häufig erst nach dem Auftreten der ersten Fraktur gestellt. 
Osteoporotische Frakturen treten hauptsächlich im Bereiche der Wirbelsäule, des proximalen Femurs und des distalen Radius auf. Das Risiko nach dem 50. Lebensjahr eine osteoporosebedingte Fraktur zu erleiden, wird für Frauen auf ca. 40\%, für Männer auf $13 \%$ beziffert [Melton et al. 1992]. Ist bereits eine Fraktur aufgetreten, so steigt das Risiko für eine Zweitfraktur um $86 \%$ [Kanis et al. 2004].

Unter Osteoporose zeigt sich eine deutliche Beeinträchtigung der Frakturheilung. Sie ist sowohl in quantitativer als auch in qualitativer Hinsicht um etwa $30 \%$ verlangsamt [Lill et al. 2002 a, b]. In Untersuchungen zur frühen Phase (Woche 1-3) der Frakturheilung am Femurschaft ovarektomierter Ratten zeigte sich gegenüber der nicht ovarektomierten Kontrollgruppe ein um $40 \%$ geringerer Kallusquerschnitt. Die BMD des Kallus war um $23 \%$ reduziert. Im biomechanischen Test wies die Frakturüberbrückung des osteoporotischen Knochens eine deutlich geringere Stabilität und Elastizität auf [Namkung-Matthai et al. 2001].

Auch in der mittleren und späten Phase (Woche 4-18) der Frakturheilung zeichnet sich der Kallus unter Osteoporose durch eine niedrigere BMD und schlechtere biomechanische Eigenschaften aus. Als Ursache für die Beeinträchtigung der Frakturheilung wird eine Kombination aus gesteigerter Osteoklastenaktivität und verlangsamten Mineralisierungsvorgängen angenommen [Wang et al. 2005 a].

\subsubsection{Diagnostik}

Die Basisdiagnostik der Osteoporose besteht nach Empfehlung des Dachverbands Osteologie (DVO) [DVO-Leitlinie zur Osteoporose 2006, Pfeilschifter 2006] aus Anamnese, klinischer Untersuchung, DXA-Knochendichtemessung (siehe 1.3.7.4, S. 18), konventionellem Röntgen der Brust- und Lendenwirbelsäule und Labordiagnostik. Eine gezielte, frühzeitige

Tabelle 4: Empfehlung für die Durchführung einer Basisdiagnostik (modifiziert nach Pfeilschifter [2006], S. 160)

\begin{tabular}{|l|l|l|}
\hline \multicolumn{2}{|l|}{ Alter (Jahre) } & Risikoprofil, bei dem eine Basisdiagnostik empfohlen wird \\
\hline Frau & Mann & \\
\hline \hline $50-60$ & $60-70$ & $\begin{array}{l}\text { Wirbelkörperfraktur } \\
\text { periphere Fraktur als Einzelfallentscheidung }\end{array}$ \\
\hline $60-70$ & $70-80$ & $\begin{array}{l}\text { Wirbelkörperfraktur } \\
\text { periphere Fraktur } \\
\text { proximale Femurfraktur eines Elternteils } \\
\text { Untergewicht } \\
\text { Nikotinkonsum } \\
\text { multiple Stürze } \\
\end{array}$ \\
& & $\begin{array}{l}\text { Immobilität } \\
\text { Lebensalter als Risiko ausreichend }\end{array}$ \\
\hline$>70$ & $>80$ &
\end{tabular}


Diagnostik ist die Grundlage für eine adäquate Therapie, die insbesondere zur Prävention pathologischer Frakturen beitragen soll.

Die Indikation zur Durchführung der Basisdiagnostik wird anhand des 10-Jahres-FrakturRisikos gestellt, das auf Grundlage klinischer Risikofaktoren abgeschätzt wird. Ab einem Risiko von $20 \%$ sollten die entsprechenden Untersuchungen durchgeführt werden. Dieser Wert wird für die in Tab.4 aufgeführten Konstellationen erreicht.

\subsubsection{Anamnese}

Die Anamnese ist der erste wichtige Schritt zur Diagnostik der Osteoporose. Es sollten Informationen über vorliegende Risikofaktoren (siehe Tab. 3), aktuelle Beschwerden wie Schmerzen oder funktionelle Einschränkungen, Vorerkrankungen und die Einnahme von Medikamenten abgefragt werden. Weitere wichtige Aspekte sind Alter, Gewichts- und Körpergrößenentwicklung, zuvor aufgetretene Frakturen und Stürze.

Auf Basis der Anamnese wird die Indikation für eine weiterführende Diagnostik (siehe 1.3.7 gestellt. Zudem geben die gewonnenen Informationen erste Hinweise zur Differenzierung zwischen primärer und sekundärer Osteoporose.

\subsubsection{Klinische Untersuchung}

Im Zentrum der klinischen Untersuchung steht die Fragestellung nach bereits eingetretenen pathologischen Veränderungen als Folge von Wirbelkörperfrakturen. Dazu sollte auf Größenverlust, Körperhaltung, Klopfschmerz, Bewegungseinschränkung und Hartspann der Muskulatur untersucht werden.

Im fortgeschrittenen Stadium der Osteoporose kommt es durch multiple Wirbelkörperfrakturen zu einer deutlichen Höhenminderung der Wirbelsäule von mehr als $4 \mathrm{~cm}$ mit Ausprägung einer Hyperkyphosierung der Brustwirbelsäule ("Witwenbuckel") bei gleichzeitiger Hyperlordosierung der Halswirbelsäule. Dabei treten typische Hautfalten im Bereich des Rückens auf, die von kraniomedial nach kaudolateral verlaufen (,Tannenbaumphänomen").

Zur Beurteilung von Muskelkraft und Koordination wird der „Timed-up and go"-Test [Podsiadlo und Richardson 1991] oder „Chair rising“-Test [Guralnik et al. 1995] empfohlen. Die dadurch gewonnenen Informationen ermöglichen die Einschätzung des bestehenden Sturzrisikos.

\subsubsection{Konventionelles Röntgen}

Das konventionelle Röntgen von Brust- und Lendenwirbelsäule hat in der Osteoporosediagnostik zwei wichtige Aufgaben. Zum einen gilt es als Standardverfahren zur Erfassung 
und Verlaufskontrolle von Wirbelkörperfrakturen. Zum anderen ist es bei der Abgrenzung gegenüber möglichen Differentialdiagnosen (z.B.: Osteomalazie oder maligne Knochenläsionen) von wesentlicher Bedeutung [Jergas und Schmid 1999]. Für den Einsatz in der Osteoporose-Frühdiagnostik ist das konventionelle Röntgen nicht geeignet, da erst ein Knochenmasseverlust zwischen 20 und $40 \%$ im Röntgenbild sichtbar wird [Grampp et al. 1993; Genant et al. 1996].

Unter fortgeschrittener Osteoporose kommt es im Röntgenbild der Wirbelsäule zu charakteristischen Veränderungen. Sinterungsfrakturen und Einbrüche der Grund- und Deckplatten führen zur Ausbildung von Fisch-, Keil- und Plattwirbeln. Als Folge der starken Rarefizierung des trabekulären Knochens erscheinen die inneren Wirbelkörperanteile weniger röntgendicht. Die Kortikalis, die deutlich langsamer abgebaut wird, wirkt dahingegen prominent (vgl. 1.3.2, S. 10). Dieses Phänomen wird als „Rahmenwirbel“ bezeichnet.

\subsubsection{Osteodensitometrie}

Unter dem Begriff der Osteodensitometrie sind verschiedene Untersuchungsverfahren zusammengefasst, die es ermöglichen, genauere Informationen über Mineralgehalt (Bone mineral content; BMC; in g) und Mineraldichte (Bone mineral density; BMD; in $\mathrm{g} / \mathrm{cm}^{2}$ oder $\mathrm{g} / \mathrm{cm}^{3}$ ) des Knochens zu erlangen. Sie werden in der Frühdiagnostik und Verlaufskontrolle der Osteoporose eingesetzt.

Aus der ermittelten Knochendichte kann eine Aussage zum bestehenden Frakturrisiko gemacht werden. So stellt eine niedrige Dichte einen insbesondere vom Alter [Siris et al. 2004] unabhängigen Risikofaktor für das Auftreten einer osteoporotischen Fraktur dar [Johnell et al. 2005; Marshall et al. 1996].

Die Osteodensitometrie nach der DXA-Methode gilt als Grundlage für die Definition und Stadieneinteilung der Osteoporose nach WHO [1994] (siehe 1.3.1, S. 9).

Im Folgenden werden die wichtigsten Verfahren zur Knochendichtemessung erläutert.

\section{Dual-X-Ray-Absorptiometrie}

Die Dual-X-Ray-Absorptiometrie (DXA) ist nach Angabe der WHO und DVO-Leitlinie [Pfeilschifter 2006] das Standardverfahren zur Ermittlung der Knochendichte. Sie gilt als die am umfangreichsten erforschte und am besten geeignete Untersuchungsmethode zur Abschätzung des Frakturrisikos bei Frauen [Marshall et al. 1996; Kanis und Glüer 2000]. Physikalische Grundlage der DXA ist die Tatsache, dass Gewebe wie Muskel, Knochen oder Fett für Strahlen unterschiedlicher Energie jeweils ein spezifisches Absorptionsverhalten zeigen. So werden bei der DXA zwei energetisch verschiedene Röntgenstrahlen erzeugt und durch das zu untersuchende Areal gelenkt. Beim Durchdringen des Gewebes kommt 
es zur Energieabsorption, die im Wesentlichen durch Kalziumhydroxylapatitkristalle des Knochens verursacht wird.

Auf der entgegengesetzten Seite wird die Abschwächung der Strahlung für die zwei Energiestufen separat detektiert. Basierend auf dem sich voneinander unterscheidenden Absorptionsprofil der zwei Röntgenstrahlen, kann der weichteilbedingte Anteil der Absorption bestimmt und eleminiert werden. Aus den ermittelten Daten wird der Mineralgehalt des Knochens errechnet und als flächenprojizierte Masse (Flächendichte) in g Kalziumhydoxylapatit $/ \mathrm{cm}^{2}$ angegeben.

$\mathrm{Zu}$ den wesentlichen Vorteilen der DXA zählt neben der sehr geringen Strahlenbelastung und der hohen Messgenauigkeit die Möglichkeit, zentrale osteoporose- und somit frakturgefährdete Skelettanteile direkt zu vermessen [Bartl R und Bartl C 2008; Blake und Fogelman 1997]. Aufgrund ihrer klinischen Relevanz und der häufig differierenden Messergebnisse zwischen verschiedenen Skelettarealen [El Maghraoui et al. 2007; Mounach et al. 2008] wird die standardmäßige Untersuchung der Wirbelsäule (Lendenwirbel 1-4) und des Femurs (Oberschenkelhals, Ward-Dreieck, Trochanterregion und Schaft) empfohlen [Leib et al. 2004; O'Gradaigh at al. 2003].

Die DXA liefert keine Informationen über die dreidimensionale Struktur des Knochens. Somit macht diese Untersuchung keine Aussage zur Qualität der trabekulären Mikroarchitektur, die neben der Knochendichte wesentlichen Einfluss auf die Knochenstabilität hat [NIH Consensus Development Panel on Osteoporosis 2001].

\section{Quantitative Computertomographie}

Die Quantitative Computertomographie (QCT) ermöglicht als einzige osteodensitometrische Methode die direkte Messung der volumetrischen Knochendichte (in mg Kalziumhydroxylapatit $/ \mathrm{cm}^{3}$ ). Sie stellt neben der DXA ein Standardverfahren zur Osteodensitometrie dar [Genant et al. 1996].

Die QCT erlaubt eine separate Bewertung von Kortikalis und trabekulärem Knochen. Als Standardmessort gilt der trabekuläre Anteil der Lumbalwirbelkörper. Dieser ist von wesentlicher Bedeutung für die Knochenfestigkeit und zeigt aufgrund einer hohen Umbaudynamik sowohl bei der Ausbildung einer Osteoporose als auch bei antiosteoporotischer Therapie frühzeitig Veränderungen der BMD [Guglielmi und Lang 2002].

Die Messungen können mit herkömmlichen klinischen Ganzkörpertomographen durchgeführt werden. Zusätzlich wird ein spezielles Messprotokoll und ein standardisiertes mineralsalzäquivalentes Referenzphantom benötigt.

Zu den Nachteilen der QCT gegenüber der DXA-Methode zählen die höhere Strahlenbelastung, die längere Untersuchungszeit und die höheren Kosten [Raisz 2005].

Aufgrund dieser Nachteile konnte sich die QCT bisher nicht gegen das Standardverfahren DXA durchsetzen. So findet diese Methode vorwiegend bei speziellen Fragestellungen 
und als alternatives diagnostisches Mittel bei nicht verwendbaren DXA-Ergebnissen Anwendung [Grampp et al. 2004]. Nach Prevrhal und Genant [1999] stellen der begrenzte Zugang zu CT-Scannern, die Abhängigkeit der Ergebnisse vom Untersucher und die eingeschränkten Möglichkeiten zur Vermessung des Femurs weitere Gründe für die geringe klinische Akzeptanz dar.

Eine Sonderform der QCT ist das periphere QCT (pQCT). Dieses Verfahren erlaubt die Knochendichtemessung der Extremitäten bei geringer Strahlenbelastung. Sie kann mit vergleichsweise kleinen, transportablen Geräten durchgeführt werden. Als Standardmessort gilt der distale Radius [Augat et al. 1998]. Wesentlicher Nachteil dieser Methode ist die fehlende Möglichkeit zur direkten Vermessung besonders frakturgefährdeter Areale (proximales Femur, Wirbelsäule).

\section{Quantitative Ultrasonographie}

Die Quantitative Ultrasonographie (QUS) ist ein röntgenfreies Verfahren zur Ermittlung der peripheren Knochendichte. Zu den wesentlichen Vorteilen dieser nichtinvasiven Methode zählt neben den geringen Kosten auch die einfach und schnell durchzuführende Messung, die mit transportablen Geräten erfolgen kann.

Bei der QUS werden Ultraschallwellen durch den zu untersuchenden Knochen geleitet und die Veränderung dieser auf der entgegengesetzten Seite detektiert. Als Messparameter finden die Schallgeschwindigkeit (Speed of sound; SOS; in $\mathrm{m} / \mathrm{s}$ ) und die Schallschwächung (Broadband ultrasound and attenuation; BUA; in $\mathrm{dB} / \mathrm{MHz}$ ) Verwendung.

Die QUS erlaubt nur die Untersuchung peripherer Skelettanteile wie Kalkaneus, Tibia, Radius und Phalangen. Aus den ermittelten Werten wird auf die Knochendichte und Frakturgefährdung zentraler Skelettanteile geschlossen.

Der für die Messung gut zugängliche Kalkaneus gilt als Standardmessort für die QUS. Dieser zeichnet sich als gewichtstragender Kochen durch einen hohen trabekulären Anteil aus, wodurch eine gewisse Vergleichbarkeit zur Wirbelsäule gegeben ist, jedoch sind osteoporotische Frakturen des Kalkaneus eine Rarität. Wie aus mehreren Studien hervorgeht, kann das absolute Frakturrisiko insbesondere bei postmenopausalen Frauen mit Hilfe der QUS am Kalkaneus ähnlich gut abgeschätzt werden wie durch die zentrale DXA-Methode [Glüer et al. 2004; Huopio et al. 2004; Hans et al. 1996].

Nach Glüer et al. [1994] liefert die QUS im Gegensatz zur DXA auch Daten zur Stuktur der Knochen. So gibt dieses Verfahren zusätzliche Informationen über Kompaktastärke und Bälkchenarchitektur [Bartl R und Bartl C 2008].

Eine verbesserte Einschätzung des Frakturrisikos durch eine Kombination aus DXA und QUS konnte bisher nicht nachgewiesen werden [Frost et al. 2001].

Zu den wesentlichen Nachteilen der QUS zählen die fehlende Möglichkeit zur direkten Vermessung besonders frakturgefährdeter Skelettareale (proximales Femur und Wirbelsäule) 
und die geringen Langzeiterfahrungen hinsichtlich des Therapie-Monitorings. Zudem seien nach Pallamar und Friedrich [2005] die bisherigen Standardisierungs- und Qualitätssicherungsmaßnahmen unzureichend.

Die DVO-Leitlinie [Pfeilschifter 2006] sieht aufgrund der aktuellen Datenlage die DXAMessung als Standardverfahren der Osteoporosediagnostik. Den Einsatz der QUS zur Erstdiagnostik empfiehlt sie nur in Ausnahmesituationen.

\subsubsection{Labor}

Im Regelfall zeigen Patienten, die unter primärer Osteoporose leiden, keine wesentlichen Auffälligkeiten der Laborparameter [Bartl R et al. 2003]. Zum Ausschluss einer sekundären Form der Osteoporose und zur differentialdiagnostischen Abgrenzung gegenüber der Osteomalazie, die ebenfalls mit einer verminderten Knochendichte einhergeht, empfiehlt die DVO-Leitlinie [Pfeilschifter 2006] jedoch die Durchführung eines Basislabors (siehe Tab.5). Diese Untersuchung sollte insbesondere bei Frakturen nach Bagatelltrauma, einem T-Score $<2$ (DXA) und bei anamnestischen Hinweisen auf eine sekundäre Osteoporose erfolgen.

Neben den in Tab.5 aufgeführten Laborparametern stehen verschiedene Marker zur Beurteilung des Knochenstoffwechsels zur Verfügung. So gelten erhöhte Werte von Desoxypyridinolin, Pyridinolin, C- und N-terminalem Telopeptid, die beim Abbau von Knochenkollagen freigesetzt werden, als Hinweis auf einen erhöhten Knochenverlust. Als Marker, die hingegen für eine erhöhte Knochensynthese sprechen, zählen die knochenspezifische alkalische Phosphatase und Osteocalcin, die von Osteoblasten synthetisiert werden. Diese Marker ermöglichen neben der Differenzierung zwischen High- und Low-turnover-Osteoporose die Beurteilung der Krankheitsaktivität [Garnero und Delmas 2004; Seibel 2003]. Für Screeninguntersuchungen oder die Erstdiagnostik der Osteoporose werden sie dahingegen nicht empfohlen [Pfeilschifter 2006].

Tabelle 5: Empfohlene Basislaborparameter (modifiziert nach Pfeilschifter [2006], S. 233)

\begin{tabular}{|l|}
\hline Empfohlene Laborparameter \\
\hline Serum-Kalzium \\
Serum-Phosphat \\
Alkalische Phosphatase (Serum) \\
$\gamma$-GT \\
Serum-Kreatinin \\
Blutkörperchensenkungsgeschwindigkeit \\
C-Reaktives Protein \\
Serum-Eiweißelektrophorese \\
TSH \\
\hline
\end{tabular}




\subsubsection{Therapie}

Im Folgenden werden Basismaßnahmen und die spezifische medikamentöse Therapie zur Prävention und Behandlung der Osteoporose vorgestellt. Die Darstellung orientiert sich an der DVO Leitlinie zur Osteoporose 2006 [Pfeilschifter 2006].

\subsubsection{Prävention und Basistherapie}

$\mathrm{Zu}$ den wesentlichen nichtmedikamentösen Maßnahmen der Osteoporose- und Frakturprävention zählen die Förderung körperlicher Aktivität und die Vermeidung der unter 1.3.5 (S. 15) aufgeführten Risikofaktoren.

In Anbetracht der Tatsache, dass über $90 \%$ der Hüftfrakturen auf einen Sturz zurückzuführen sind, sollte bei älteren Menschen besonderer Wert auf die Reduktion des Sturzrisikos gelegt werden [Woolf und Akesson 2003]. Dies kann beispielsweise eine Optimierung des häuslichen Umfeldes oder die Anwendung von Gehhilfen erreichen. Zudem sollten orthostatisch oder sedierend wirksame Medikamente nur unter strenger Indikationsstellung eingesetzt werden. Ab dem 70. Lebensjahr wird die jährliche Durchführung einer Sturzanamnese angeraten.

Zur Basistherapie und Prävention der Osteoporose empfiehlt die DVO-Leitlinie eine ausreichende Supplementierung von Vitamin D und Kalzium bei Mangelzuständen. Es ist von einer Kalziumunterversorgung auszugehen, wenn die erforderliche Tagesdosis von 12001500 mg nicht über die Nahrung aufgenommen werden kann. Beträgt die Zeit der täglichen Sonnenlichtexposition weniger als 30 Minuten, so ist ein Vitamin-D-Mangel zu erwarten [vgl. 1.2.1.5, S. 6. Die Kombinationstherapie aus Kalzium und Vitamin D reduziert bei Männern und Frauen, die älter als 65 Jahre sind und im Pflegeheim leben, den Knochenabbau und das Risiko extravertebraler Frakturen [Dawson-Hughes et al. 1997]. Auch bei Frauen ab dem 45. Lebensjahr ist eine osteoprotektive Wirkung belegt [Di Daniele et al. 2004].

Nach osteoporotischen Frakturen empfiehlt die DVO-Leitlinie eine Schmerztherapie nach dem WHO-Stufenschema, um eine frühe Mobilisierung zu ermöglichen. Des Weiteren sollten Rehabilitationsmaßnahmen, Physiotherapie, Funktionstraining, eine psychosoziale Betreuung und eine antiosteoporotische Pharmakotherapie (siehe 1.3.8.2 eingeleitet werden.

\subsubsection{Spezifische medikamentöse Therapie}

Derzeit werden von der DVO-Leitlinie Alendronat, Ibandaronat, Östrogene, Raloxifen, Risedronat, Strontium Ranelat und Teriparatid zur Therapie der postmenopausalen Osteoporose empfohlen. Für die Behandlung der Osteoporose bei Männern ab dem 60. Lebensjahr besteht in Deutschland derzeit eine ausschließliche Empfehlung für Alendronat. 
Es gibt zwei wesentliche Indikationen für die spezifische medikamentöse Therapie. Zum einen sollte sie bei manifester Osteoporose (T-Wert DXA $<-2,5)$ mit bereits aufgetretenen Wirbelkörperfrakturen eingeleitet werden. Eine zweite Indikation stellt ein erhöhtes 10-Jahres-Frakturrisiko dar. So wird empfohlen, ab einem 30-prozentigen Risiko für Wirbelkörper- und Femurfrakturen eine medikamentöse Therapie durchzuführen. Tab.6 gibt eine Übersicht der Konstellationen aus Alter, Geschlecht und T-Wert, die mit einem entprechenden Frakturrisiko assoziiert sind.

Tabelle 6: T-Werte in Abhängigkeit von Lebensalter und Geschlecht, die im Mittel mit einem 30-prozentigem Frakturrisiko für Wirbelkörper- und proximale Femurfrakturen in 10 Jahren assoziiert sind (nach Pfeilschifter [2006], S. 265)

\begin{tabular}{|l|l|l|}
\hline \multicolumn{2}{|l|}{ Lebensalter in Jahren } & \multirow{2}{*}{ T-Wert (niedrigerer Wert der beiden Messungen } \\
\cline { 1 - 2 } Frau & Mann & aWS und dem prox. Gesamtfemur) \\
\hline \hline $50-60$ & $60-70$ & $-4,0$ \\
\hline $60-65$ & $70-75$ & $-3,5$ \\
\hline $65-70$ & $75-80$ & $-3,0$ \\
\hline $70-75$ & $80-85$ & $-2,5$ \\
\hline$>75$ & $>85$ & $-2,0$ \\
\hline
\end{tabular}

Liegen zusätzliche Risikofaktoren, wie periphere Frakturen, Schenkelhalsfrakturen eines Elternteils, Nikotinkonsum, multiple Stürze oder Immobilität vor, so sollte bereits bei geringeren BMD-Verlusten eine Therapie eingeleitet werden.

Bei Osteoporosemedikamenten lassen sich zwei wesentliche Wirkmechanismen unterscheiden. So gibt es antiresorptive Medikamente, die ihre osteoprotektive Wirkung durch eine Hemmung des Knochenabbaus entfalten. Im Gegensatz dazu führen osteoanabole Substanzen zu einer Steigerung der Knochensynthese. Strontium Ranelat ist derzeit das einzige zugelassene Medikament mit dualem Wirkmechanismus, das sowohl den Knochenabbau hemmt als auch die Knochensynthese fördert.

Es wird empfohlen die medikamentöse Therapie über 3 bis 5 Jahre fortzusetzen (Ausnahme: Teriparatid nur 18 Monate). Anschließend sollte anhand einer Reevaluation des Frakturrisikos über die weiterführende Therapie entschieden werden.

\subsubsection{Hormonersatztherapie}

Unter dem Begriff der Hormonersatztherapie (hormone replacement therapy; HRT) versteht man die Substitution von Östrogen bzw. Östrogen und Gestagen, um dem postmenopausalen endogenen Hormonmangel entgegenzuwirken. Diese Therapie führt zu einer deutlichen Linderung klimakterischer Beschwerden. Im Knochengewebe zeigt Östrogen einen anabolen Effekt [Rossouw et al. 2002; Spelsberg et al. 1999]. 
Die Östrogenmonotherapie erhöht das Risiko für Endometriumkarzinome. Dem kann die zusätzliche Verabreichung von Gestagen entgegenwirken [Beral et al. 2005]. Frauen mit intaktem Uterus sollten somit immer ein Östrogen/Gestagen-Kombinationspräparat erhalten. Die Östrogenmonotherapie wird nur für Frauen empfohlen, bei denen bereits eine Hysterektomie durchgeführt wurde.

Im Rahmen einer groß angelegten randomisierten, placebokontrollierten Studie in den USA (Women's Health Initiative; WHI) wurden die Auswirkungen der zwei zuvor beschriebenen Therapieoptionen an 161.809 postmenopausalen Frauen untersucht. Hierbei zeigte sich, dass es durch die HRT zu einer signifikanten Senkung vertebraler und extravertebraler Frakturen kommt [Rossouw et al. 2002; Anderson et al. 2004]. So reduzierte die Kombinationstherapie das Risiko für Hüft- und Wirbelkörperfrakturen um ein Drittel [Rossouw et al. 2002]. Gleichzeitig wurde jedoch ein deutlicher Anstieg des relativen Risikos für kardiovaskuläre Erkrankungen und Brustkrebs registriert [Rossouw et al. 2002]. Die Östrogen-Monotherapie führte zu einem vermehrten Auftreten von Schlaganfällen [Anderson et al. 2004]. So mussten beide Studienarme vorzeitig abgebrochen werden.

Auch in einer zweiten großen Studie (Million Women Studie) mit 1.084.110 Probandinnen bestätigte sich, dass insbesondere die Kombinationstherapie zu einem erhöhten Brustkrebsrisiko führt [Beral 2003]. Außerdem wurde ein Anstieg des relativen Risikos für Ovarialkarzinome beschrieben [Beral et al. 2007].

In Untersuchungen an ovarektomierten Ratten zeigte Östrogen einen positiven Einfluss auf die Frakturheilung. Es beschleunigt den Heilungsvorgang und führt zur Ausbildung eines relativ kleinen, aber widerstandsfähigen und elastischen Kallus [Kolios et al. 2009; Ouyang et al. 2004; Stürmer et al. 2008; Tian et al. 2006].

Bis Ende der 90er-Jahre wurde die Indikation zur HRT relativ großzügig gestellt. Die zuvor aufgeführten Erkenntnisse über die Nebenwirkungen einer solchen Therapie führten dazu, dass die Hormonsubstitution heute nur noch sehr zurückhaltend eingesetzt wird. Nach Empfehlung der DVO-Leitlinie sollte die HRT aufgrund des ungünstigen NutzenRisikoverhältnisses nur unter strenger Indikation erfolgen. Sie empfiehlt ihren Einsatz zur Sekundärprävention bei Unverträglichkeit oder Kontraindikationen gegenüber anderen zugelassenen Osteoporosemedikamenten. Das individuelle Risiko-Nutzenprofil sollte immer in die Entscheidung mit einbezogen werden.

\subsubsection{Selektive Östrogen-Rezeptor-Modulatoren}

„Selektive Östrogen-Rezeptor-Modulatoren“ (SERMs) sind Substanzen, die organselektiv eine östrogenagonistische oder östrogenantagonistische Wirkung zeigen. Sie können beispielsweise einen östrogenen Effekt auf das Knochengewebe und den Fettstoffwechsel haben, während sie auf Brust- und Uterusgewebe keinen Einfluss zeigen. Ihre Wirkung entfalten diese Substanzen durch direkte Interaktion mit den Östrogenrezeptoren (ER) $\alpha$ und 
$\beta$. ER $\alpha$ ist in die Regulation der Kochenreifung und Aufrechterhaltung der Knochenmineraldichte sowohl bei Frauen als auch bei Männern involviert. ER $\beta$ ist überwiegend im zentralen Nervensystem, Lungengewebe, Urogenitaltrakt, kardiovaskulären System, Ovar, Hoden, Nierengewebe und Kolon vorzufinden. Die Ursachen für die organselektive Wirkung der SERMs sind sehr komplex. Sie wird u.a. auf die gewebespezifische Konstellation von ER-Typen und Coregulatoren zurückgeführt [Dutertre und Smith 2000].

Als Beispiel für diese antiresorptiv wirksame Substanzgruppe ist das in der vorliegenden Arbeit untersuchte Raloxifen anzuführen. Es ist derzeit der einzige weltweit zugelassene SERM zur Prävention und Behandlung postmenopausaler Osteoporose und vertebraler Frakturen [Gennari et al. 2007]. In der evidenzbasierten DVO-Leitlinie wird Raloxifen als Klasse-A-Medikament (beste Evidenzklasse) zur Therapie der postmenopausalen Osteoporose empfohlen.

Eine internationale Studie zum Einsatz von Raloxifen bei postmenopausalen Frauen zeigte, dass dieser SERM das Risiko für das Erstauftreten einer Wirbelkörperfraktur halbiert (MORE-Studie). Die Inzidenz extravertebraler Frakturen blieb im Gegensatz dazu unbeeinflusst. Über den Therapiezeitraum von zwei Jahren wurde eine durchschnittliche Zunahme der BMD um 2-3\% beobachtet [Ettinger et al. 1999]. Raloxifen stimuliert weder die Brustdrüse noch das Endometrium und scheint das Risiko für Brustkrebs zu reduzieren [Cummings et al. 1999].

Derzeit liegen nur wenige Daten zum Einfluss von Raloxifen auf die Frakturheilung bei osteoporotischem Knochen vor. In Untersuchungen zur metaphysären Frakturheilung an ovarektomierten Ratten führte Raloxifen zu einer signifikanten Verbesserung der Frakturheilung. So konnte gezeigt werden, dass es die Ausbildung eines widerstandsfähigen, elastischen Kallus fördert [Stürmer et al. 2008]. SERMs verursachen eine leichte Suppression des Kallusremodelings. In Untersuchungen zur Frakturheilung am Femurschaft ovarektomierter Ratten zeigte Raloxifen gegenüber Östrogen keine signifikanten Unterschiede [Cao et al. 2002; Komatsubara und Mori 2005].

\subsubsection{Bisphosphonate}

Bisphosphonate sind künstlich hergestellte Analoga des natürlich vorkommenden Pyrophosphats. Aufgrund ihrer veränderten chemischen Struktur werden sie im menschlichen Körper nicht metabolisiert.

Bisphosphonate zählen zur Gruppe der antiresorptiv wirksamen Osteoporosemedikamente. Sie reichern sich auf der Knochenoberfläche an, bevorzugt in Resorptionslakunen. Dort entfalten sie u.a. durch eine Inhibition der osteoklastischen Aktivität ihre osteoprotektive Wirkung [Bartl R und Bartl C 2008]. 
Bisphosphonate sind seit über 30 Jahren auf dem deutschen Markt zugelassen. Derzeit finden in der Osteoporosetherapie insbesondere die drei Aminobisphosphonate Alendronat, Risedronat und Ibandronat Verwendung.

Alendronat und Risedronat gehören nach der DVO-Leitlinie zur Therapie der ersten Wahl. Beide Substanzen zeigen bei postmenopausalen Frauen mit Osteoporose eine signifikante Reduktion des Risikos für vertebrale und nichtvertebrale Frakturen um etwa $50 \%$ [Black et al. 1996; Cummings et al. 1998; Harris et al. 1999; McClung et al. 2001; Pols et al. 1999].

Ibandronat, das im Rahmen der BONE-Studie untersucht wurde, führt ebenfalls zur Reduktion vertebraler Frakturen. In Abhängigkeit von der Applikationsfrequenz kann das Risiko um Werte zwischen 50 und $62 \%$ gesenkt werden [Chesnut et al. 2004]. Ein sicherer Effekt auf das Risiko extravertebraler Frakturen ist derzeit nicht ausreichend belegt [Grey und Reid 2006].

\subsubsection{Strontiumranelat}

Strontiumranelat setzt sich chemisch aus einem organischen Anteil, der Ranelicsäure, und zwei Atomen des Erdalkalimetalls Strontium zusammen. Es bewirkt sowohl eine Steigerung der Knochenneubildung als auch eine Verminderung der Knochenresorption [Marie et al. 2001]. Dabei basiert der antiresorptive Effekt auf einer Hemmung der Differenzierung und Aktivität osteoklastischer Zellen. Der osteoanabole Effekt wird auf eine Steigerung der Präosteoblastenreplikation und der ossären Kollagensynthese zurückgeführt [Reginster et al. 2003].

Zur Untersuchung der Wirksamkeit von Strontiumranelat wurden zwei große klinische Studien (SOTI-Studie $=$ Spinal Osteoporosis Therapeutic Intervention-Studie; TROPOSStudie $=$ Treatment of Peripheral Osteoporosis-Studie) an postmenopausalen Frauen mit Osteoporose durchgeführt. Dabei zeigte sich, dass diese Therapie zu einer signifikanten Reduktion vertebraler und extravertebraler Frakturen führt [Meunier et al. 2004; Reginster et al. 2005]. Das Risiko für das Erstauftreten einer Wirbelkörperfraktur konnte im ersten Therapiejahr um $49 \%$ reduziert werden [Meunier et al. 2004]. Bei besonders gefährdeten Patientinnen wurde das relative Risiko für Hüftfrakturen um $36 \%$ gesenkt [Reginster et al. 2005]. Über den Therapiezeitraum von 3 Jahren führte Strontiumranelat zu einem deutlichen Anstieg der Knochenmineraldichte. Dieser belief sich auf 14,4\% in der Lumbalwirbelsäule und 8,3\% im proximalen Femur [Meunier et al. 2004]. 


\subsubsection{Parathormon}

Derzeit werden sowohl das PTH-Fragment PTH(1-34) (Teriparatid; rhPTH(1-34)) als auch das vollständige rekombinante PTH(1-84) für Forschungs- und Therapiezwecke eingesetzt.

Wird PTH im therapeutischen Rahmen unphysiologischerweise pulsatil verabreicht, so zeigt es einen deutlichen osteoanabolen Effekt bei Tieren und Menschen. Es kommt trabekulär, endostal, intrakortikal und periostal zu einer Zunahme der Knochenmasse [Kim und Jahng 1999; Sehmisch et al. 2009].

PTH führt zu einer Verbesserung der knöchernen Mikroarchitektur [Jiang et al. 2003; Tezval et al. 2009 b]. So wurde im spongiösen Knochen eine Zunahme der Trabekeldicke und der Anzahl der Trabekelkreuzungen beobachtet [Dempster et al. 2001; Zhang et al. 2002]. In Versuchen an ovarektomierten Ratten konnte durch eine PTH-Therapie die biomechanische Belastbarkeit des proximalen Femurs gegenüber der untherapierten Kontrollgruppe und der Estradioltherapie signifikant verbessert werden [Tezval et al. 2009 b].

PTH ist ein hoch potentes Medikament zur Unterstützung der Frakturheilung. Es führt bei Ratten zu einem größeren Kallusvolumen, einer höheren Knochenmineraldichte und einer gesteigerten mechanischen Belastbarkeit der Frakturüberbrückung [Alkhiary et al. 2005; Andreassen et al. 2001; Kim und Jahng 1999]. Diese positiven Effekte werden u.a. auf die frühe Stimulation der Osteoprogenitorzellen, den Vorläuferzellen der Osteoblasten, eine gesteigerte Produktion von Knochenmatrix und die Hemmung der Osteoblastenapoptose zurückgeführt [Nakajima et al. 2002; Bartl R und Bartl C 2008].

Die Therapie postmenopausaler Patientinnen mit Osteoporose führt sowohl unter PTH(134) als auch unter PTH(1-84) zu einer signifikanten Zunahme der BMD. Im Gegenzug nimmt das Risiko für vertebrale (PTH(1-34) und PTH(1-84)) und extravertebrale (PTH(134)) Frakturen ab [Greenspan et al. 2007; Neer et al. 2001].

Derzeit sind beide Substanzen als Fertigarzneimittel erhältlich. Sie sind zur Therapie der postmenopausalen Osteoporose mit hohem bis sehr hohem Frakturrisiko zugelassen. Die Applikation erfolgt einmal täglich subcutan. Eine Behandlungszeit von 18 Monaten (PTH(1-34)) bzw. 24 Monaten (PTH(1-84)) sollte nicht überschritten werden.

\subsubsection{Phytoöstrogene}

Phytoöstrogene sind natürlich vorkommende pflanzliche Substanzen, die eine östrogene Aktivität aufweisen. Sie gehören in chemischer Hinsicht zu den Polyphenolen. Biologisch zählen sie zu den sekundären Pflanzenstoffen, die Pflanzen u.a. als Abwehrstoffe gegen Schädlinge, als Wachstumsregulatoren oder als Farbstoffe dienen. Die Phytoöstrogene lassen sind im Wesentlichen in drei Strukturklassen einteilen: Isoflavone, Lignane und Coumestane. 
Aufgrund struktureller Ähnlichkeiten zum 17 $\beta$-Östradiol ist eine Interaktion mit dem Östrogenrezeptor $\alpha$ und $\beta$ möglich. Weitere Wirkmechanismen werden diskutiert [Kulling und Watzl 2003]. Wie die Gruppe der SERMs zeigen Phytoöstrogene sowohl östrogene als auch antiöstrogene Aktivität [Brzezinski und Debi 1999]. Sie werden daher auch als „Phyto-SERMs" bezeichnet.

Die pharmakologische Potenz dieser Substanzen ist um den Faktor 100 bis 10.000 geringer als die von 17 $\beta$-Östradiol. Allerdings können sie in bis zu 10.000fach höherer Konzentration im Körper vorliegen [Kulling und Watzl 2003].

Der beschriebene hormonelle Effekt der Phytoöstrogene, verbunden mit einer im Vergleich geringeren Inzidenz der Osteoporose in Populationen, die sich vermehrt mit sojahaltigen Produkten ernähren, hat dazu geführt, dass die Wissenschaft zunehmendes Interesse an diesen Wirkstoffen zeigt. So besteht die Hoffnung, unter ihnen Substanzen zu finden, die postmenopausalen Frauen die Vorteile der Hormonersatztherapie bringen, ohne dass die Risiken einer solchen Therapie (siehe 1.3.8.3, S. 23) in Kauf genommen werden müssen. Im Folgenden werden die Eigenschaften der in dieser Arbeit untersuchten Phytoöstrogene Cimicifuga racemosa, Equol und Genistein genauer dargelegt.

\section{Cimicifuga racemosa}

Die Traubensilberkerze (Cimicifuga racemosa; CR; engl.: black cohosh) stammt aus dem Osten Nordamerikas. Sie gehört zur Familie der Hahnenfußgewächse (Ranunculaceae). Pharmakologisch finden Wurzelstock (Rhizom) und Wurzeln Verwendung, die als wirksame Inhaltsstoffe u.a. Triterpenglykoside, Phenolcarbonsäuren und Flavonoide enthalten. Der Extrakt der Traubensilberkerze BNO 1055 hat sowohl östrogene als auch antiöstrogene Wirkung. Es ist bisher unklar, welche Substanzen für diese Effekte verantwortlich sind [Seidlova-Wuttke et al. 2003 a]. Jarry et al. [2003] fanden heraus, dass die beschriebene Wirkung nicht durch eine Interaktion mit $\operatorname{ER} \alpha$ oder $\beta$ vermittelt wird. Vielmehr wird ein Wirkmechanismus über eine bisher unbekannte Bindungsstelle vermutet [Jarry et al. 2003]. Bei Ratten verhindert BNO 1055 teilweise den metaphysären Knochenmasseverlust nach Ovarektomie. Auf den Uterus zeigt sich dahingegen kein Einfluss [Seidlova-Wuttke et al. 2003 a].

In einer klinischen Studie konnten Wuttke et al. [2006] laborchemisch nachweisen, dass CR bei postmenopausalen Frauen zu einer Stimulation der Osteoblastenaktivität mit Förderung des Remodelings führt. Auf die Vaginalschleimhaut zeigte sich eine schwache östrogene Wirkung. Auswirkungen auf die Brustdrüse wurden nicht beobachtet [Ruhlen et al. 2007]. Daten zur Frakturheilung liegen bisher nicht vor.

Aufgrund der aufgeführten Erkenntnisse steht BNO 1055 im Interesse der Forschung zur Prävention und Therapie der Osteoporose. Derzeit erhältliche Fertigarzneimittel sind für 
die Therapie des Klimakterischen und des Prämenstruellen Syndroms mit neurovegetativer Beschwerdesymptomatik zugelassen. Sie stellen eine gut verträgliche, pflanzliche Alternative zur HRT dar. Ein positiver Effekt dieser Präparate auf die perimenopausalen Beschwerden konnte durch klinische Studien bisher nicht gesichert werden [Borrelli und Ernst 2008].

\section{Equol}

Equol (EQ) ist ein aktiver Hauptmetabolit des Phytoöstrogens Daidzein. Daidzein kommt in großen Mengen in Sojabohnen vor und zählt zur Gruppe der Isoflavone. Die Metabolisierung zum etwa 100 fach potenteren EQ erfolgt durch spezifische Bakterien im menschlichen Darm [Decroos et al. 2005; Wang et al. 2005 b; Sathyamoorthy und Wang 1997]. Nach Atkinson et al. [2005] können aufgrund der individuell unterschiedlichen Darmflora nur ca. 30-50 \% aller Menschen Soja zu EQ metabolisieren. Bei der menschlichen Metabolisierung wird ausschließlich der Entantiomer S-Equol gebildet. Dieser weist eine hohe Affinität zum $\operatorname{ER} \beta$ auf [Setchell et al. 2005].

Die Auswirkungen von EQ werden derzeit kontrovers diskutiert. Nach Fujioka et al. [2004] reduziert EQ bei Mäusen den Knochenmasseverlust nach Ovarektomie. Eine östrogenagonistische Wirkung auf die Reproduktionsorgane zeigte sich in dieser Untersuchung nicht. Auch am Femur ovarektomierter Ratten ließ sich ein osteoprotektiver Effekt nachweisen [Mathey et al. 2007; Tezval et al. 2009 a]. Durch eine in vitro Untersuchung an Mauszellen wurde eine signifikante Inhibition der Osteoklastenformation durch EQ festgestellt [Ohtomo et al. 2008].

Demgegenüber stehen die Ergebnisse von Rachon et al. [2008 und 2007 b]. Hiernach zeigt EQ bei ovarektomierten Ratten uterotrope und mammotrope Effekte. Ein Einfluss auf den Knochenverlust in der proximalen Tibia wurde nicht festgestellt. Dahingegen zeigten die Lumbalwirbelkörper nicht nur eine Reduktion des Knochenverlusts, es kam sogar zu einem Anstieg der BMD [Rachon et al. 2007 a]. Daten zur Frakturheilung liegen derzeit nicht vor.

\section{Genistein}

Genistein (GEN) gehört zur Gruppe der Isoflavone. Diese sind in pflanzlicher Nahrung sehr weit verbreitet. Hauptquelle für GEN ist die Sojabohne.

GEN weist strukturelle Ähnlichkeiten zum Östrogen auf und entfaltet seine Wirkung über die Interaktion mit dem $\operatorname{ER} \alpha$ und $\beta$. Dabei zeigt es eine höhere Affinität zu ER $\beta$ [Kuiper er al. 1997]. Des Weiteren gibt es Hinweise auf nicht-östrogene Wirkmechanismen [Fanti et al. 1998].

GEN zeigt bei ovarektomierten Ratten einen osteoprotektiven Effekt [Mathey et al. 2007; Picherit et al. 2000; Sehmisch et al. 2008]. Es reduziert den Verlust von trabekulärem und 
kortikalem Knochen [Fanti et al. 1998]. Li und Yu [2003] beobachteten am Mausmodell, dass GEN den Verlust an Knochenmasse sowohl durch Hemmung der Knochenresorption als auch durch Stimulation der Knochenneubildung reduziert. Es zeigten sich allerdings geringe Nebeneffekte auf Uterus und Serum-Östrogenspiegel. Bei In-vitro-Versuchen von Gao und Yamaguchi [2000] wurde für Genistein eine osteoklasteninhibierende Wirkung festgestellt. Daten zur Frakturheilung liegen derzeit nicht vor [Gao und Yamaguchi 2000]. Untersuchungen von Hertrampf et al. [2007] legen nahe, dass der kochenprotektive Effekt von GEN ER $\alpha$-vermittelt ist und in besonderem Maße durch physische Aktivität während der Therapie positiv beeinflusst wird.

Die Genisteintherapie führt bei postmenopausalen Frauen zu einem Anstieg der BMD [Marini et al. 2007; Morabito et al. 2002]. Zudem werden vasomotorische Symptome reduziert, ohne dass sich dabei nachteilige Effekte auf das Endometrium zeigen [D'Anna et al. 2007].

\subsection{Die Ratte als Modelltier der postmenopausalen Osteoporose}

Die ovarektomierte Ratte gilt als gut erforschtes und etabliertes Modelltier der postmenopausalen Osteopenie bzw. Osteoporose [Kalu 1991; Frost und Jee 1992; Wronski und Yen 1991]. Ihr Knochen eignet sich nach Frost und Jee [1992] für Studien zur Untersuchung der Frakturheilung unter Einfluss verschiedener Wirkstoffe. Auch die FDA-Richtlinie (Food and Drug Administration; USA) [Thompson et al. 1995] empfiehlt, erste Studien zur medikamentösen Prävention und Therapie der Osteoporose zunächst an Ratten durchzuführen. In diesem Rahmen wurde die Ratte bereits in diversen Untersuchungen eingesetzt.

Durch die operative Entfernung der Ovarien wird bei der Ratte ein Östrogenmangel induziert. Dieser führt zu einer die Knochenneubildung übertreffenden Resorption von Knochensubstanz mit Folge der Ausbildung einer Osteopenie bzw. Osteoporose. Dieser Knochensubstanzverlust betrifft insbesondere die Spongiosa der proximalen Tibia, des distalen Femurs und der Lendenwirbelsäule. Diese Skelettareale gelten somit für die Beurteilung der Wirksamkeit potentieller Wirkstoffe zur Therapie der Osteoporose als besonders geeignet [Thompson et al. 1995]. Wronski et al. [1985] und Seidlová-Wuttke et al. [2003] konnten zeigen, dass die in der vorliegenden Arbeit untersuchte proximale Tibiametaphyse bereits drei Monate nach Ovarektomie einen Knochenmasseverlust von ca. $50 \%$ aufweist.

Trotz der Tatsache, dass sich die Osteoporose bei der Ratte nur unwesentlich im Bereich der Diaphyse manifestiert, basierten bisherige Untersuchungen zur Frakturheilung unter Osteoporose fast ausnahmslos auf Frakturen des Knochenschafts von Tibia und Femur. In der vorliegenden Arbeit wurde die Osteotomie an der proximalen Tibiametaphyse durchgeführt (siehe 2.4. S. 33). Dies ermöglichte die Untersuchung der Frakturheilung am Ort der Osteoporosemanifestation. 


\section{Material und Methoden}

Die nachstehend beschriebenen Versuche wurden mit Genehmigung der Bezirksregierung Braunschweig durchgeführt (AZ 509.42502 / 01-53.03, 12.05.2003).

\subsection{Versuchsaufbau}

Der Versuch erstreckte sich über insgesamt 98 Tage. Zu Beginn wurden 84 weibliche, drei Monate alte Ratten ovarektomiert. Diese erhielten über den Zeitraum von 62 Tagen Futter auf sojafreier Basis. Aufgrund des so induzierten Östrogenmangels kam es zur Ausbildung einer manifesten Osteoporose. Bereits in vorhergehenden Studien konnte gezeigt werden, dass weibliche Ratten drei Monate nach der operativen Entfernung der Ovarien einen Knochenmasseverlust von über $50 \%$ im Bereich der metaphysären Tibia aufweisen [Wronski et al. 1985; Seidlova-Wuttke et al. 2003 b]. Am 63. Tag erfolgte bei allen Versuchstieren die Osteotomie der Tibiametaphyse beidseits mit anschließender osteosynthetischer Versorgung. Postoperativ wurden die Ratten in sechs Testgruppen und eine Kontrollgruppe zu je zwölf Tieren aufgeteilt. Ab diesem Zeitpunkt erhielten die Testgruppen ihren gruppenspezifischen Wirkstoff. Zusätzlich wurden den Tieren im Rahmen einer Polychromen Sequenzmarkierung (siehe 2.10, S. 47) vier verschiedene Fluorochrome (XO, CG, AK, TC) zu unterschiedlichen Zeitpunkten der Frakturheilung verabreicht. Die Obduktion der Tiere erfolgte am 98. Versuchstag bzw. 35 Tage nach der Osteotomie. Anschließend wurden an den präparierten Tibiae biomechanische und morphologische Untersuchen durchgeführt.

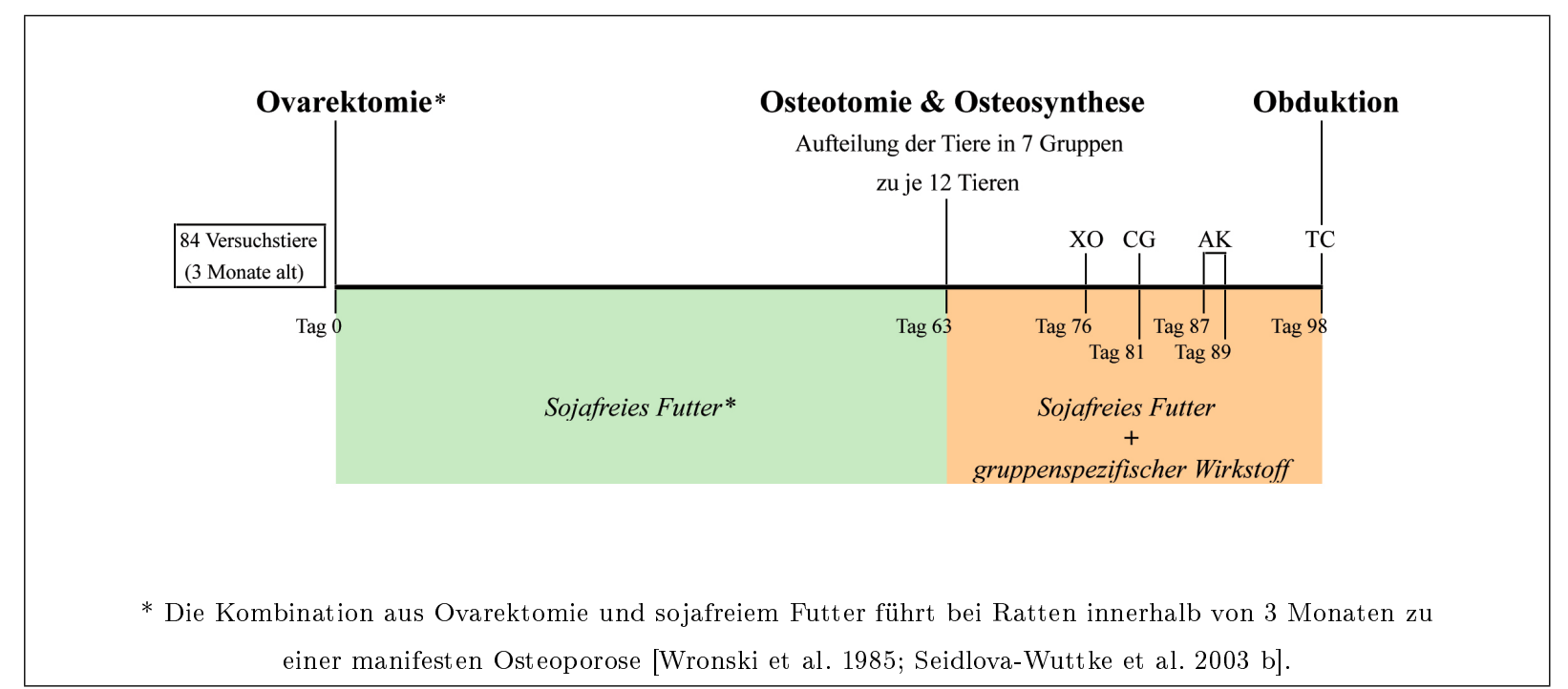

Abbildung 2: Versuchsaufbau 
Tabelle 7: Testgruppen und Substanzen mit Abkürzungen

\begin{tabular}{|l|c|}
\hline Testgruppe / Substanz & Abkürzung \\
\hline \hline Kontrollgruppe & $\mathrm{C}$ \\
\hline Estradiol (Estradiolbenzoat) & E2 \\
\hline Raloxifen & $\mathrm{R}$ \\
\hline Cimicifuga racemosa & $\mathrm{CR}$ \\
\hline Equol & EQ \\
\hline Genistein & GEN \\
\hline Parathormon (PTH $(1-34))$ & PTH \\
\hline
\end{tabular}

Tabelle 8: Gruppenzuordnung der Tiere

\begin{tabular}{|c|c|}
\hline Tiernummer & Testgruppe [Käfignr.] \\
\hline \hline $01-12$ & C [01-03] \\
\hline $13-24$ & E2 [04-06] \\
\hline $25-36$ & R [07-09] \\
\hline $37-48$ & CR [10-12] \\
\hline $49-60$ & EQ [13-15] \\
\hline $61-72$ & GEN [16-18] \\
\hline $73-84$ & PTH [19-21] \\
\hline
\end{tabular}

\subsection{Versuchstiere und Versuchstierhaltung}

Die Versuche wurden mit 84 weiblichen Ratten der Rasse Sprague-Dawley (Zuchtanstalt Fa. Winkelmann, Borken, Deutschland) durchgeführt. Zu Versuchsbeginn waren die Tiere drei Monate alt. Das durchschnittliche Körpergewicht (KG) betrug 233,8 g (211-262 g). Die Haltung der Ratten erfolgte in der Zentralen Tierexperimentellen Einrichtung des Universitätsklinikums Göttingen. Während des gesamten Versuchablaufs war eine fachgerechte Betreuung der Versuchstiere durch Veterinäre und Tierpfleger gewährleistet. Für die Unterbringung in Gruppen von drei bis fünf Tieren wurden Makrolon@-Käfige vom Typ IV verwendet. Die Reinigung der Käfige erfolgte alle drei Tage. Futter und Wasser standen zur freien Verfügung. Die Raumtemperatur betrug $20^{\circ} \mathrm{C}$ bei einer relativen Luftfeuchtigkeit von $55 \%$. Mit einer Periodik von $12 \mathrm{~h}$ wurde zwischen Tag (Beleuchtung) und Nacht (keine Beleuchtung) gewechselt. Der Futterverbrauch wurde zweimal pro Woche, das Körpergewicht der Tiere wöchentlich einmal bestimmt. Zusätzliche Messungen erfolgten vor Ovarektomie, Osteotomie/Osteosynthese und Obduktion (siehe Tab. 14. S. 54). 


\subsection{Ovarektomie}

Die Tiere wurden zunächst mit $\mathrm{CO}_{2}$ sediert und anschließend mit einem Gemisch aus Ketamin (Medistar, Holzwickede, Deutschland) und Xylazin (Riemser, Greifswald-Insel Riems, Deutschland) im Verhältnis 5:3 intraperitoneal narkotisiert. Die Dosierung erfolgte anhand des Körpergewichtes $(0,01 \mathrm{ml} / \mathrm{g} \mathrm{KG})$. Nach Rasur und Desinfektion des Operationsgebietes wurde die Haut paravertebral eröffnet, bis zum Peritoneum in die Tiefe präpariert und die Bauchhöhle eröffnet. Mit einer Pinzette wurde das ipsilaterale Ovar samt angrenzender Strukturen exploriert, die Tuba uterina ligiert und das Ovar anschließend scharf abgetrennt. Der Peritonealverschluss erfolgte mit Vicryl-Fäden (Ethicon, Johnson \& Johnson, Norderstedt, Deutschland), der Hautverschluss mit Klammern (Michel wound brackets $12 \times 3$ mm, Gebrüder Martin GmbH \& Co.KG, Tuttlingen, Deutschland). Auf der kontralateralen Körperseite wurde entsprechend verfahren.

Um im Versuchsverlauf jedes Tier gut identifizieren zu können, erhielten alle Tiere einen Transponder (Uno Micro-Id-System, Iso-Transponder (12 mm), UNO Roestvaststaal BV, Zevenaar, Niederlande). Diese wurden mit Hilfe eines Injektors im subkutanen Fettgewebe des Nackens platziert.

Zur Prävention eines postoperativen Volumenmangels erhielten alle Tiere nach der Operation s.c. $3 \mathrm{ml}$ isotone Kochsalzlösung. Abschließend wurden sie in einen mit Zellstoff ausgekleideten, gewärmten Käfig gelegt und bis zum Erwachen beobachtet.

\subsection{Osteotomie und Osteosynthese}

Die Narkose erfolgte analog zu 2.3. Beide Hinterläufe der Ratten wurden rasiert und desinfiziert. Anschließend erfolgte ein $3 \mathrm{~cm}$ langer Hautschnitt über der medio-ventralen Tibia. Dann wurden die Muskulatur und die ventrale Tibiakante dargestellt und die Beugemuskulatur unter Schonung des Periosts scharf vom Knochen abgetrennt.

Im nächsten Schritt wurde eine 5-Loch-Leibinger-Platte aus Titan (57-05140 XS-Titanfixationsplatte T-Form 90 ${ }^{\circ}$ Stryker Trauma, Selzach, Schweiz) am Knochen manuell fixiert, sodass die beiden proximalen Plattenlöcher in Höhe der Epiphyse lagen. Nun wurde zunächst der poximale zephale Schraubenkanal vorgebohrt und zur leichten Fixierung der Platte mit einer Schraube besetzt (vgl. Abb. 3). Mit dem am weitesten distal gelegenen Kanal wurde entsprechend verfahren. Dann erfolgte die Bohrung des proximalen kaudalen und des zweiten distalen Schraubenkanals, ohne folgende Besetzung mit Schrauben. Im Bereich des Plattenlochs über der geplanten Osteotomielinie wurde keine Bohrung vorgenommen.

Anschließend entfernte der Operateur das Osteosynthesematerial temporär und führte die Osteotomie unter Schonung angrenzender Weichteilstrukturen mit gepulstem Ultraschall (OT 7 Piezosurgery@), Mectron Medical Technology, Carasco, Italien) durch. Die 


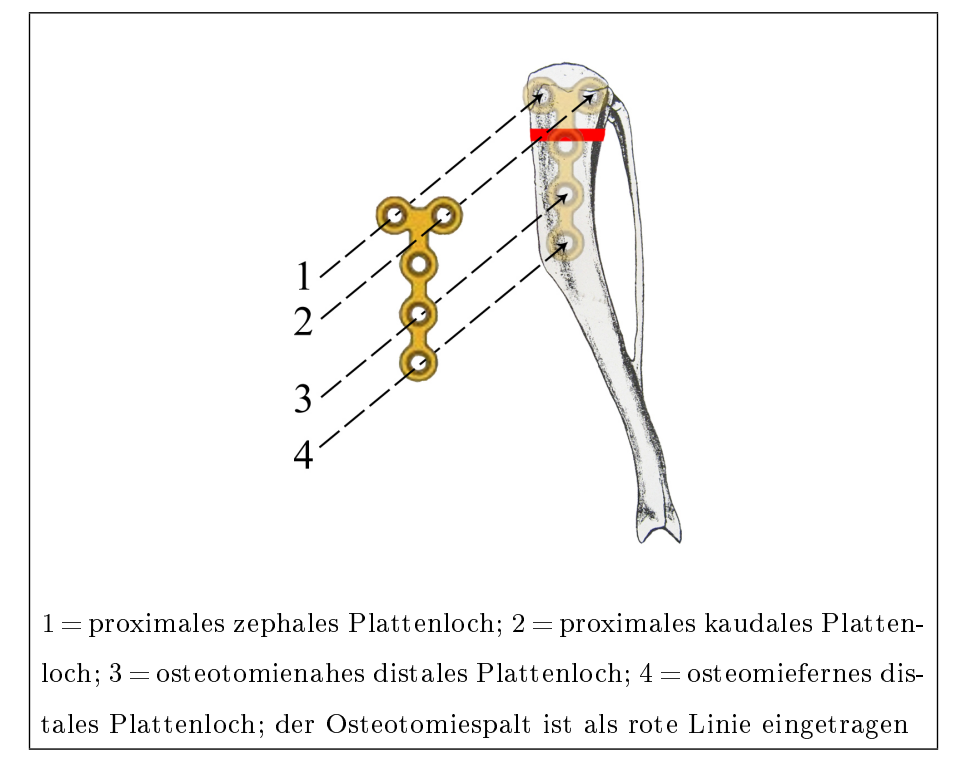

Abbildung 3: Osteotomie und Osteosynthese. Rechte Tibia und Fibula der Ratte; Ansicht von medial

Osteomielinie war dabei mittig zwischen den zwei proximalen und den zwei distalen Bohrkanälen lokalisiert (ca. $7 \mathrm{~mm}$ distal des Tibiaplateaus; vgl. Abb. 3). Nach der Osteotomie wurde die Titanplatte proximal mit zwei $7 \mathrm{~mm}$ 1.1er Schrauben und distal mit jeweils einer $5 \mathrm{~mm}$ und einer $4 \mathrm{~mm}$ 1.1er Schraube refixiert.

Durch dieses Operationsverfahren, bei der die Position der Platte durch Bohren der Schraubenkanäle vor Durchführung der Osteotomie festgelegt wird, verbleibt ein standardisierter Osteotomiespalt von 0,5 mm. Dies entspricht der Dicke des verwendeten OT 7 Piezosurgery@-Sägeblattes.

Abschließend wurde die Beugemuskulatur mittels 4.0 Vicryl Naht (Ethicon, Johnson \& Johnson, Norderstedt, Deutschland) readaptiert und die Haut durch Klammerung (Michel wound brackets $12 \times 3$ mm, Gebrüder Martin GmbH \& Co.KG, Tuttlingen, Deutschland) verschlossen.

Am kontralateralen Hinterlauf wurde entsprechend vorgegangen.

Nach der Operation erhielten die Tiere einmalig s.c. Decentan ( $5 \mathrm{mg} / \mathrm{kg}$ KG, Merck, Darmstadt, Deutschland) und $3 \mathrm{ml}$ isotone NaCl-Lösung. Anschließend wurden sie in einen mit Zellstoff ausgekleideten, gewärmten Käfig gelegt und bis zum Erwachen beobachtet.

Während der folgenden zwei Tage wurde den Tieren zur Schmerzmedikation zweimal täglich Rimadyl s.c. (4 mg/kg KG, Pfizer, Karlsruhe, Germany) verabreicht.

In der weiteren Arbeit werden, orientiert an der zuvor beschriebenen Lage des Osteosynthesematerials, die Begriffe "Plattenebene" und "Schraubenebene" verwendet. Die Plattenebene ist durch die flächige Ausbreitung der 5-Loch-Leibinger-Platte über der medioventralen Tibia definiert. Die Schraubenebene steht im rechten Winkel zu dieser und entspricht der Ebene, in der die Bohrkanäle verlaufen. 


\subsection{Futter und Testsubstanzen}

Als Basisfutter erhielten alle Tiere über den gesamten Versuchszeitraum sojafreie Nahrung (ssniff SM R/M, 10 mm-Pellets; ssniff Spezialitäten GmbH, Soest, Deutschland). Bei den Versuchsgruppen, die ihren gruppenspezifischen Wirkstoff oral aufnehmen sollten (E2, R, CR, EQ, GEN), wurde das Basisfutter nach der Osteotomie durch den entsprechenden Futterzusatz ergänzt (siehe Tab.9) und über fünf Wochen bis zur Obduktion verabreicht. Allein Parathormon (PTH(1-34)) wurde in diesem Versuch subkutan appliziert. Die Tiere der Testgruppe PTH erhielten über den gleichen Zeitraum eine tägliche Dosis von 0,014 mg. Die Wirkstoffe, mit Ausnahme des PTHs, wurden freundlicherweise von der Abteilung "Klinische und Experimentelle Endokrinologie" (Leitung: Herr Prof. W. Wuttke) zur Verfügung gestellt.

Tab.10 gibt detaillierte Informationen über den Futterverbrauch in den einzelnen Käfigen und die daraus errechnete durchschnittliche tägliche Wirkstoffaufnahme pro Tier.

Tabelle 9: Wirkstoffkonzentration im Futter

\begin{tabular}{|c|c|}
\hline Testsubstanz & Konzentration im Futter [g/kg Futter] \\
\hline \hline E2 & 0,01 \\
\hline R & 0,1665 \\
\hline CR & 1,65 \\
\hline EQ & 0,4 \\
\hline GEN & 1,0 \\
\hline
\end{tabular}


Tabelle 10: Futter- und Wirkstoffaufnahme

\begin{tabular}{|c|c|c|c|c|}
\hline Käfig & $\begin{array}{c}\text { Anzahl } \\
\text { der Tiere }\end{array}$ & Testgruppe & $\begin{array}{c}\text { Futterverbrauch } \\
\text { pro Käfig } \\
{[\mathrm{g} / \mathbf{3 5 d}]} \\
\end{array}$ & $\begin{array}{c}\text { Wirkstoffaufnahme pro } \\
\text { Tier und Tag } \\
{[\mathrm{mg} / \mathrm{d}]}\end{array}$ \\
\hline 1 & 4 & C & 2080 & 0 \\
\hline 2 & 4 & $\mathrm{C}$ & 2161 & 0 \\
\hline 3 & 4 & $\mathrm{C}$ & 2074 & 0 \\
\hline 4 & 5 & E2 & 1682 & $0,096^{*}$ \\
\hline 5 & 4 & E2 & 1312 & $0,094^{*}$ \\
\hline 6 & 3 & E2 & 1071 & $0,102^{*}$ \\
\hline 7 & 4 & $\mathrm{R}$ & 1680 & $1,998^{*}$ \\
\hline 8 & 4 & $\mathrm{R}$ & 1798 & $2,138^{*}$ \\
\hline 9 & 4 & $\mathrm{R}$ & 1611 & $1,916^{*}$ \\
\hline 10 & 4 & $\mathrm{CR}$ & 1850 & $21,804^{*}$ \\
\hline 11 & 4 & $\mathrm{CR}$ & 1869 & $22,028^{*}$ \\
\hline 12 & 4 & $\mathrm{CR}$ & 1853 & $21,839^{*}$ \\
\hline 13 & 4 & EQ & 1892 & $5,406^{*}$ \\
\hline 14 & 4 & EQ & 1824 & $5,211^{*}$ \\
\hline 15 & 4 & EQ & 1878 & $5,366^{*}$ \\
\hline 16 & 4 & GEN & 1953 & $13,950^{*}$ \\
\hline 17 & 4 & GEN & 2011 & $14,364^{*}$ \\
\hline 18 & 4 & GEN & 2008 & $14,343^{*}$ \\
\hline 19 & 4 & PTH & 1995 & 0,014 \\
\hline 20 & 4 & PTH & 1939 & 0,014 \\
\hline 21 & 4 & PTH & 1923 & 0,014 \\
\hline
\end{tabular}

*durchschnittlicher Wert; aus "Futterverbrauch pro Käfig" berechnet

\subsection{Obduktion}

Die Obduktion erfolgte am 35. Tag nach der Osteotomie. Dazu wurden die Tiere zunächst mit $\mathrm{CO}_{2}$ sediert und anschließend dekapitiert. Eine der beiden randomisiert ausgewählten Tibiae wurde im Kniegelenk und oberen Sprunggelenk exartikuliert und unter Erhalt des Verbundes aus Tibia und Fibula sorgsam freipräpariert. Anschließend erfolgte die Entfernung des Osteosynthesematerials. Bis zum Beginn der nachfolgenden Untersuchungen wurden die gewonnenen Präparate bei $-20^{\circ} \mathrm{C}$ gelagert. Der Kallus der kontralateralen Tibia wurde zur späteren genanalytischen Untersuchung bei $-80^{\circ} \mathrm{C}$ gelagert.

\subsection{Röntgenbilder}

Die Röntgenbilder wurden mit einem Faxitron-Röntgengerät (Modell-Nr. 43855A, Faxitron X-ray system, Hewlett-Packard, San Diego, USA) auf AGFA-Film (AGFA Structurix D4 DW ETE ISO 9001, AGFA Graphics Germany GmbH \& Co. KG, Düsseldorf, 
Deutschland) angefertigt. Die Belichtung erfolgte bei einer Röhrenspannung von $40 \mathrm{kV}$ und einer Stromstärke von 0,3 mA über 6 min. Der Verbund aus Tibia und Fibula wurde in Schrauben- und Plattenebene geröntgt.

Die Bewertung der Röntgenbilder erfolgte unter nachstehenden Kriterien:

1. Achse in Plattenebene: Kalluswinkel zwischen proximalem und distalem Tibiaanteil in Plattenebene (in Winkelgrad)

2. Achse in Schraubenebene: Kalluswinkel zwischen proximalem und distalem Tibiaanteil in Schraubenebene (in Winkelgrad)

3. Fibulafraktur: Liegt eine akzessorische Fibulafraktur vor? Falls dies der Fall ist, kann zusätzlich entschieden werden, ob es sich dabei um eine alte, intravitale Fraktur (Kallusbildung) oder um eine frische, postmortale Fraktur (keine Kallusbildung) handelt.

4. Kallus: Umfang der Kallusbildung? Mineralisierung des Kallusgewebes? Ist der Frakturspalt überbrückt? Hat sich eine Pseudarthrose ausgebildet?

5. Infektzeichen: Zeigen sich im Röntgenbild Zeichen einer Infektion?

\subsection{Biomechanischer Test}

\subsubsection{Prinzip des biomechanischen Tests}

Das Ziel dieses Tests besteht darin, von der Frakturüberbrückung ein biomechanisches Profil zu erstellen. Dazu übte der Untersucher mittels einer Werkstoffprüfmaschine eine Kraft orthogonal zur Längsachse der Tibia aus. Als Angriffspunkt wurde die ventrale Tibiakante auf Höhe der früheren Osteotomielinie gewählt. Während der Prüfung wurde die einwirkende Kraft gegen den Weg (Durchbiegen der Tibia) aufgetragen.

\subsubsection{Versuchsaufbau und -ablauf}

Vor Versuchsbeginn wurde der zu prüfende Knochen über fünf Stunden aufgetaut. Um ein Verkippen oder Verrutschen während der mechanischen Prüfung zu verhindern, wurde der Verbund aus Tibia und Fibula anschließend horizontal in einem Hartgipsbett (GC Fujirock@ EP; GC EUROPE N.V., Leuven, Belgien) gelagert. Dabei sollte die Fibula komplett durch Gips bedeckt sein. Der Tibia wurde nur im Bereich der Kondylen und der distalen tibiofibularen Synostose eine Auflagefläche geschaffen (siehe Abb. 4). So konnte ein freies Schwingen im Bereich der metaphysären Frakturüberbrückung, des Tibiaschaftes und der distalen Meta- und Epiphyse bei zunehmender Krafteinwirkung (vgl. 2.8.1) weitgehend sichergestellt werden. 


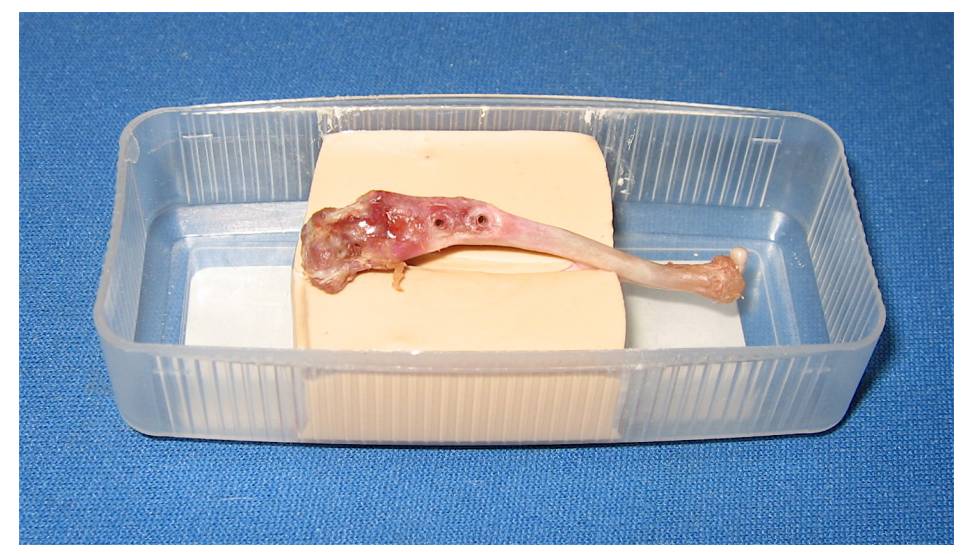

Abbildung 4: Lagerung der Tibia im Gipsbett zur biomechanischen Prüfung

Nach dem Aushärten des Gipses spannte der Untersucher das Versuchsobjekt samt Gipsbett in die Werkstoffprüfmaschine (Typ 145660 Z020/TND Zwick/Roell, Ulm, Deutschland) (siehe Abb.5) ein. Die Kraftübertragung auf die ventrale Tibiakante erfolgte mittels eines Rollenstempels mit zirkulärer Nut [Stürmer et al. 2006]. Für die Steuerung der Maschine und die Aufzeichnung der Daten wurde die Software "testXpertß)" (Zwick/Roell, Ulm, Deutschland) verwendet.

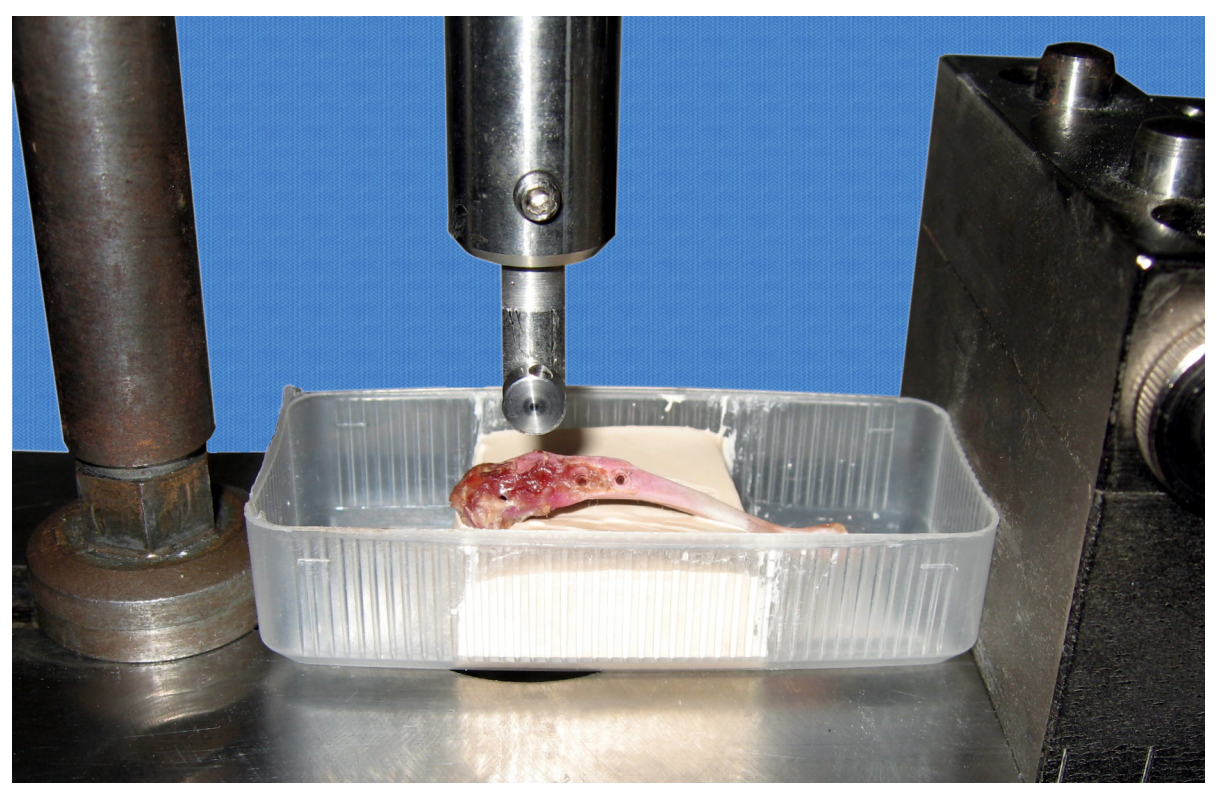

Abbildung 5: Eingebettete Tibia in der Werkstoffprüfmaschine

Im nächsten Arbeitsschritt wurde der Druckstempel direkt über der früheren Osteotomielinie abgesenkt, eine Vorkraft von $1 \mathrm{~N}$ erzeugt und die korrekte Position der ventralen Tibiakante in der Nut der Metallrolle überprüft. Anschließend startete der Untersucher die Elastizitätsprüfung. Dabei wurde der Druck über die Metallrolle durch deren Auslenkung $(50 \mathrm{~mm} / \mathrm{min})$ zunehmend erhöht und gleichzeitig ein Kraft-Weg-Diagramm aufgezeichnet. Der Kurvenverlauf konnte vom Untersucher während des Tests am Monitor direkt mitverfolgt werden. Der Versuch wurde vom Untersucher manuell abgebrochen, bevor es zu einer 
Fraktur des Kallus kam. Dies war möglich, da sich das Brechen des Knochens durch einen Steigungsabfall des zuvor linearen Kurvenverlaufs im Kraft-Weg-Diagramm vorankündigt (siehe 2.8.3). Nach Abschluss der Versuche wurde der Knochen aus dem Gipsbett gelöst und von allen Gipsresten befreit.

\subsubsection{Auswertung des biomechanischen Tests}

Die ermittelten Kraft-Weg-Diagramme zeichnen sich durch einen von Stürmer et al. [2006] beschriebenen charakteristischen Kurvenverlauf aus (siehe Abb.6). Danach ist der Graph in zwei wesentliche Abschnitte zu unterteilen.

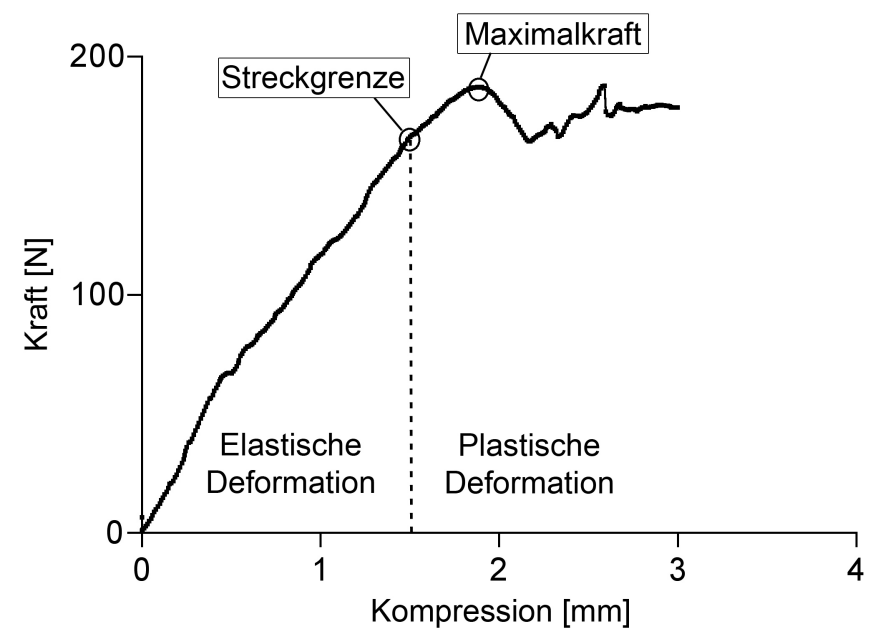

Abbildung 6: Typisches Kraft-Weg-Diagramm eines biomechanischen Kompressionstests am Beispiel einer Rattentibia

In der ersten Phase findet eine elastische und somit reversible Verformung des Knochens statt. Hierbei kommt es hauptsächlich zur Dehnung kollagener Fasern. Endet die Belastung in dieser Phase, so nimmt der Knochen wieder seine ursprüngliche Form ein. Im Kurvenverlauf zeigt sich eine lineare Steigung.

Wird durch die fortschreitende Belastung eine von Knochen zu Knochen variierende Belastungsgrenze erreicht, treten Mikrofrakturen und Trabekelbrüche auf. In dieser zweiten Phase kommt es somit zur irreversiblen, plastischen Deformation des Knochens. Im Kurvenverlauf zeigt sich ein deutlicher Steigungsabfall. Die Grenze zwischen Phase eins und zwei ist als Streckgrenze (engl.: yield load) definiert.

Anschließend steigt der Graph zunächst weiter an, erreicht ein Maximum (Maximalkraft) und fällt letztendlich bei kompletter Fraktur des getesteten Knochens steil ab.

In den durchgeführten Untersuchungen wurde der Test bereits zu Beginn der zweiten Phase durch den Untersucher manuell abgebrochen. Dadurch konnte ein Zerbrechen des 
Knochens zuverlässig verhindert werden. Ein komplett frakturiertes Präparat wäre für weitere Untersuchungen unbrauchbar gewesen.

\subsubsection{Messparameter}

\subsubsection{Elastizität}

Die Elastizität entspricht der linearen Steigung im Kraft-Weg-Diagramm während der reversiblen, elastischen Verformung (vgl. 2.8.3).

\subsubsection{Streckgrenze}

Die Streckgrenze entspricht der maximalen Kraft, die ein Knochen aufnehmen kann, ohne dass es zu bleibenden strukturellen Veränderungen kommt. Sie stellt somit die Grenze zwischen reversibler, elastischer Verformung und irreversibler, plastischer Verformung dar. In Korrelation findet sich im Kraft-Weg-Diagramm eine deutliche Abnahme der zuvor linearen Steigung (vgl. 2.8.3. Um die Streckgrenze zu bestimmen, muss zunächst die Regressionsgerade des linearen Kurvenabschnitts und dessen Standardabweichung ermittelt werden. Ein Steigungsabfall um mehr als die doppelte Standardabweichung wird als Streckgrenze gewertet [Stürmer et al. 2006].

\subsection{Mikroradiographie}

\subsubsection{Histologische Aufarbeitung und Anfertigung der Mikroradiographien}

Nach dem biomechanischen Test wurden die Tibiae über eine aufsteigende Alkoholreihe (40\%,70\%, 80\%, $100 \%$ für jeweils eine Woche) entwässert und entfettet. Anschließend erfolgte die separate Einbettung der Tibiae in Rollrandflaschen (40 ml; 80 x $30 \mathrm{~mm}$ ). Dazu wurde ein Gemisch aus $1000 \mathrm{ml}$ Methylmethacrylsäure (MMA), $200 \mathrm{ml}$ Dibutylphthalat und $29 \mathrm{~g}$ Benzoylperoxid verwendet. Nach einer ca. dreiwöchigen Aushärtungsphase wurden die MMA-Blöcke samt Tibiae aus den Flaschen gelöst und mit einer Innenlochsäge (Leica SP 1600 Sägemikrotom; Bensheim; Deutschland) fortlaufend in $120 \mu \mathrm{m}( \pm 10 \mu \mathrm{m})$ dicke Schnitte gesägt. Als sagittale Schnittebene diente die frühere Schraubenebene (vgl. 2.4. S. 33.

Aus den gewonnenen sagittalen Schnitten jeder Tibia wurden drei zentrale, aufeinander folgende histologische Präparate für die mikroradiographische Untersuchung ausgewählt. Die Mikroradiographien wurden mit einem Faxitron-Röntgengerät (Modell-Nr. 43855A, Faxitron X-ray system, Hewlett-Packard, San Diego, USA) auf Kodak Professional Film (INDUSTREX SR45 Film ISO 9002, Rochester, New York) angefertigt. Die Belichtung 
erfolgte bei einer Röhrenspannung von $10 \mathrm{kV}$ und einer Stromstärke von $0,3 \mathrm{~mA}$ über $3 \mathrm{~min}$.

Für die nachfolgende Auswertung der Polychromen Sequenzmarkierung (siehe 2.10, S. 47) wurden die radiographierten Knochenschnitte mit Eukitt@(Fa. Kindler, Freiburg, Deutschland) auf Objektträgern (52x $76 \mathrm{~mm})$ eingedeckt.

\subsubsection{Auswertung der Mikroradiographien}

Die Mikroradiographien wurden mit einem Leica Stereomakroskop (MZ 7-5, Bensheim, Deutschland) begutachtet. Als Lichtquelle diente eine Kaltlichtlampe (Leica KL 1500 LCD, Bensheim, Deutschland). Eine Kamera (Leica DC 300F; Bensheim; Deutschland) ermöglichte das Einlesen der Bilder in den Computer (Intel Pentium 4, $2.6 \mathrm{GHz}$ ) zur anschließenden morphometrischen Auswertung mit der Software Leica Quantimet QWin 2003 (Leica, Bensheim, Deutschland). Durch Vorversuche wurden die unterschiedlichen Konfigurationsmöglichkeiten der zuvor genannten Apparaturen ausgetestet und die folgenden Einstellungen für die Auswertung als optimal befunden:

Am Makroskop wurde ein 1,0er Objektiv verwendet. Alle zur Auswertung bestimmten Strukturen konnten so bei guter Ausnutzung der Monitorgröße vollständig abgebildet werden.

Die mechanische Blende der Kaltlichtlampe wurde auf Schalterposition B eingestellt und somit eine mäßige Blendenöffnung erreicht (A: minimale Blendenöffnung; E: maximale Blendenöffnung). Die Temperatur der Halogenlampe betrug $2750 \mathrm{~K}$.

Aufgrund der unterschiedlichen Helligkeit der Mikroradiographien, die auf eine leicht variierende Dicke der geröntgen Schnittpräparate zurückzuführen ist, musste die Belichtungszeit für jedes Bild individuell angepasst werden. Hierbei wurde der Bereich von 345 bis $460 \mathrm{~ms}$ nie verlassen.

\subsubsection{Algorithmus zur digitalen morphometrischen Auswertung}

Die digitale morphometrische Auswertung der Mikroradiographien erfolgte mit Hilfe der Software Leica Quantimet QWin 2003. Alle Arbeitsabläufe wurden dabei durch einen eigens für diese Zwecke programmierten Algorithmus festgelegt. Die Auswertung der Mikroradiographien erfolgte blind. So war dem Untersucher zum Zeitpunkt der Messungen die Gruppenzugehörigkeit eines Präparates nicht bekannt.

\section{Arbeitsschritt 1: Einlesen der Mikroradiographie}

Zum Einlesen der Mikroradiographien in den Computer wurden die unter 2.9.2 beschriebenen Apparaturen und Einstellungen verwendet. Alle Bilder wurden so positioniert, dass die plattennahen Knochenanteile links, die plattenfernen rechts, die proximalen oben und 
die distalen unten lagen (siehe Abb.7). Die zu vermessenden Strukturen sollten immer auf die gleiche Weise in einem standardisierten Messrahmen $\left(2 \times 5 \mathrm{~mm}^{2}\right.$; vertikal x horizontal $)$ platziert werden. Als Orientierungshilfe diente eine horizontale Linie, an der die distale Osteotomielinie zentral auszurichten war.

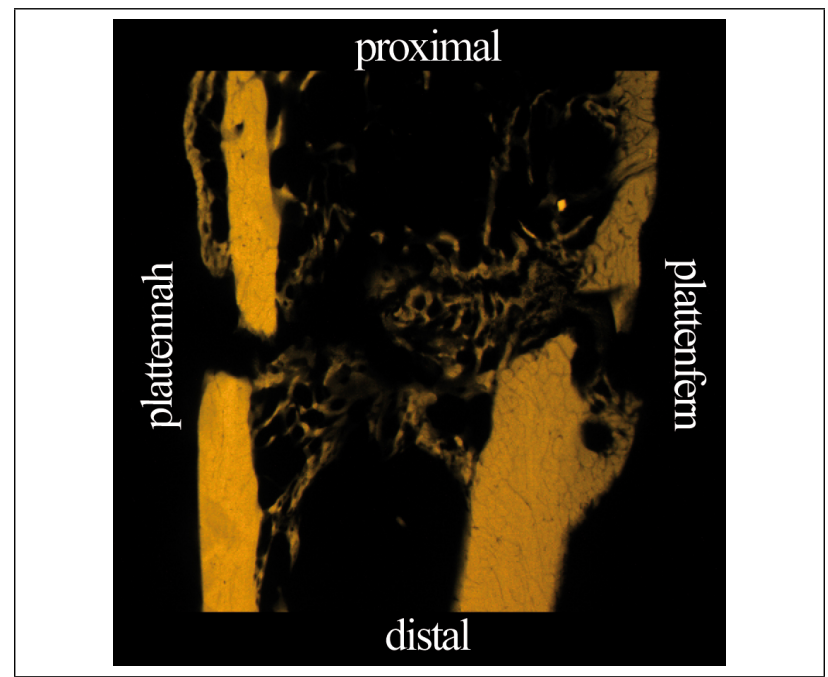

Abbildung 7: Mikroradiographisches Bild mit Kennzeichnung der anatomischen Ausrichtung; Testgruppe E2; Ratte 16; 16-fache Vergrößerung

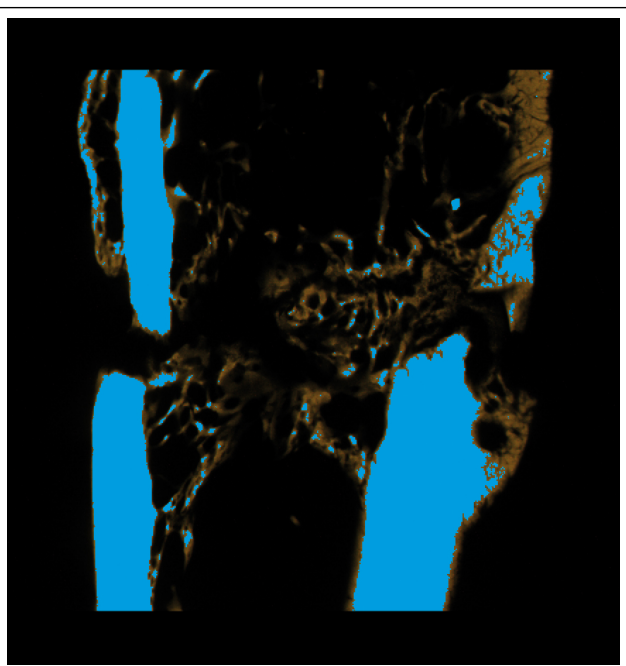

(a) Automatische Graudetektion. Die als "Knochen" detektierte Fläche ist blau markiert. Nicht detektierter Knochen ist gelb/braun dargestellt. Die knöchernen Strukturen sind nur unvollständig von der Software erfasst.

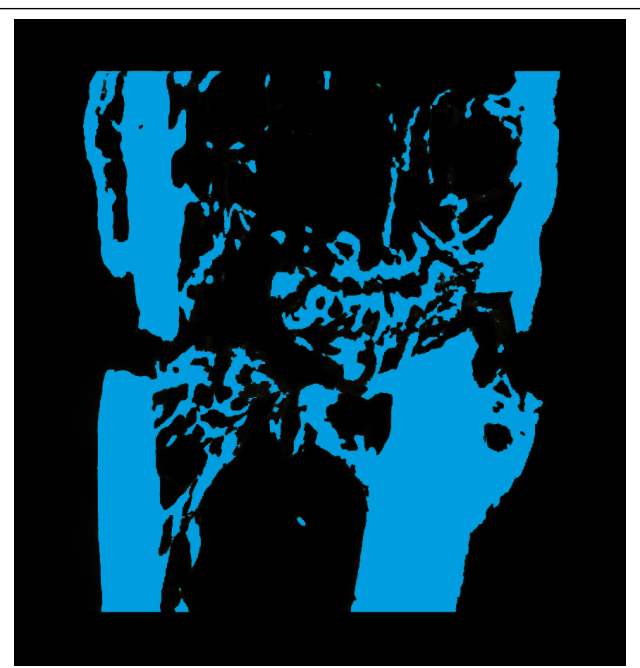

(b) Mikroradiographie nach manueller Graudetektion. Alle sichtbaren knöchernen Anteile sind von der Software als "Knochen" detektiert.

Abbildung 8: Auswertung der Mikroradiographien: Graudetektion (Arbeitsschritt 2); Testgruppe E2; Ratte 16; 16-fache Vergrößerung 


\section{Arbeitsschritt 2: Graudetektion}

Die Graudetektion dient der Erfassung aller sichtbaren Knochenanteile durch die Software. Zunächst erfolgte eine automatische, computergesteuerte Detektion (siehe Abb.83). Anschließend hatte der Untersucher die Möglichkeit, diese durch Veränderung der Detektionssensitivität zu korrigieren (siehe Abb. 8b). So wurde die Fehlinterpretation der Bilder in Form einer Über- oder Unterdetektion verhindert.

\section{Arbeitsschritt 3: Flächendefinition}

Die Definition der einzelnen Flächen erfolgte durch manuelles Umfahren mit dem Mauszeiger. Zur Kontrolle wurde die Flächengrenze als Linie (Linienstärke 2,1 Pixel entspricht 6,73 $\mathrm{m}$ ) aufgezeichnet. Bei Bedarf konnten im Nachhinein Korrekturen am Linienverlauf vorgenommen werden. Zudem bestand bei Kontinuitätsunterbrechung einer Fläche die Möglichkeit, mehrere getrennte Areale zu umfahren und zu einer Fläche zusammenzufassen. Eine Mehrfachzuordnung desselben Areals zu verschiedenen Flächen wurde durch den Algorithmus verhindert.

In Abb.9 werden die im Folgenden beschriebenen Flächen an einem mikroradiographischen Bild veranschaulicht.

Die Flächendefinition wurde in der nachstehenden Reihenfolge durchgeführt:

\section{a. Gesamte Knochenfläche inklusive Kallus}

Hierbei wurde über den Messrahmen hinaus die gesamte auszuwertende Knochenfläche umfahren. Abgesprengte und dislozierte Knochenanteile konnten so von den folgenden Messungen ausgeschlossen werden.

\section{b. Kortikalisfläche proximal plattennah}

In diesem Arbeitsschritt wurde die proximale, plattennahe Kortikalis von der Knochengesamtfläche abgegrenzt. Die Kortikalis zeichnet sich durch eine hohe Knochendichte aus.

c. Kortikalisfläche proximal plattenfern (vgl. Flächendefinition b)

d. Kortikalisfläche distal plattennah (vgl. Flächendefinition b)

e. Kortikalisfläche distal plattenfern (vgl. Flächendefinition b)

\section{f. Kallusfläche plattennah}

Die Abgrenzung der Kallusfläche von der Kortikalis ist bereits durch die vorhergehenden Arbeitsschritte erfolgt. Als Grenze zwischen dem plattennahen und dem endostalen Kallus wurde eine mittige Verbindungslinie zwischen proximaler und distaler Kortikalis gewählt. 
g. Kallusfläche plattenfern (vgl. Flächendefinition f)

\section{h. Kallusfläche endostal}

Der endostale Kallus weist eine wesentlich höhere Knochendichte und kompaktere Struktur auf als die angrenzende Trabekelfläche. Eine Abgrenzung vom kortikalen Knochen und periostalen Kallus ist bereits durch vorhergehende Arbeitsschritte erfolgt.

\section{i. Trabekelfläche proximal}

Diese Fläche wurde durch die bereits erfolgten Arbeitsschritte freigestellt und musste nicht gesondert umfahren werden. In manchen Präparaten grenzte ein Schraubenkanal mit zusätzlicher Kallusbildung an diese Fläche. Hier war es erforderlich diesen "Schraubenkallus" von der Trabekelfläche auszuschließen.

j. Trabekelfläche distal (vgl. Flächendefinition i)

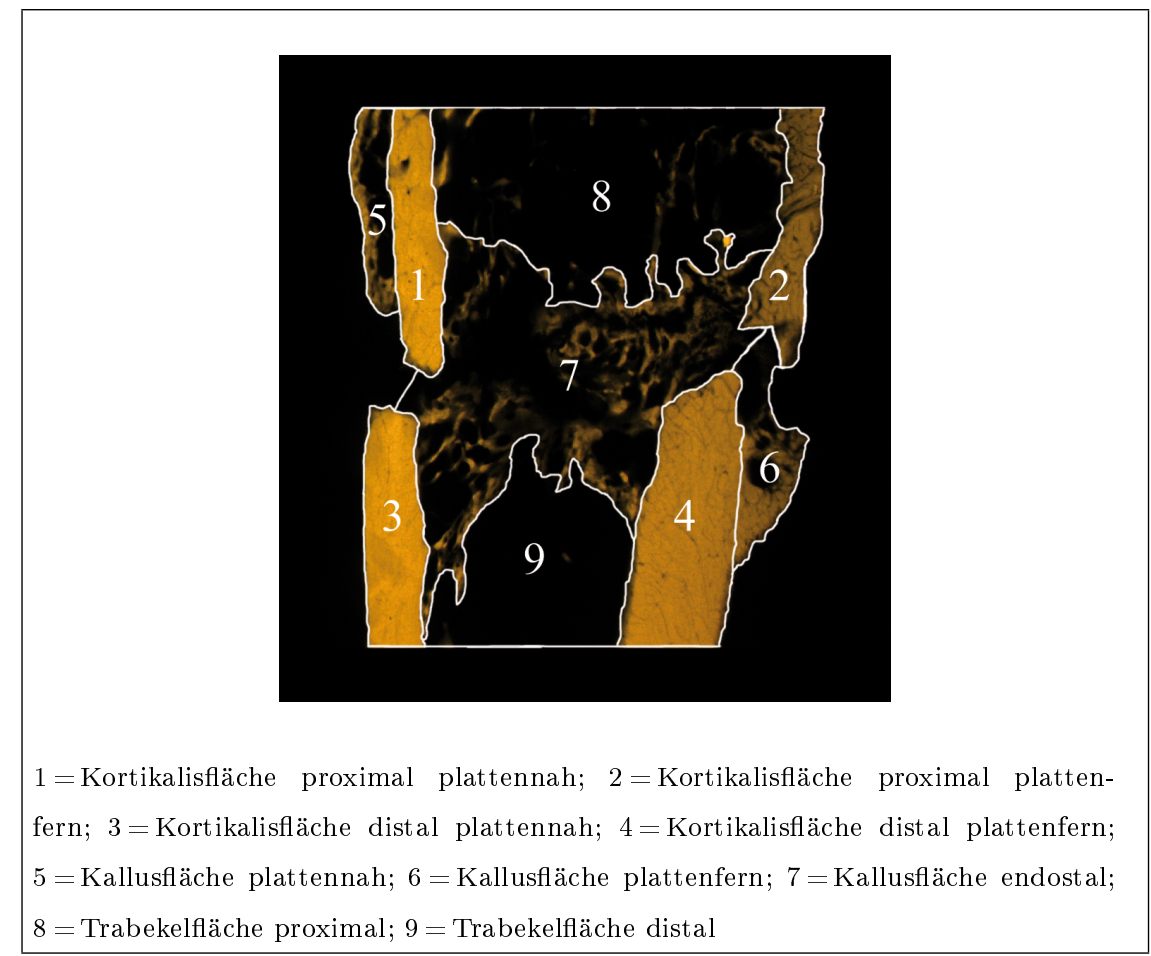

Abbildung 9: Auswertung der Mikroradiographien: Flächendefinition (Arbeitsschritt 3); Testgruppe E2; Ratte 16; 16-fache Vergrößerung

\section{Arbeitsschritt 4: Kortikalisdicke distal plattennah}

In diesem Arbeitsschritt wurden durch den Untersucher osteotomienah fünf Vektoren orthogonal zur Knochenlängsachse durch die Kortikalis gelegt (siehe Abb.10a). Diese sollten die Grenze der Kortikalisfläche überragen. Anschließend wurde die Ausdehnung der Vektoren durch die Software auf die zuvor definierte Kortikalisfläche und somit auf die tatsächliche Kortikalisdicke begrenzt. 


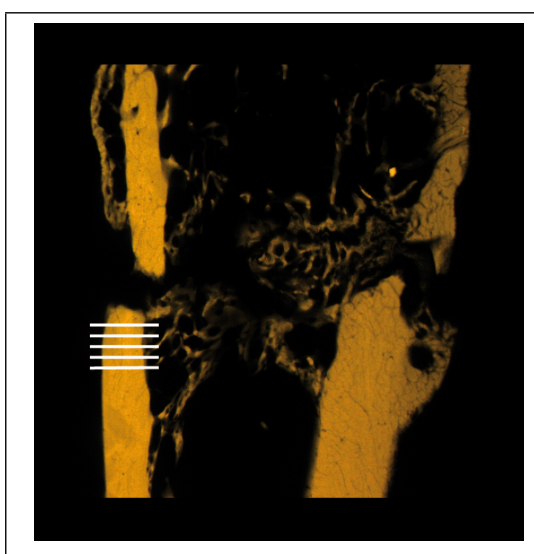

(a) Vektoren (weiße Linien) zur Bestimmung der Kortikalisdicke distal plattennah

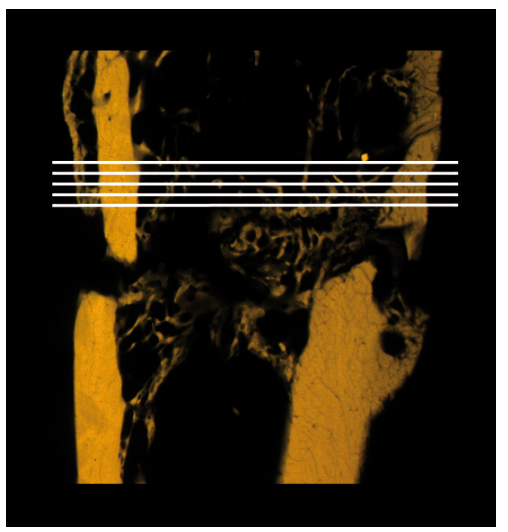

(b) Vektoren (weiße Linien) zur Bestimmung des proximalen Knochendurchmessers

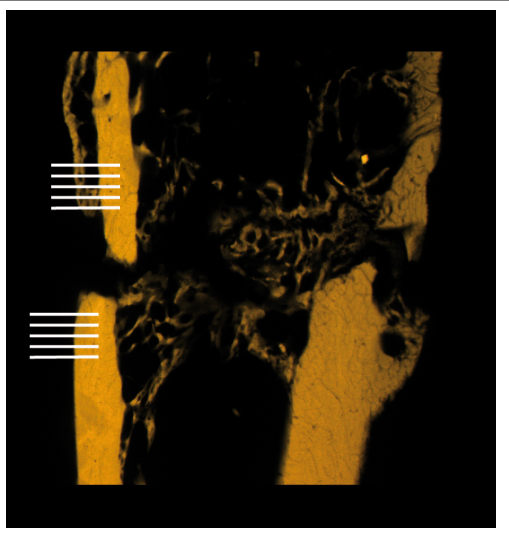

(c) Vektoren (weiße Linien) zur Bestimmung der Kallusdicke plattennah

Abbildung 10: Auswertung der Mikroradiographien: Vektoren (Arbeitsschritt 4, 6 und 8); Testgruppe E2; Ratte 16; 16-fache Vergrößerung

\section{Arbeitsschritt 5: Kortikalisdicke distal plattenfern}

Vergleiche Arbeitschritt 4.

\section{Arbeitsschritt 6: Knochendurchmesser proximal der Osteotomie}

Zur Bestimmung des Knochendurchmessers wurden osteotomienah fünf Vektoren orthogonal zur Längsachse des proximalen Knochenanteils durch den gesamten Knochen gelegt (siehe Abb.10p). Die Vektoren wurden hier auf die Strecke vom plattennahen zum plattenfernen Periost gekürzt. Somit wurde der Kallus nicht in den Wert des Knochendurchmessers miteinbezogen.

\section{Arbeitsschritt 7: Knochendurchmesser distal der Osteotomie}

Vergleiche Arbeitsschritt 6.

\section{Arbeitsschritt 8: Kallusdicke plattennah}

Hierzu wurden durch den Untersucher osteotomienah zehn Vektoren orthogonal zur Knochenlängsachse durch den Kallus gelegt. Fünf Vektoren wurden dabei oberhalb, fünf Vektoren unterhalb des früheren Osteotomiespalts platziert (siehe Abb.10;). Diese sollten die Grenze des Kallus überragen. Anschließend wurde die Ausdehnung der Vektoren durch die Software auf die zuvor definierte plattennahe Kallusfläche und somit auf die tatsächliche Kallusdicke begrenzt.

\section{Arbeitsschritt 9: Kallusdicke plattenfern}

Vergleiche Arbeitsschritt 8. 


\subsubsection{Messparameter}

Aus den ermittelten Daten berechnete die Software für jeden Einzelschnitt die in Tab.11 aufgeführten Parameter.

Tabelle 11: Messparameter der mikroradiographischen Auswertung mit Berechnungsgrundlage

\begin{tabular}{|c|c|}
\hline Messparameter [Einheit] & Berechnungsgrundlage \\
\hline Kortikalisdicke distal plattennah [mm] & $\begin{array}{l}\text { Arithmetisches Mittel der durch } \\
\text { Arbeitsschritt } 4 \text { ermittelten Vektorenbeträge. }\end{array}$ \\
\hline Kortikalisdicke distal plattenfern [mm] & $\begin{array}{l}\text { Arithmetisches Mittel der durch } \\
\text { Arbeitsschritt } 5 \text { ermittelten Vektorenbeträge. }\end{array}$ \\
\hline Knochendurchmesser proximal [mm] & $\begin{array}{l}\text { Arithmetisches Mittel der durch } \\
\text { Arbeitsschritt } 6 \text { ermittelten Vektorenbeträge. }\end{array}$ \\
\hline Knochendurchmesser distal [mm] & $\begin{array}{l}\text { Arithmetisches Mittel der durch } \\
\text { Arbeitsschritt } 7 \text { ermittelten Vektorenbeträge. }\end{array}$ \\
\hline Kallusdicke plattennah [mm] & $\begin{array}{l}\text { Arithmetisches Mittel der durch } \\
\text { Arbeitsschritt } 8 \text { ermittelten Vektorenbeträge. }\end{array}$ \\
\hline Kallusdicke plattenfern [mm] & $\begin{array}{l}\text { Arithmetisches Mittel der durch } \\
\text { Arbeitsschritt } 9 \text { ermittelten Vektorenbeträge. }\end{array}$ \\
\hline $\begin{array}{l}\text { Knochenflächendichte Kortikalis distal } \\
\text { plattennah [\%] }\end{array}$ & $\begin{array}{l}\text { Prozentualer Knochenanteil der als } \\
\text { "Kortikalis distal plattennah" definierten } \\
\text { Fläche. }\end{array}$ \\
\hline $\begin{array}{l}\text { Knochenflächendichte Kortikalis distal } \\
\text { plattenfern [\%] }\end{array}$ & $\begin{array}{l}\text { Prozentualer Knochenanteil der als } \\
\text { "Kortikalis distal plattenfern" definierten } \\
\text { Fläche. }\end{array}$ \\
\hline Knochenflächendichte Kallus plattennah [\%] & $\begin{array}{l}\text { Prozentualer Knochenanteil der als "Kallus } \\
\text { plattennah" definierten Fläche. }\end{array}$ \\
\hline Knochenflächendichte Kallus plattenfern [\%] & $\begin{array}{l}\text { Prozentualer Knochenanteil der als "Kallus } \\
\text { plattenfern" definierten Fläche. }\end{array}$ \\
\hline Knochenflächendichte Kallus endostal [\%] & $\begin{array}{l}\text { Prozentualer Knochenanteil der als "Kallus } \\
\text { endostal" definierten Fläche. }\end{array}$ \\
\hline Knochenflächendichte Trabekel distal [\%] & $\begin{array}{l}\text { Prozentualer Knochenanteil der als } \\
\text { "Trabekelfläche distal" definierten Fläche. }\end{array}$ \\
\hline Anzahl Trabekelkreuzungen absolut & $\begin{array}{l}\text { Absolute Anzahl von Trabekelkreuzungen im } \\
\text { Bereich der distalen Trabekelfläche. }\end{array}$ \\
\hline Dichte Trabekelkreuzungen $\left[1 / \mathrm{mm}^{2}\right]$ & $\begin{array}{l}\text { Anzahl der Trabekelkreuzungen pro } \mathrm{mm}^{2} \text { im } \\
\text { Bereich der distalen Trabekelfläche. }\end{array}$ \\
\hline Mittlere Trabekeldicke $[\mu \mathrm{m}]$ & $\begin{array}{l}\text { Arithmetisches Mittel der } \\
\text { Trabekeldurchmesser im Bereich der distalen } \\
\text { Trabekelfläche. }\end{array}$ \\
\hline
\end{tabular}




\subsection{Polychrome Sequenzmarkierung}

\subsubsection{Prinzip der Polychromen Sequenzmarkierung}

Ziel der Polychromen Sequenzmarkierung (PSM) ist es, die Dynamik der Umbauvorgänge im Knochen während der Frakturheilung darzustellen. Zuvor beschriebene radiologische Verfahren, wie die einfache Röntgenaufnahme und die Mikroradiographie, zeigen nur isolierte Momentaufnahmen. Im Gegensatz dazu liefert die PSM Informationen über Zeitpunkt, Lokalisation und Ausmaß von knöchernen Neubildungen. Zur Durchführung der PSM werden den Versuchstieren intravital verschiedenfarbige Fluorochrome zu vorher festgelegten Zeitpunkten der Frakturheilung verabreicht. Diese bilden mit Kalzium einen fluoreszierenden Chelatkomplex, der in aktuell mineralisierende Knochenanteile eingelagert wird. Dazu zählt im vorliegenden Versuch insbesondere der zu untersuchende Frakturkallus. Durch die zeitlich versetzte Verabreichung der verschiedenen Fluoreszenzfarbstoffe bilden sich farblich unterschiedlich markierte Banden aus. Nach abschließender Präparation und Aufarbeitung (siehe 2.9.1, S. 40 kann dann eine quantitative Fluoreszenzmikroskopische Untersuchung erfolgen, in der die neu gebildeten Knochenanteile durch entsprechende fluoreszierende Eigenschaften einem bestimmten Zeitraum der Frakturheilung zugeordnet werden können.

\subsubsection{Fluorochrome}

Für die PSM wurden in Anlehnung an Rahn [1976] die Fluorochrome Xylenolorange Tetranatriumsalz (XO), Calcein-Grün (CG), Alizarinkomplexon (AK) und TetracyclinHydro- chloride (TC) (alle: Merck, Darmstadt, Deutschland) verwendet.

Die Fluorochrome wurden in isotoner Kochsalzlösung (TC) bzw. destilliertem Wasser (XO, CG, AK) gelöst und anschließend als Bolus subkutan verabreicht. Die genauen Dosierungen werden in Tab.12 aufgeführt. Wie bereits im vorhergehenden Abschnitt beschrieben, wird neu gebildeter Knochen durch die Einlagerung der Fluoreszenzfarbstoffe markiert. Dabei ist zu beachten, dass nur der Knochenanteil "angefärbt" wird, der sich bis zum Zeitpunkt der Injektion neu gebildet hat und noch nicht durch ein anderes Fluorochrom markiert ist. Tab.12 gibt Informationen über die Dosierung, den Applikationszeitpunkt, den markierten Zeitraum der Frakturheilung und die in Blaufluoreszenz zu erwartende Farbe der einzelnen Fluoreszenzfarbstoffe. 
Tabelle 12: Dosierung, Applikationstag, Markierungszeitraum und Farbe in Blaufluoreszenz der verwendeten Fluorochrome

\begin{tabular}{|c|c|c|c|c|}
\hline $\begin{array}{c}\text { Fluoro- } \\
\text { chrom }\end{array}$ & $\begin{array}{c}\text { Dosierung } \\
\text { [mg/kg KG] }\end{array}$ & $\begin{array}{c}\text { Applikationstag } \\
\text { [Tag nach Osteotomie] }\end{array}$ & $\begin{array}{c}\text { Markierungszeitraum } \\
\text { [Tag nach Osteotomie] }\end{array}$ & $\begin{array}{c}\text { Farbe in Blau- } \\
\text { fluoreszenz }\end{array}$ \\
\hline \hline $\mathrm{XO}$ & 90 & 13 & $0-13$ & orange \\
\hline $\mathrm{CG}$ & 10 & 18 & $14-18$ & grün \\
\hline $\mathrm{AK}$ & 30 & 24,26 & $19-26$ & rot \\
\hline $\mathrm{TC}$ & 25 & 35 & $27-35$ & gelb \\
\hline
\end{tabular}

\subsubsection{Auswertung der Polychromen Sequenzmarkierung}

Die Betrachtung und Auswertung der histologischen Präparate (vgl. 2.9.1, S. 40) erfolgte mit einem Auflicht-Fluoreszenz-Stereomakroskopes (Leica Stereomakroskop MZ 7-5 mit FluoCombi III, Bensheim, Deutschland) in Blaufluoreszenz. Als Lichtquelle diente eine Quecksilberhöchstdrucklampe mit einer Leistung von 50 Watt. Um die gewünschte Fluorochromanregung durch blaues Licht zu erreichen, wurde ein Anregungsfilter für den Wellenlängenbereich von 450-490 nm verwendet. Eine Kamera (Leica DC 300F, Bensheim, Deutschland) ermöglichte das Einlesen der Bilder in den Computer (Intel Pentium 4, 2.6 $\mathrm{GHz}$ ). Die anschließende morphometrische Auswertung erfolgte mit der Software Leica Quantimet QWin 2003 (Leica, Bensheim, Deutschland).

Durch Vorversuche wurden die unterschiedlichen Konfigurationsmöglichkeiten der zuvor genannten Apparaturen ausgetestet und die folgenden Einstellungen für die Auswertung als optimal befunden:

Am Makroskop wurde ein 1,0er Objektiv verwendet. Alle zur Auswertung bestimmten Strukturen konnten so bei guter Ausnutzung der Monitorgröße vollständig abgebildet werden.

Als Belichtungszeit wurde ein Bereich von 9,7 bis 12,9 s festgelegt. Über einen Gain-Regler (Bestandteil der Software) erfolgte eine Verstärkung der Bildhelligkeit um den Faktor drei.

\subsubsection{Algorithmus zur digitalen morphometrischen Auswertung}

Die digitale morphometrische Auswertung der PSM erfolgte mit Hilfe der Software Leica Quantimet QWin 2003. Alle Arbeitsabläufe wurden dabei durch einen eigens für diese Zwecke programmierten Algorithmus festgelegt. Die Auswertung der PSM erfolgte blind im Hinblick auf die Versuchsgruppen. Im Folgenden werden die einzelnen Arbeitsschritte der Auswertung dargestellt. 


\section{Arbeitsschritt 1: Einlesen des Präparates}

Zum Einlesen des Präparates in den Computer wurden die unter 2.10 .3 beschriebenen Apparaturen und Einstellungen verwendet. Alle Bilder wurden so positioniert, dass die plattennahen Knochenanteile links, die plattenfernen rechts, die proximalen oben und die distalen unten lagen (vgl. Abb.11). Die zu vermessenden Strukturen sollten immer auf die gleiche Weise in einem standardisierten Messrahmen $\left(2 \times 5 \mathrm{~mm}^{2}\right.$; vertikal $\mathrm{x}$ horizontal $)$ platziert werden. Als Orientierungshilfe diente eine horizontale Linie, an der die distale Osteotomielinie zentral auszurichten war.

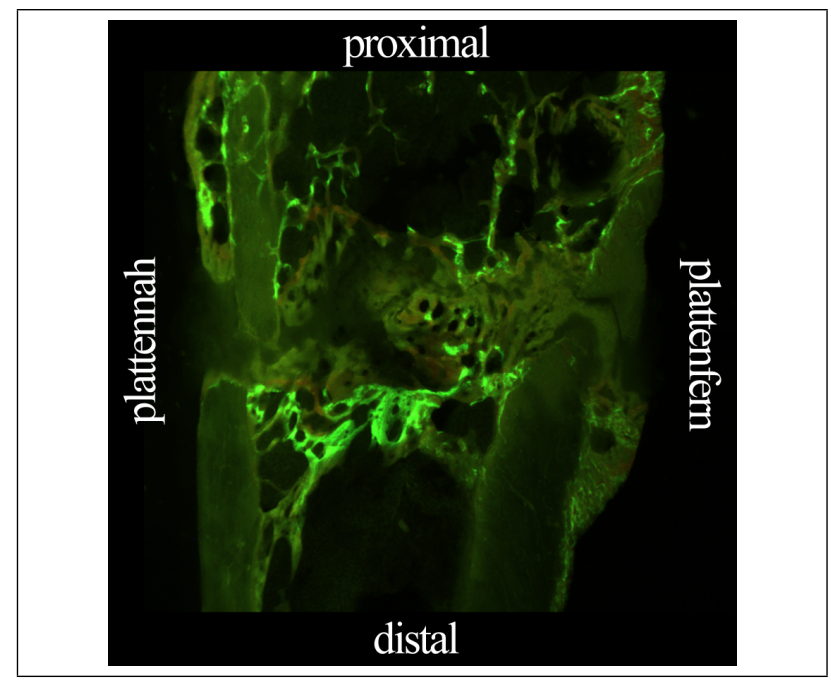

\footnotetext{
Abbildung 11: Fluoreszenz-mikroskopisches Bild mit Kennzeichnung der anatomischen Ausrichtung; Testgruppe E2; Ratte 16; 16-fache Vergrößerung
}

\section{Arbeitsschritt 2: Flächendefinition}

Die Flächendefinition erfolgte analog zu 2.9.3 (S. 43, Auswertung der Mikroradiographien; Arbeitsschritt 3). In Abb. 12 werden die im Folgenden beschriebenen Flächen an einem Fluoreszenz-mikroskopischen Bild veranschaulicht.

\section{a. Gesamte Knochenfläche inklusive Kallus}

Hierbei wurde über den Messrahmen hinaus die gesamte auszuwertende Knochenfläche umfahren. Abgesprengte und dislozierte Knochenanteile konnten so von den folgenden Messungen ausgeschlossen werden.

\section{b. Kortikalisfläche proximal plattennah}

In diesem Arbeitsschritt wurde die proximale, plattennahe Kortikalis von der Gesamtknochenfläche abgegrenzt. Die Kortikalis zeigt im Gegensatz zum Kallus nur eine geringe Fluoreszenz. Der Grund dafür ist, dass in diesem Knochenanteil fast keine Umbauvorgänge stattgefunden haben und somit keine Fluorochrome eingelagert wurden. 
c. Kortikalisfläche proximal plattenfern (vgl. Flächendefinition b)

d. Kortikalisfläche distal plattennah (vgl. Flächendefinition b)

e. Kortikalisfläche distal plattenfern (vgl. Flächendefinition b)

\section{f. Kallusfläche plattennah}

Der Kallus zeichnet sich durch eine starke Fluoreszenz aus (siehe 2.10.1, S. 47). Die Abgrenzung der Kallusfläche von der Kortikalis ist bereits durch die vorhergehenden Arbeitsschritte erfolgt. Als Grenze zwischen dem plattennahen und dem endostalen Kallus wurde die mittige Verbindungslinie zwischen proximaler und distaler Kortikalis gewählt.

g. Kallusfläche plattenfern (vgl. Flächendefinition f)

\section{h. Kallusfläche endostal}

Der endostale Kallus weist eine wesentlich stärkere Fluoreszenz und kompaktere Struktur als die angrenzende Trabekelfläche auf. Eine Abgrenzung vom kortikalen Knochen und periostalen Kallus ist bereits durch vorhergehende Arbeitsschritte erfolgt.

\section{i. Trabekelfläche proximal}

Diese Fläche wurde durch die Arbeitsschritte (a) bis (h) freigestellt und musste nicht gesondert umfahren werden. In manchen Präparaten grenzte ein Schraubenkanal mit zusätzlicher Kallusbildung an diese Fläche. Hier war es erforderlich diesen "Schraubenkallus" von der Trabekelfläche auszuschließen.

j. Trabekelfläche distal (vgl. Flächendefinition i) 


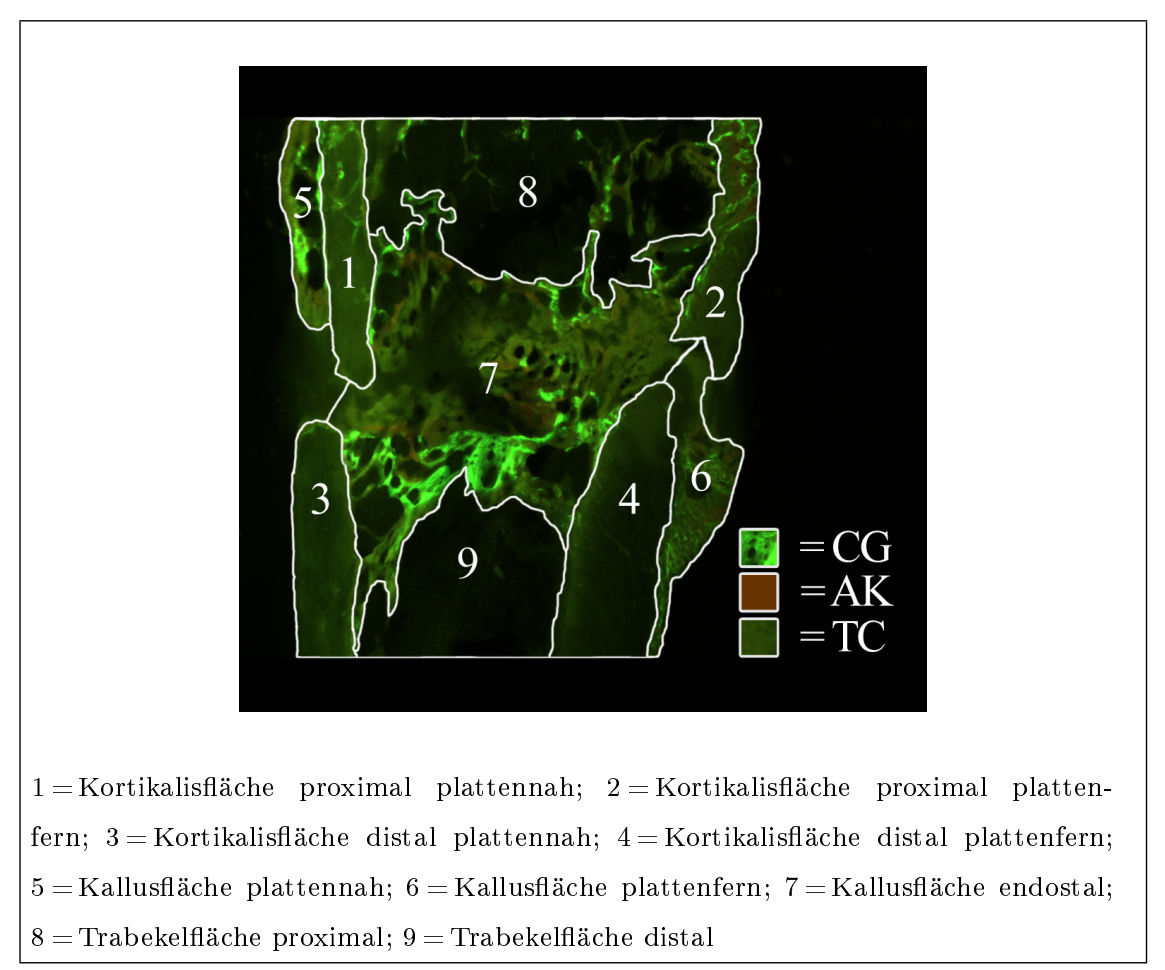

Abbildung 12: Fluoreszenz-mikroskopisches Bild mit Kennzeichnung der anatomischen Flächenzuordung und der Farb-Fluorochrom-Zuordnung; Testgruppe E2; Ratte 16; 16-fache Vergrößerung

\section{Arbeitsschritt 3: Flächen-Fluorochrom-Zuordnung}

In diesem Arbeitsschritt fand nur die plattennahe, die plattenferne und die endostale Kallusfläche Berücksichtigung. Entsprechend der zuvor beschriebenen Arbeitsweise wurden Areale mit gleichen fluoreszierenden Eigenschaften von der Gesamtfläche abgegrenzt, gruppiert und dem jeweiligen Fluorochrom zugeordnet (vgl. Abb.12). Durch den Algorithmus war die Reihenfolge der Flächen-Fluorochrom-Zuordnung ( $\mathrm{XO} \Rightarrow \mathrm{CG} \Rightarrow \mathrm{AK} \Rightarrow$ TC) vorgegeben.

Bei der Begutachtung der Präparate zeigten sich viele kleine XO-Flächen, die von CG markiertem Knochen umgeben waren. Diese XO-Flächen konnten nur bei hoher mikroskopischer Auflösung sichtbar gemacht werden. Eine Detektion und damit quantitative Analyse durch das zuvor beschriebene Verfahren war dahingegen nicht möglich. Demzufolge konnte nur die CG-, AK- und TC-Fläche ermittelt werden. Im Kallus eingeschlossene, nicht kalzifizierte Flächen wurden keinem der Fluorochrome zugeordnet.

\subsubsection{Messparameter}

Aus den ermittelten Daten errechnete die Software für jeden Einzelschnitt die in Tab.13 aufgeführten Parameter. 
Tabelle 13: Messparameter der Fluoreszenz-mikroskopischen Untersuchung

\begin{tabular}{|l|l|}
\hline Messparameter [Einheit] & Berechnungsgrundlage \\
\hline \hline Gesamtfläche Kallus plattennah $\left[\mathrm{mm}^{2}\right]$ & $\begin{array}{l}\text { Absolute Fläche des gesamten } \\
\text { plattennahen Kallus. }\end{array}$ \\
\hline CG-Fläche Kallus plattennah $\left[\mathrm{mm}^{2}\right]$ & $\begin{array}{l}\text { Absolute Fläche des CG-markierten } \\
\text { plattennahen Kallus. }\end{array}$ \\
\hline AK-Fläche Kallus plattennah $\left[\mathrm{mm}^{2}\right]$ & $\begin{array}{l}\text { Absolute Fläche des AK-markierten } \\
\text { plattennahen Kallus. }\end{array}$ \\
\hline TC-Fläche Kallus plattennah $\left[\mathrm{mm}^{2}\right]$ & $\begin{array}{l}\text { Absolute Fläche des TC-markierten } \\
\text { plattennahen Kallus. }\end{array}$ \\
\hline Gesamtfläche Kallus plattenfern $\left[\mathrm{mm}^{2}\right]$ & $\begin{array}{l}\text { Absolute Fläche des gesamten } \\
\text { plattenfernen Kallus. }\end{array}$ \\
\hline CG-Fläche Kallus plattenfern $\left[\mathrm{mm}^{2}\right]$ & $\begin{array}{l}\text { Absolute Fläche des CG-markierten } \\
\text { plattenfernen Kallus. }\end{array}$ \\
\hline AK-Fläche Kallus plattenfern $\left[\mathrm{mm}^{2}\right]$ & $\begin{array}{l}\text { Absolute Fläche des AK-markierten } \\
\text { plattenfernen Kallus. }\end{array}$ \\
\hline TC-Fläche Kallus plattenfern $\left[\mathrm{mm}^{2}\right]$ & $\begin{array}{l}\text { Absolute Fläche des TC-markierten } \\
\text { plattenfernen Kallus. }\end{array}$ \\
\hline Gesamtfläche Kallus endostal $\left[\mathrm{mm}^{2}\right]$ & $\begin{array}{l}\text { Absolute Fläche des gesamten endostalen } \\
\text { Kallus. }\end{array}$ \\
\hline CG-Fläche Kallus endostal $\left[\mathrm{mm}^{2}\right]$ & $\begin{array}{l}\text { Absolute Fläche des CG-markierten } \\
\text { endostalen Kallus. }\end{array}$ \\
\hline AK-Fläche Kallus endostal $\left[\mathrm{mm}^{2}\right]$ & $\begin{array}{l}\text { Absolute Fläche des AK-markierten } \\
\text { endostalen Kallus. }\end{array}$ \\
\hline TC-Fläche Kallus endostal $\left[\mathrm{mm}^{2}\right]$ & $\begin{array}{l}\text { Absolute Fläche des TC-markierten } \\
\text { endostalen Kallus. }\end{array}$ \\
\hline Additivkallus $\left[\right.$ mm $\left.{ }^{2}\right]$ & $\begin{array}{l}\text { Absolute Kallusfläche. Summe der } \\
\text { plattennahen, plattenfernen und } \\
\text { endostalen Kallusfläche. }\end{array}$ \\
\hline
\end{tabular}

\subsection{Benutzerspezifität und Reproduzierbarkeit der Messergeb- nisse}

Die unter 2.9.2 (S. 41) und 2.10.3 (S. 48) beschriebenen Auswertmethoden sind aufgrund vieler manueller Arbeitsschritte, die nicht vom Computer übernommen werden konnten, maßgeblich durch den Untersucher beeinflusst. Um benutzerbedingte Messschwankungen auf ein Minimum zu reduzieren, wurden alle Präparate durch denselben Untersucher ausgewertet. Zudem erfolgte vor Beginn der Untersuchungen eine Überprüfung der Messergebnisse auf Reproduzierbarkeit. Dazu wurden fünf Präparate an fünf aufeinander folgenden Tagen wiederholt ausgewertet. Die Abweichung der Einzelergebnisse vom Mittelwert durfte dabei den Wert von $\pm 10 \%$ nicht überschreiten. Diese Bedingung wurde für alle Messparameter erfüllt. 


\subsection{Statistik}

Die statistische Auswertung wurde mit dem Programm GraphPad Prism (Version 4.00c, April 2003, GraphPad Software, San Diego, USA) durchgeführt. Nach Testgruppen getrennt, erfolgte für jeden unter 2.8.4 (S. 40), 2.9.4 (S. 46) und 2.10.5 (S. 51) beschriebenen Messparameter zunächst eine Prüfung der Ergebnisse auf Gauß'sche Normalverteilung. Diese konnte für alle Daten nachgewiesen werden. Anschließend wurden jeweils Mittelwert und Standardabweichung ermittelt. Zur Prüfung der Ergebnisse auf signifikante Unterschiede zwischen den Testgruppen wurde die Kombination aus univarianter Varianzanalyse (one-way ANOVA) und Tukey-Kramer post-hoc-Test gewählt. In der nachfolgenden Ergebnispräsentation wird das Signifikanzniveau " $\mathrm{p} \leq 0,05=$ signifikant $=$ *" verwendet. 


\section{Ergebnisse}

\subsection{Körpergewicht}

Tabelle 14: Entwicklung des durchschnittlichen Körpergewichts in den einzelnen Testgruppen

\begin{tabular}{|c|c|c|c|}
\hline Testgruppe & $\begin{array}{c}\text { KG [g] bei } \\
\text { Ovarektomie }\end{array}$ & $\begin{array}{l}\text { KG [g] bei } \\
\text { Osteotomie }\end{array}$ & $\begin{array}{l}\text { KG [g] bei } \\
\text { Obduktion }\end{array}$ \\
\hline $\mathrm{C}$ & $228,8 \pm 14,04$ & $347,6 \pm 19,97$ & $342,2 \pm 19,91$ \\
\hline E2 & $238,0 \pm 12,53$ & $347,8 \pm 16,06$ & $280,3 \pm 12,05$ \\
\hline $\mathrm{R}$ & $233,7 \pm 6,33$ & $339,3 \pm 14,41$ & $291,3 \pm 24,13$ \\
\hline CR & $235,9 \pm 11,83$ & $332,5 \pm 26,18$ & $317,3 \pm 23,31$ \\
\hline EQ & $233,1 \pm 8,74$ & $321,3 \pm 25,53$ & $308,8 \pm 24,28$ \\
\hline GEN & $232,7 \pm 10,74$ & $344,7 \pm 36,44$ & $330,7 \pm 38,02$ \\
\hline PTH & $234,1 \pm 8,17$ & $330,3 \pm 13,52$ & $324,9 \pm 19,38$ \\
\hline
\end{tabular}

Zu Beginn der Versuche betrug das durchschnittliche Körpergewicht aller Tiere 233,8 g. Neun Wochen nach Ovarektomie zeigte sich eine Zunahme des mittleren Gewichts um 44,4\% auf 337,7 g, die durch Körperwachstum und den Mangel an Östrogen hervorgerufen wurde. So ist bekannt, dass ein Östrogendefizit bei Ratten zu verminderter Aktivität und vermehrter Nahrungsaufnahme führt und so das Körpergewicht ansteigen lässt [Asarian und Geary 2006; Roepke 2009]. Bis zum Zeitpunkt der Osteotomie unterschieden sich die Gewichte der einzelnen Tiere nur wenig. Dies änderte sich nach der Osteotomie durch die Wirkung der gruppenspezifischen Testsubstanzen. So kam es beispielsweise in der Gruppe E2 zu einer massiven Abnahme des durchschnittlichen Körpergewichts um $67,5 \mathrm{~g}$ durch die Umkehrung des zuvor beschriebenen Effekts der Ovarektomie. Das Gewicht in der Kontrollgruppe C blieb dahingegen fast konstant. Um dieser unterschiedlichen Gewichtsentwicklung der verschiedenen Versuchsgruppen gerecht zu werden, wurde der biomechanische Test zusätzlich unter Berücksichtigung des Körpergewichts ausgewertet. Hinsichtlich der Knochengröße und des Knochendurchmessers (vgl. 3.4.4. S. 63 und 3.4.5. S. 63 zeigten sich zwischen den Testgruppen keine bedeutsamen Unterschiede, sodass die histomorphometrischen Untersuchungen unabhängig vom Körpergewicht bewertet wurden.

\subsection{Röntgenbilder}

Alle Röntgenbilder der Tibiae wurden anhand der unter 2.7 (S. 36) aufgeführten Kriterien untersucht. Von den 84 Knochen waren 71 geheilt (siehe Abb. 13 und 14). 13 Tibiae 
zeigten eine rein bindegewebige Frakturüberbrückung (Pseudarthrose). Diese Knochen wurden von weiteren Untersuchungen ausgeschlossen. Offensichtlich ist hier die Bewertung der biomechanischen Eigenschaften und die Untersuchung des knöchernen Kallus durch graphische Verfahren nicht sinnvoll.

Präparate mit akzessorischer, intravitaler Fibulafraktur mussten ebenfalls von weiteren Untersuchungen ausgeschlossen werden. Die aus der zusätzlichen Fraktur resultierende primär hohe Instabilität hat zu einer gesteigerten interfragmentären Beweglichkeit mit Anregung der Kallusbildung geführt (vgl. 1.2.2.2. S. 7). Bei sehr hoher Instabilität kam es sogar zu einer Lockerung des Osteosynthesematerials, mit Folge einer deutlichen Achsabweichung zwischen proximalem und distalem Tibiafragment in Platten- und/oder Schraubenebene von mehr als $40^{\circ}$ bis maximal $88^{\circ}$. Es ist davon auszugehen, dass bei den betroffenen Knochen der Einfluss der Testsubstanzen auf die Kallusbildung geringer ist als der Einfluss der biomechanischen Kräfte.

Orientiert an den zuvor aufgeführten Ausschlusskriterien, wurden aus C und E2 jeweils fünf, R und CR jeweils drei, EQ zwei, GEN sechs und PTH vier Knochen nicht weiter untersucht.

In keinem der Röntgenbilder fanden sich Anzeichen einer Infektion.

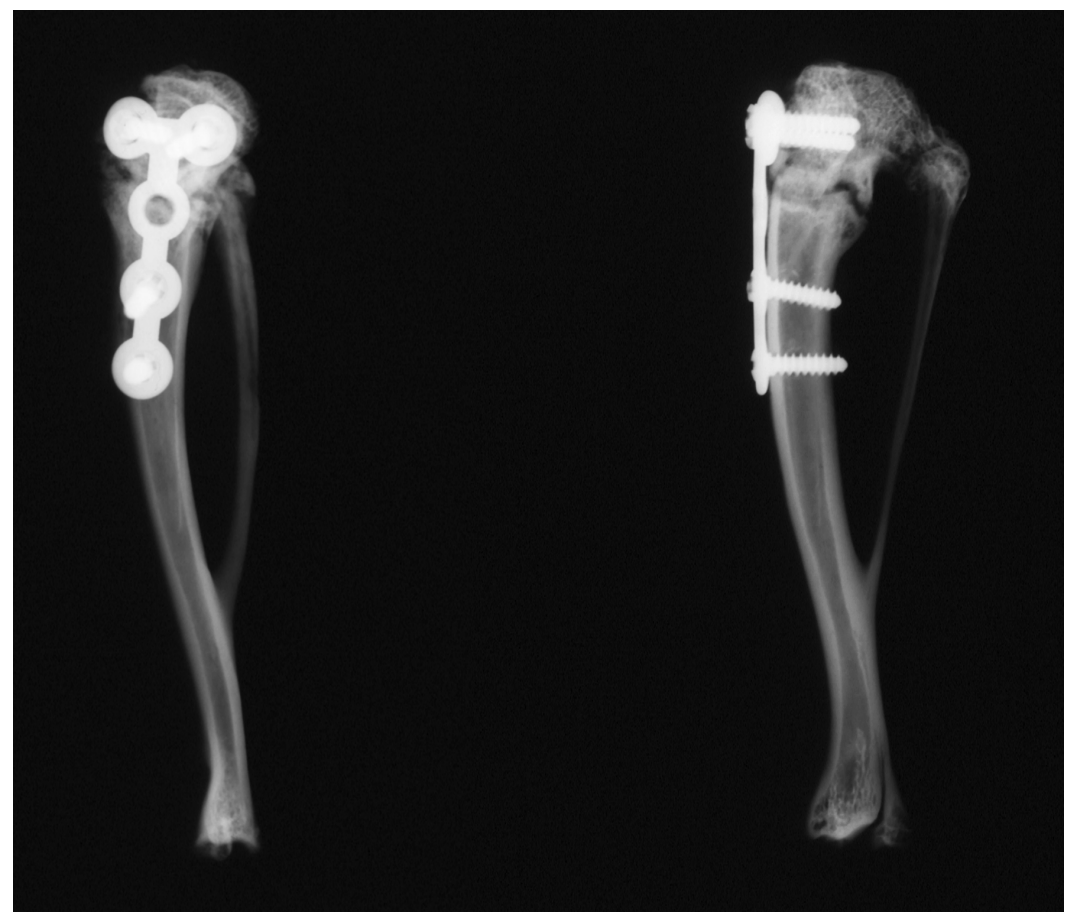

Abbildung 13: Röntgenbild einer Tibia mit Osteosynthesematerial; fünf Wochen nach Osteotomie; in Plattenebene (links) und Schraubenebene (rechts) 


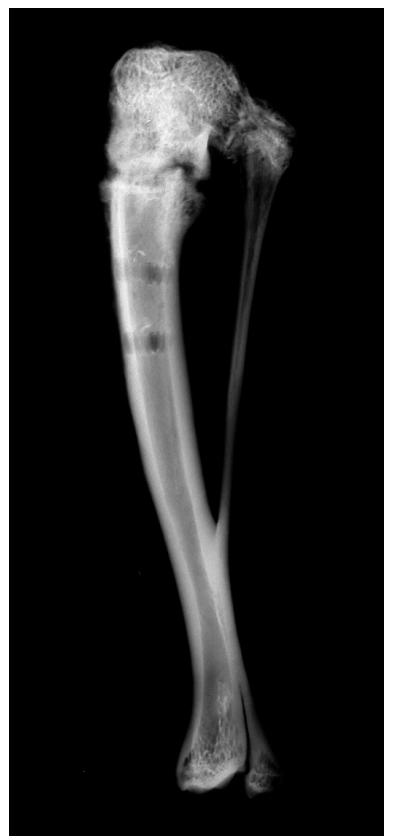

Abbildung 14: Röntgenbild einer Tibia nach Entferung des Osteosynthesematerials; fünf Wochen nach Osteotomie; in Schraubenebene

\subsection{Biomechanischer Test}

\subsubsection{Auswertung und Ergebnispräsentation des biomechanischen Tests}

Nachstehend werden die Ergebnisse des biomechanischen Kompressionstests aufgeführt. Hierbei erfolgt zunächst eine Präsentation in Form von Säulendiagrammen unter Angabe der Mittelwerte, Standardabweichungen und Signifikanzen. Signifikante $\left(\mathrm{p} \leq 0,05={ }^{*}\right)$ Unterschiede zwischen den Gruppen werden in Kästchen oberhalb der Säulen angegeben. So bedeutet beispielsweise die Angabe [PTH *], dass sich der Wert der zugehörigen Testgruppe signifikant von PTH unterscheidet. Am Ende des Kapitels findet sich eine tabellarische Zusammenfassung aller ermittelten Ergebnisse (siehe Tab.15, S. 59). 


\subsubsection{Elastizität}

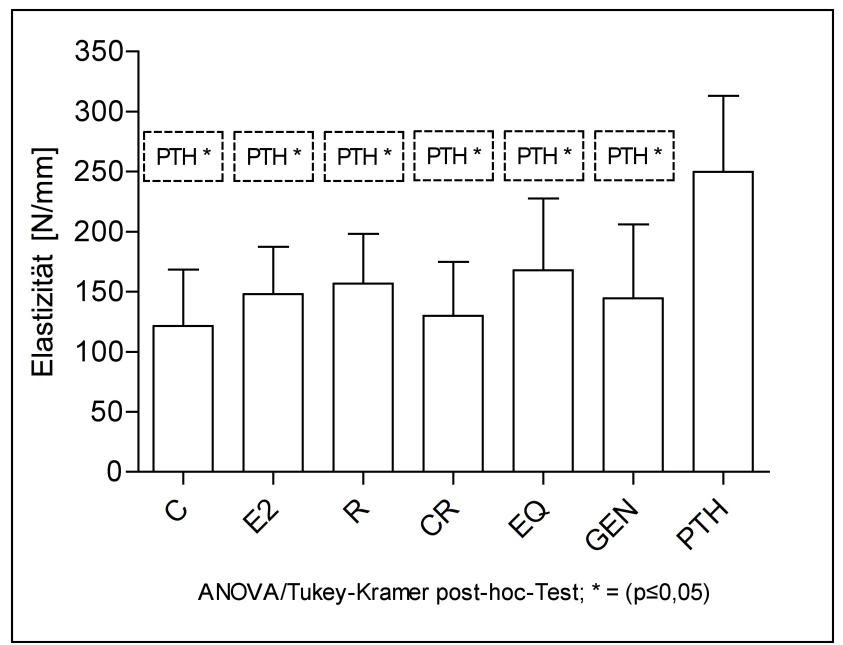

Abbildung 15: Messergebnisse für den Parameter 'Elastizität'

PTH zeichnet sich durch eine alle Vergleichsgruppen deutlich übertreffende Elastizität aus. So besteht ein signifikanter Unterschied zu C, E2, R, CR, EQ und GEN. Die geringste Elastizität zeigt der Kallus der Kontrollgruppe C.

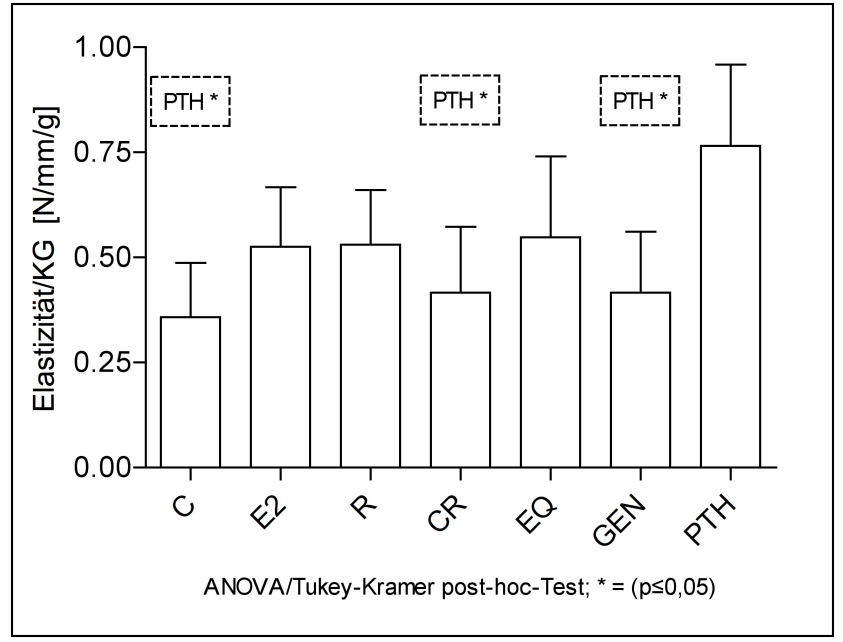

Abbildung 16: Messergebnisse für den Parameter 'Elastizität in Bezug auf das Körpergewicht'

Setzt man den Meßwert Elastizität in Bezug auf das Körpergewicht, so wird der beste Wert wiederum von PTH erreicht. Signifikante Unterschiede zeigen sich jedoch nicht mehr zu allen Vergleichsgruppen. So sind lediglich die Werte der Testgruppen C, CR und GEN signifikant niedriger. Der geringste Wert wird von der Kontrollgruppe C erreicht. 


\subsubsection{Streckgrenze}

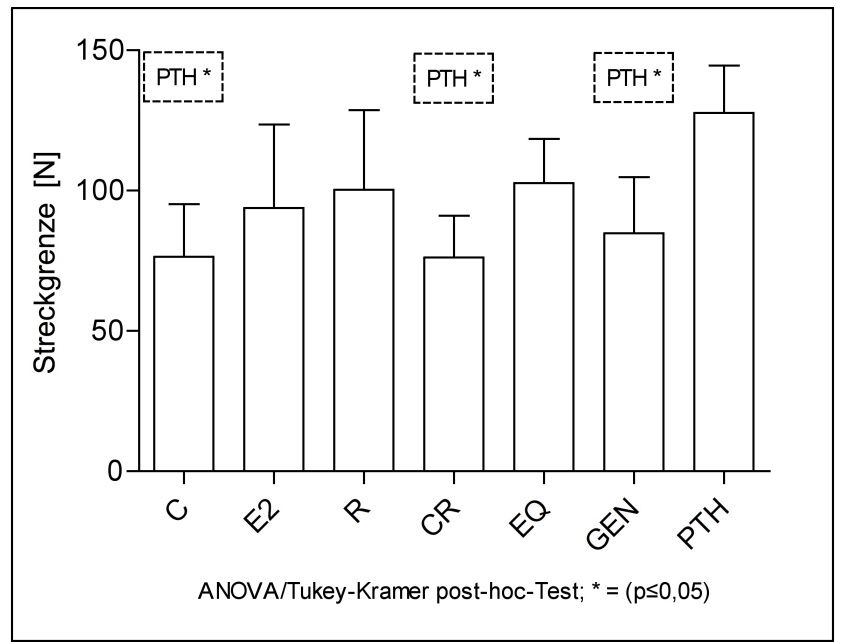

Abbildung 17: Messergebnisse für den Parameter 'Streckgrenze'

Den höchsten ermittelten Wert erreicht wiederum die Gruppe PTH. Dieser unterscheidet sich von C, CR und GEN signifikant. Die niedrigste Streckgrenze zeigt die Gruppe CR, dicht gefolgt von $\mathrm{C}$.

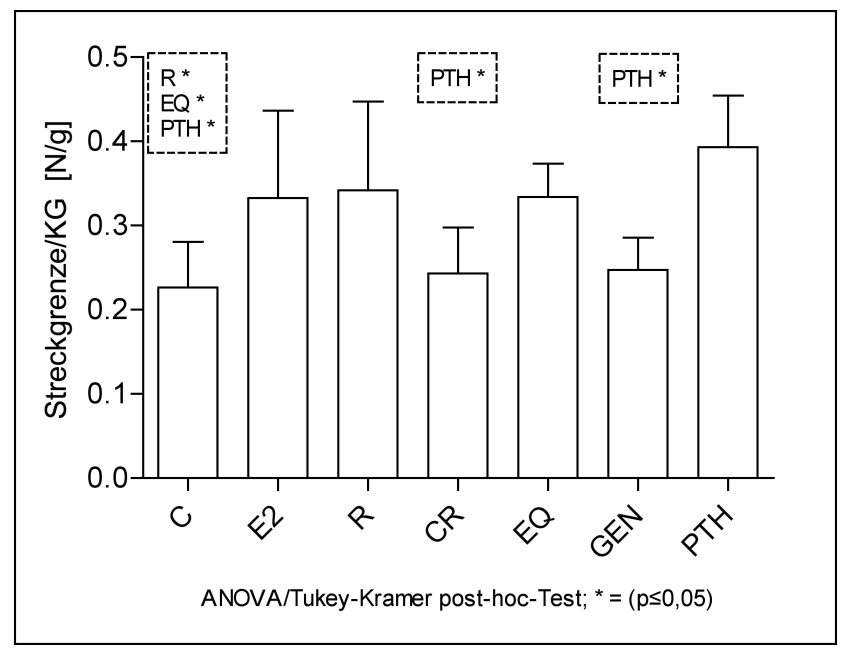

Abbildung 18: Messergebnisse für den Parameter 'Streckgrenze in Bezug auf das Körpergewicht'

Bezieht man bei der Streckgrenze das Körpergewicht mit ein, so bleibt der signifikante Unterschied für C, CR und GEN gegenüber PTH bestehen. Zusätzlich zeigen R und EQ signifikant höhere Werte als C. Der niedrigste Wert wird von der Kontrollgruppe erreicht. 
Tabelle 15: Ergebnisse des biomechanischen Tests

\begin{tabular}{ccccc}
\hline & EL $[\mathrm{N} / \mathrm{mm}]$ & $\mathrm{EL} / \mathrm{KG}[\mathrm{N} / \mathrm{mm} / \mathrm{g}]$ & Streckgrenze $[\mathrm{N}]$ & Streckgrenze $/ \mathrm{KG}[\mathrm{N} / \mathrm{g}]$ \\
\hline \hline $\mathrm{C}$ & $121,4 \pm 47,08$ & $0,36 \pm 0,13$ & $76,41 \pm 18,83$ & $0,23 \pm 0,05$ \\
$\mathrm{E} 2$ & $147,9 \pm 39,38$ & $0,53 \pm 0,14$ & $93,84 \pm 29,68$ & $0,33 \pm 0,10$ \\
$\mathrm{R}$ & $156,9 \pm 41,18$ & $0,53 \pm 0,13$ & $100,3 \pm 28,37$ & $0,34 \pm 0,11^{*}$ \\
$\mathrm{CR}$ & $129,8 \pm 44,93$ & $0,42 \pm 0,16$ & $76,21 \pm 14,91$ & $0,24 \pm 0,05$ \\
$\mathrm{EQ}$ & $167,8 \pm 59,90$ & $0,55 \pm 0,19$ & $102,6 \pm 15,81$ & $0,33 \pm 0,04^{*}$ \\
$\mathrm{GEN}$ & $144,5 \pm 61,52$ & $0,42 \pm 0,14$ & $84,76 \pm 20,00$ & $0,25 \pm 0,04$ \\
$\mathrm{PTH}$ & $249,8 \pm 63,26^{*} \#$ & $0,77 \pm 0,19^{*}$ & $127,7 \pm 16,84^{*}$ & $0,39 \pm 0,06^{*}$ \\
\hline \multicolumn{4}{l}{ Angabe als Mittelwert \pm Standardabweichung; KG = Körpergewicht, EL $=$ Elastizität, } \\
$*$
\end{tabular}

\subsection{Mikroradiographie}

\subsubsection{Auswertung und Ergebnispräsentation der Mikroradiographie}

In Abb. 19 und 20 werden repräsentative mikroradiographische Bilder der einzelnen Versuchsgruppen dargestellt. Die korrespondierenden Fluoreszenz-mikroskopischen Bilder finden sich unter 3.5.1 (S. 71).

Bereits bei bloßer Betrachtung der Mikroradiographien zeigten sich deutliche Unterschiede zwischen den Testgruppen. PTH hob sich in besonderem Maße von allen anderen Gruppen ab.

Die Parathormon-Applikation führte bei allen Knochen zu einer deutlichen Zunahme der Kallusdichte, der Kallusfläche und zur Verdickung der metaphysären Trabekel. Dadurch verschwammen im mikroradiographischen Präparat die Grenzen zwischen dem Kallus, der proximalen und der distalen Trabekelfläche. Dies machte eine Differenzierung zwischen metaphysären Trabekeln und knöchernem Kallus für die Software der quantitativen Auswertung unmöglich. Folglich konnten in der Testgruppe PTH keine quantitativen Daten über die Trabekel gewonnen werden. Zu den betroffenen Messwerten zählen: „Knochenflächendichte Trabekel distal”, „Anzahl Trabekelkreuzungen absolut”, “Dichte Trabekelkreuzungen”, „Mittlere Trabekeldicke”. Diese sind im Folgenden durch „n.a.“ (nicht angegeben) gekennzeichnet.

Nachstehend werden die Ergebnisse der mikroradiographischen Auswertung aufgeführt. Hierbei erfolgt zunächst eine Präsentation in Form von Säulendiagrammen unter Angabe der Mittelwerte, Standardabweichungen und Signifikanzen (vgl. 3.3.1. S. 56). Am Ende des Kapitels findet sich eine tabellarische Zusammenfassung aller ermittelter Ergebnisse (siehe Tab.16, S. 70). 


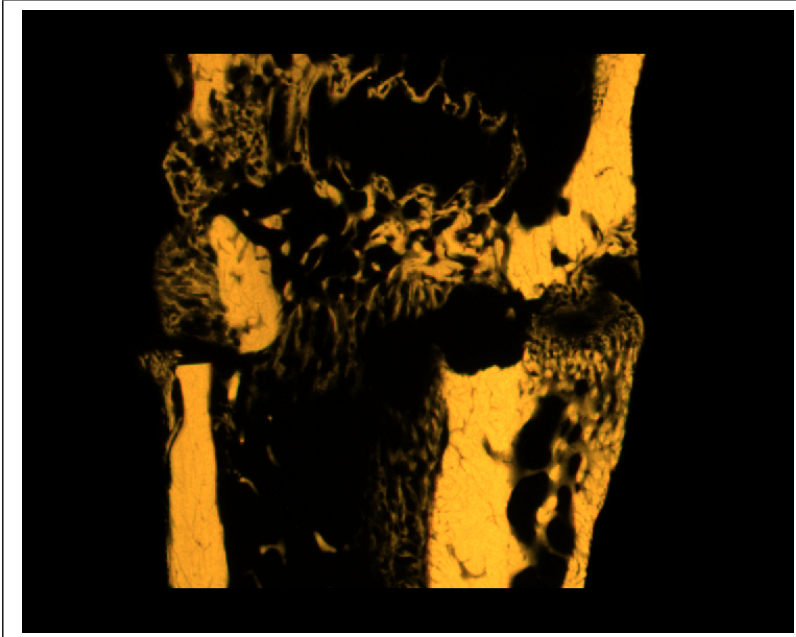

(a) Mikroradiographisches Bild aus der Testgruppe C; Ratte Nr. 4; 16-fache Vergrößerung

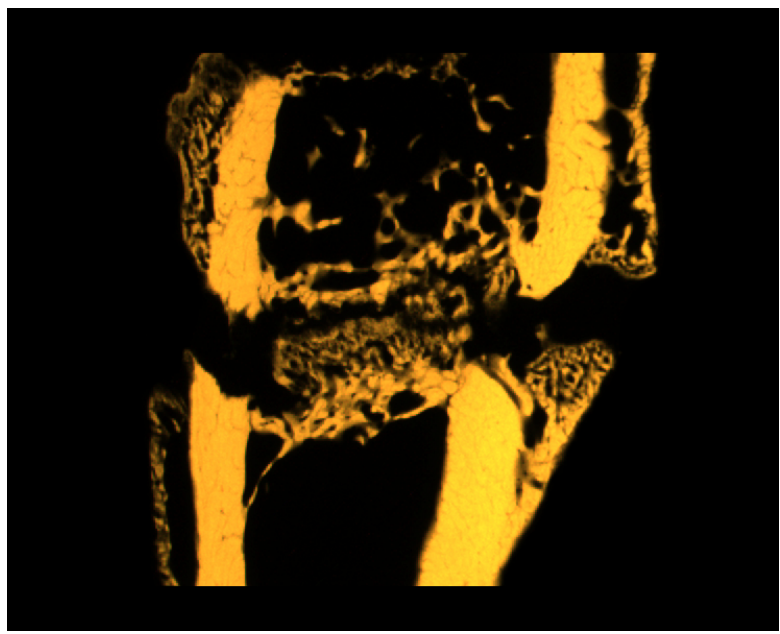

(c) Mikroradiographisches Bild aus der Testgruppe R; Ratte Nr. 32; 16-fache Vergrößerung

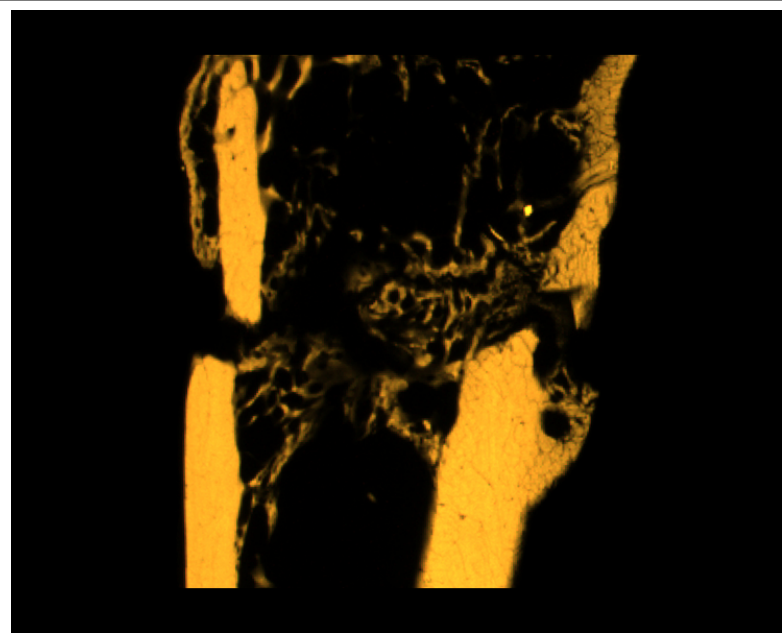

(b) Mikroradiographisches Bild aus der Testgruppe E2; Ratte Nr. 16; 16-fache Vergrößerung

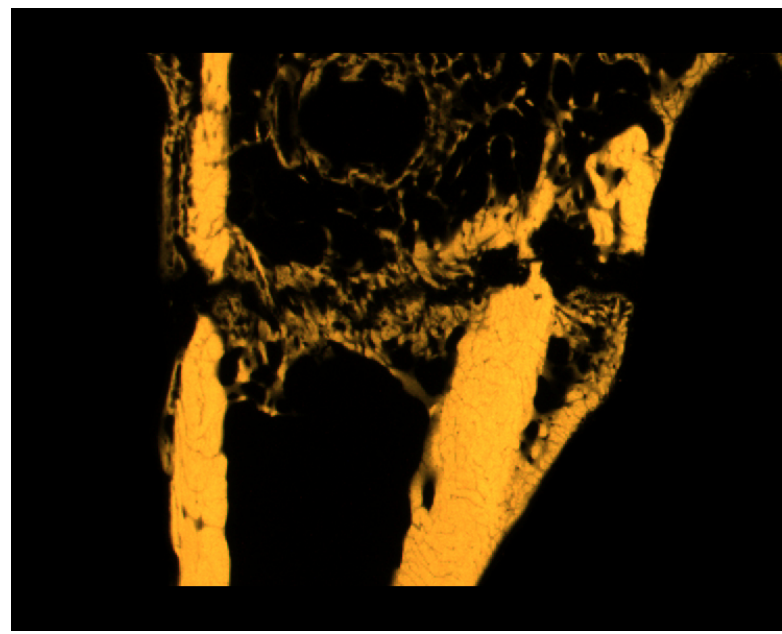

(d) Mikroradiographisches Bild aus der Testgruppe CR; Ratte Nr. 37; 16-fache Vergrößerung

Abbildung 19: Repräsentative mikroradiographische Bilder der Testgruppen C, E2, R und CR 


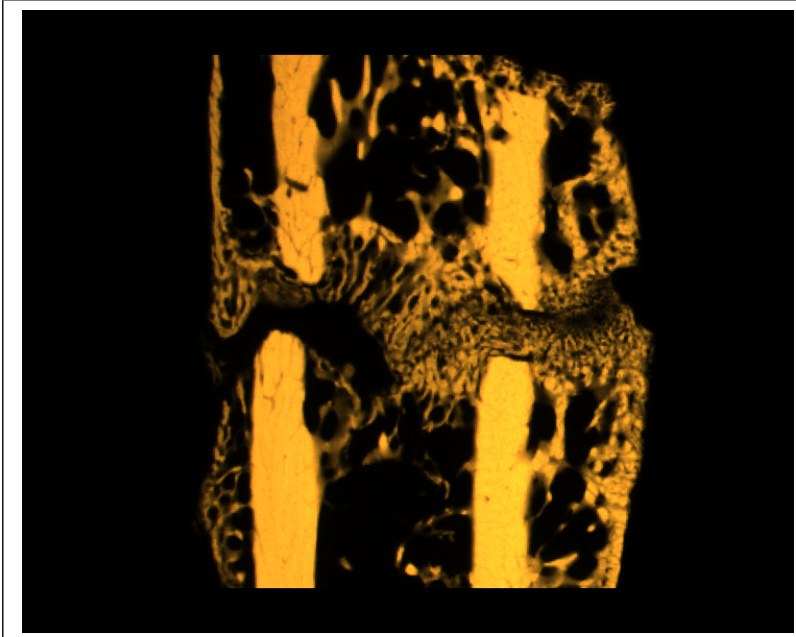

(a) Mikroradiographisches Bild aus der Testgruppe EQ; Ratte Nr. 57; 16-fache Vergrößerung

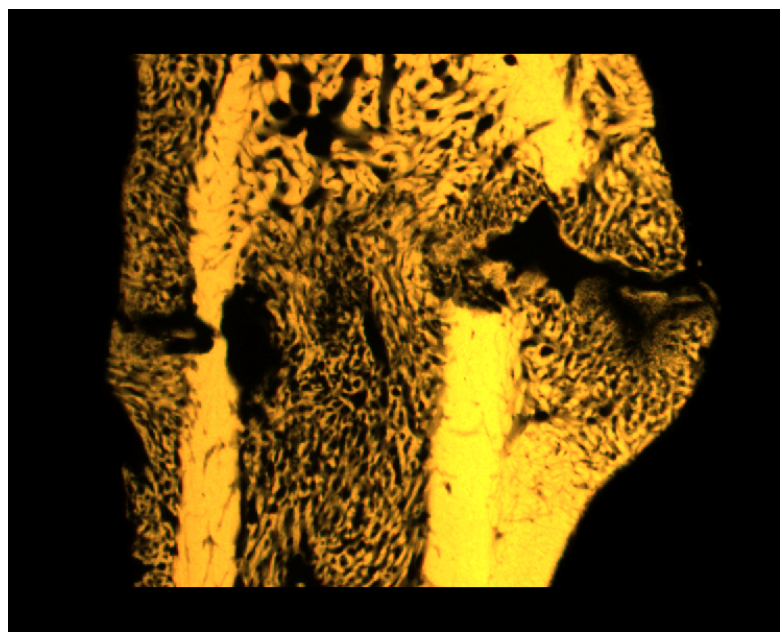

(c) Mikroradiographisches Bild aus der Testgruppe PTH; Ratte Nr. 76; 16-fache Vergrößerung

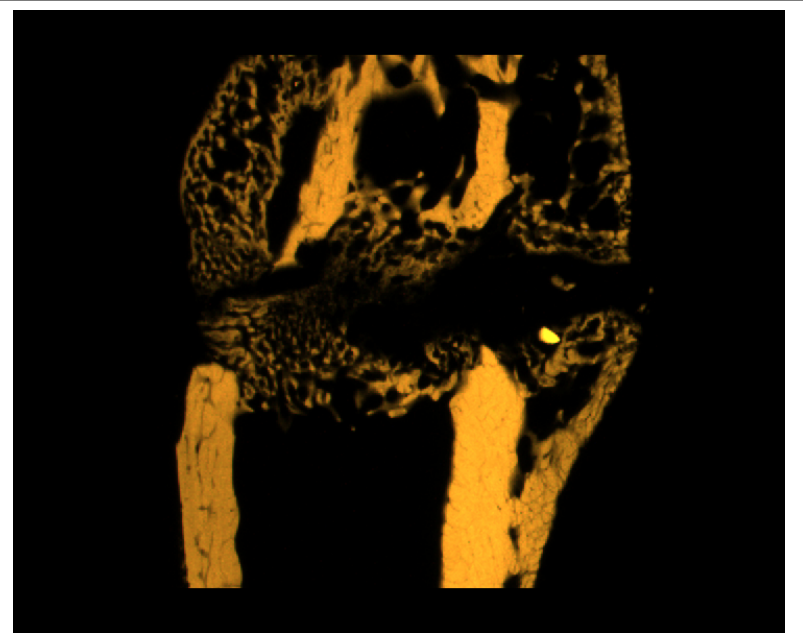

(b) Mikroradiographisches Bild aus der Testgruppe GEN; Ratte Nr.67; 16-fache Vergrößerung

Abbildung 20: Repräsentative mikroradiographische Bilder der Testgruppen EQ, GEN und PTH 


\subsubsection{Kortikalisdicke distal plattennah}

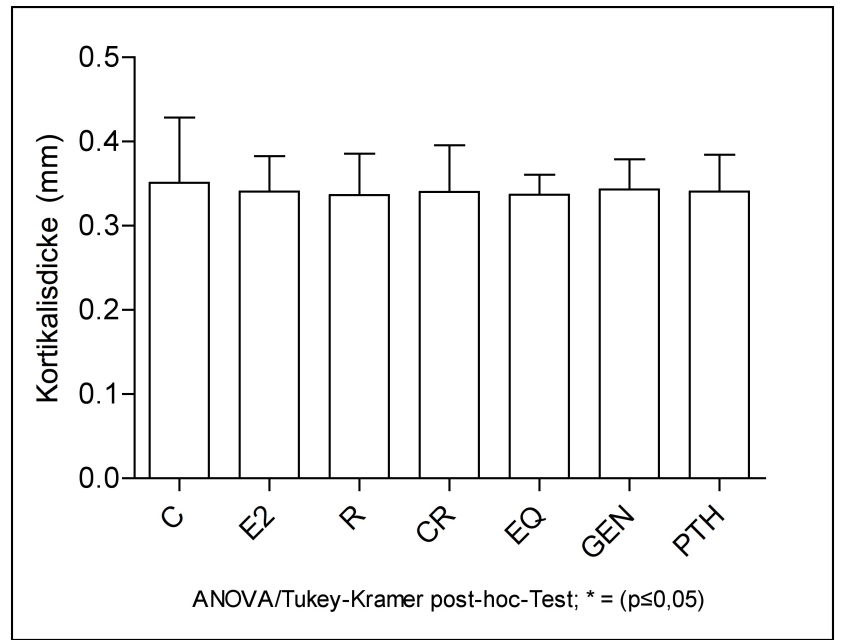

Abbildung 21: Messergebnisse für den Parameter 'Kortikalisdicke distal plattennah'

Die distale plattennahe Kortikalisdicke ist bei allen Gruppen annähernd gleich. Es zeigen sich keine signifikanten Unterschiede zwischen den Testgruppen.

\subsubsection{Kortikalisdicke distal plattenfern}

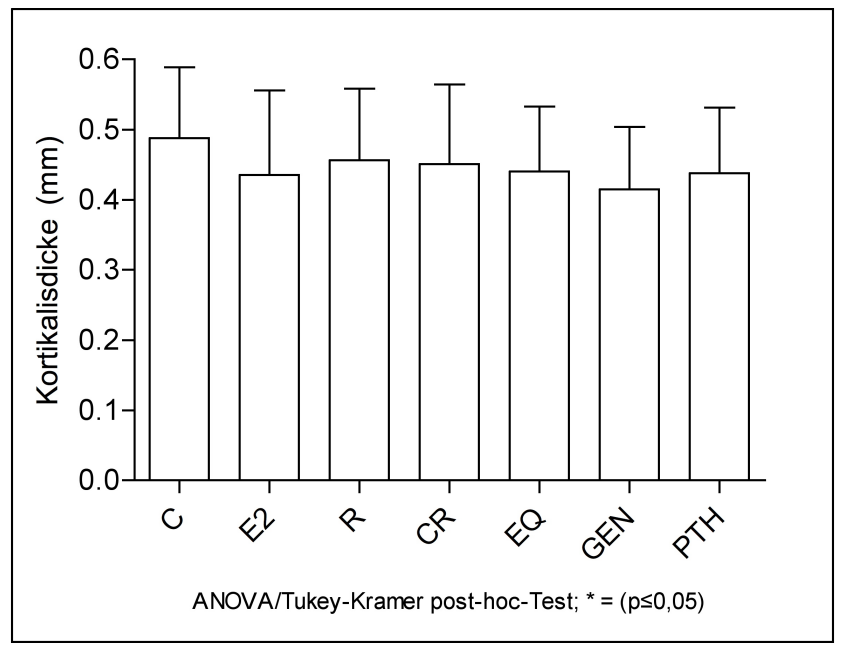

Abbildung 22: Messergebnisse für den Parameter 'Kortikalisdicke distal plattenfern'

Bezüglich der distalen plattenfernen Kortikalisdicke zeigen sich keine signifikanten Unterschiede zwischen den Testgruppen. 


\subsubsection{Knochendurchmesser proximal}

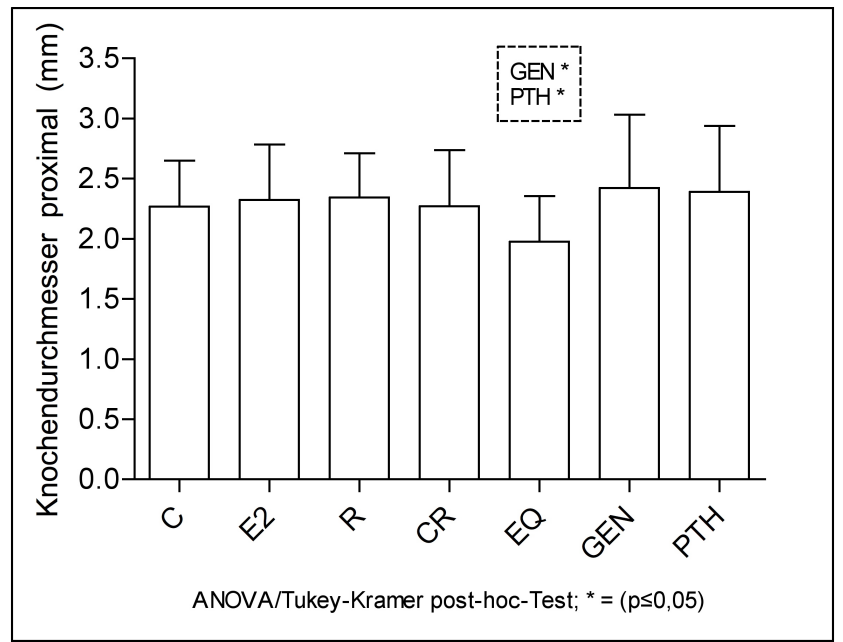

Abbildung 23: Messergebnisse für den Parameter 'Knochendurchmesser proximal'

Der proximale Knochendurchmesser der Testgruppe EQ ist gegenüber PTH und GEN signifikant verringert. Alle weiteren Gruppen unterscheiden sich nur wenig.

\subsubsection{Knochendurchmesser distal}

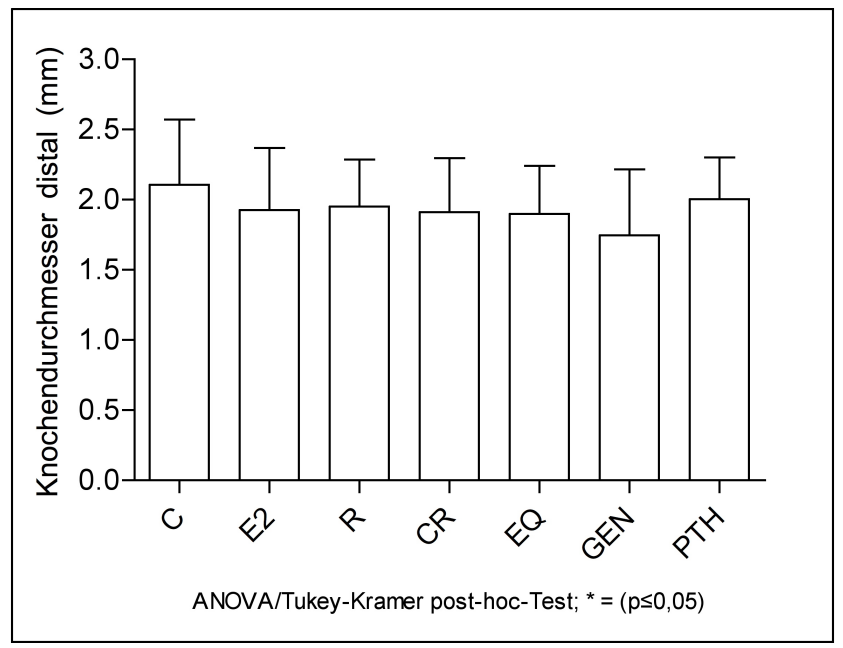

Abbildung 24: Messergebnisse für den Parameter 'Knochendurchmesser distal'

Der distale Knochendurchmesser erweist sich über alle Gruppen hinweg als relativ konstante Größe. Es zeigen sich keine signifikanten Unterschiede zwischen den Gruppen. 


\subsubsection{Kallusdicke plattennah}

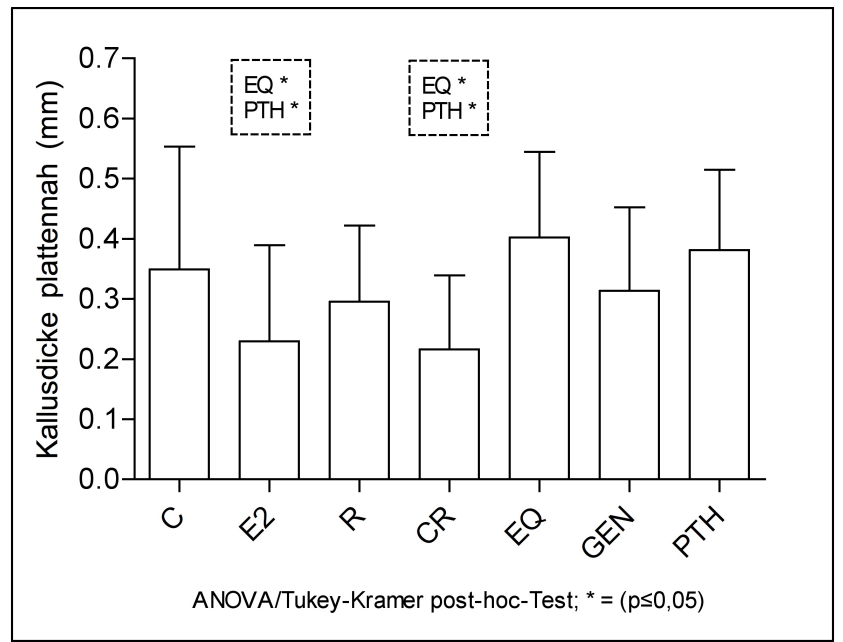

Abbildung 25: Messergebnisse für den Parameter 'Kallusdicke plattennah'

Die höchsten Werte für die plattennahe Kallusdicke werden von den Gruppen EQ und PTH erreicht. Beide Gruppen unterscheiden sich von E2 und CR signifikant.

\subsubsection{Kallusdicke plattenfern}

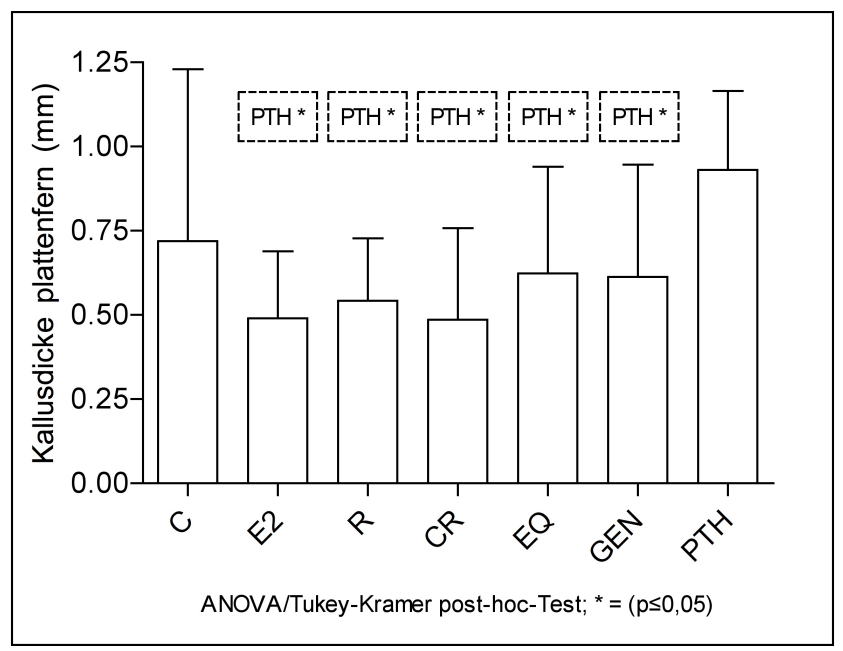

Abbildung 26: Messergebnisse für den Parameter 'Kallusdicke plattenfern'

PTH zeichnet sich durch eine alle Gruppen übertreffende plattenferne Kallusdicke aus. Ein signifikanter Unterschied besteht gegenüber E2, R, CR, EQ und GEN. 


\subsubsection{Knochenflächendichte Kortikalis distal plattennah}

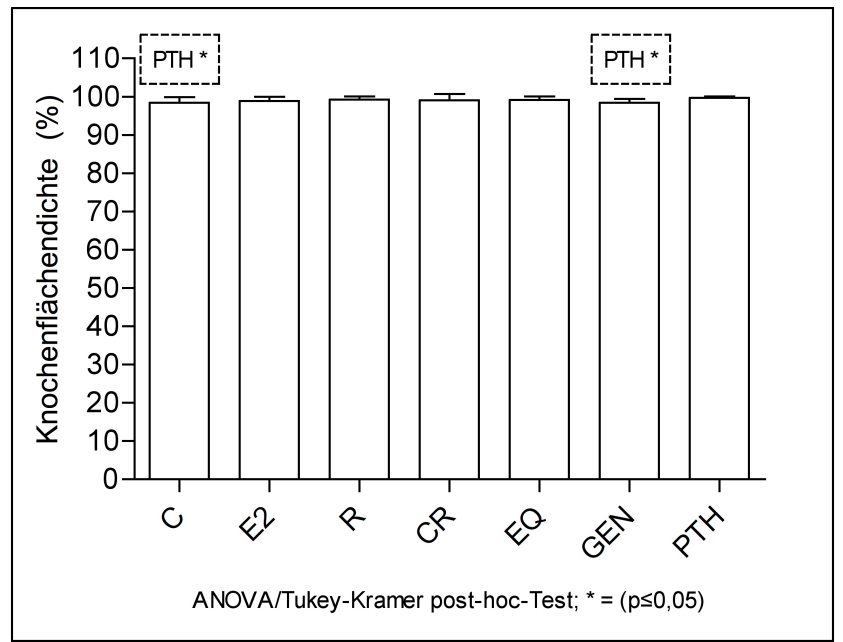

Abbildung 27: Messergebnisse für den Parameter 'Knochenflächendichte Kortikalis distal plattennah'

Bei C und GEN ist im Vergleich zu PTH die Knochenflächendichte der distalen plattennahen Kortikalis signifikant niedriger. Weitere signifikante Unterschiede bestehen nicht.

\subsubsection{Knochenflächendichte Kortikalis distal plattenfern}

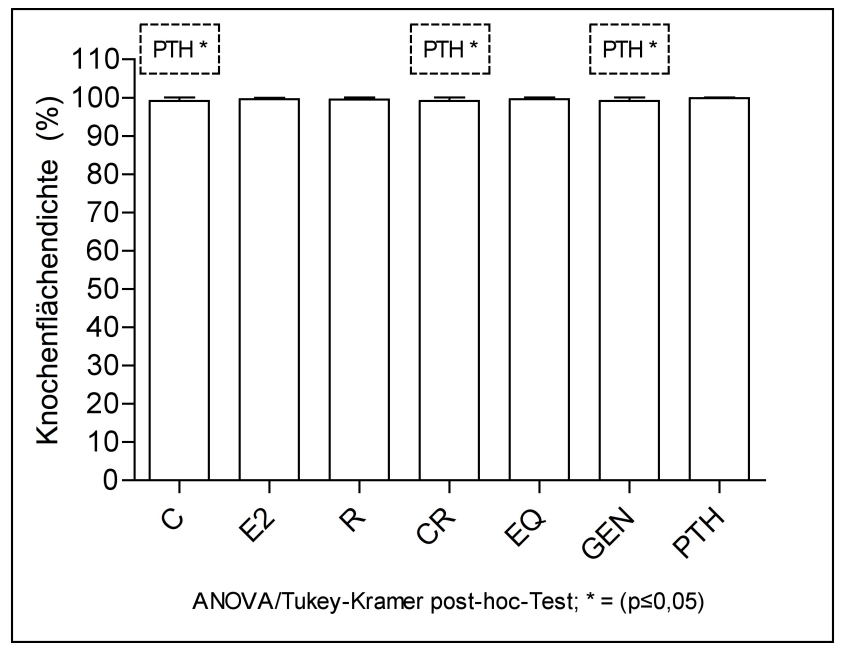

Abbildung 28: Messergebnisse für den Parameter 'Knochenflächendichte Kortikalis distal plattenfern'

Die Knochenflächendichte der distalen plattenfernen Kortikalis von C, CR und GEN ist signifikant niedriger als die von PTH. Zwischen den restlichen Gruppen zeigen sich keine wesentlichen Unterschiede. 


\subsubsection{Knochenflächendichte Kallus plattennah}

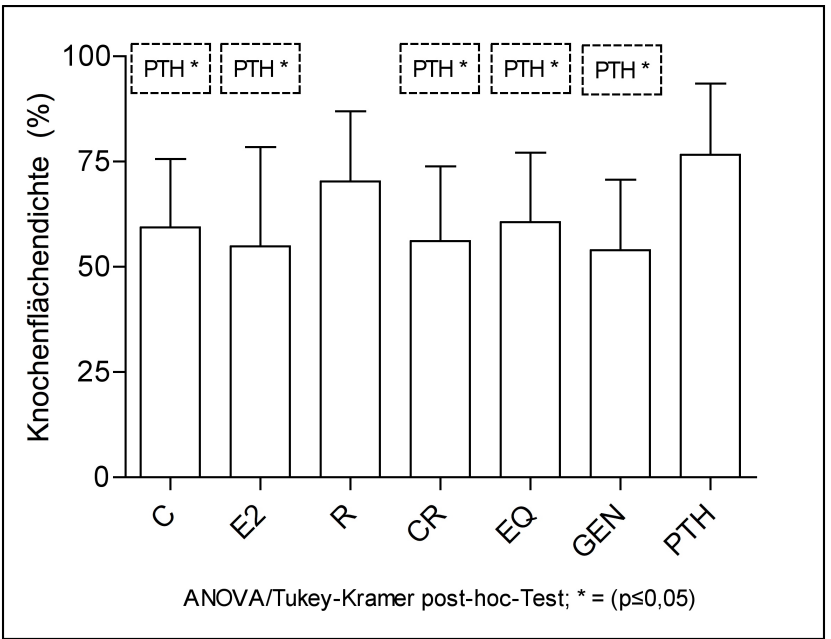

Abbildung 29: Messergebnisse für den Parameter 'Knochenflächendichte Kallus plattennah'

Die höchste Knochenflächendichte des plattennahen Kallus wird in der Testgruppe PTH erreicht. Diese unterscheidet sich von C, E2, CR, EQ und GEN signifikant.

\subsubsection{Knochenflächendichte Kallus plattenfern}

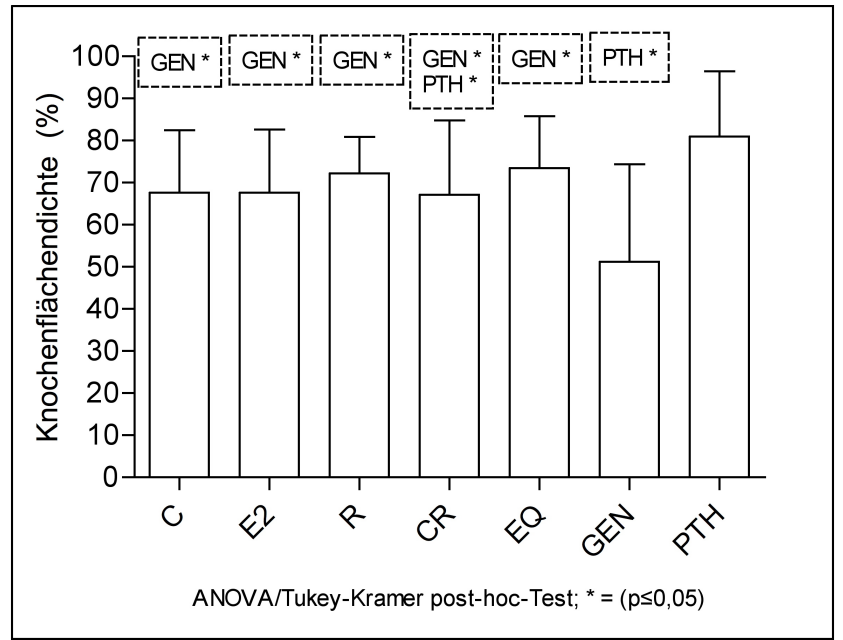

Abbildung 30: Messergebnisse für den Parameter 'Knochenflächendichte Kallus plattenfern'

PTH weist im plattenfernen Kallus die höchste Knochenflächendichte aller Testgruppen auf und erreicht einen signifikant höheren Wert als CR und GEN. Die mit Abstand niedrigste Dichte findet sich in der Gruppe GEN. GEN unterscheidet sich von allen anderen Testgruppen signifikant. 


\subsubsection{Knochenflächendichte Kallus endostal}

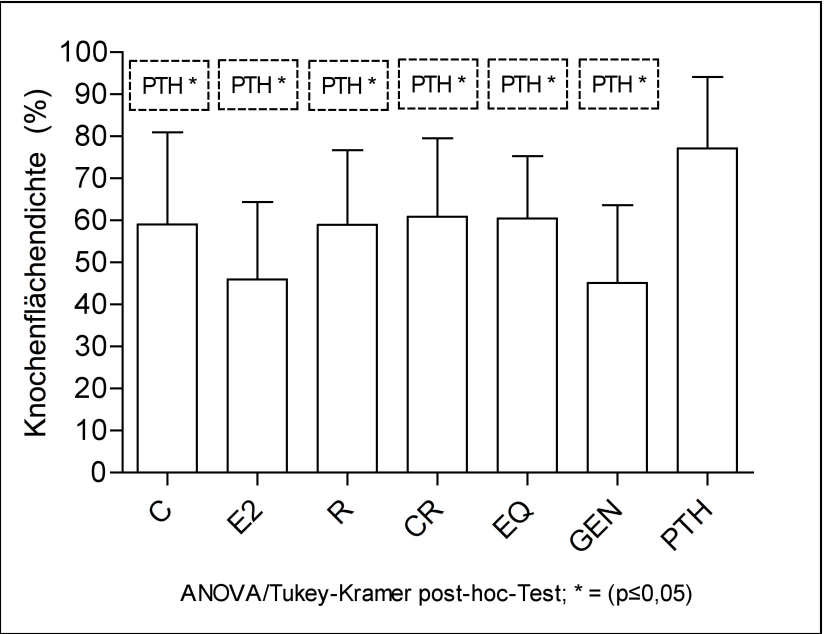

Abbildung 31: Messergebnisse für den Parameter 'Knochenflächendichte Kallus endostal'

PTH zeigt eine signifikant höhere endostale Knochenflächendichte als alle anderen Testgruppen. Weitere signifikante Unterschiede bestehen nicht.

\subsubsection{Knochenflächendichte Trabekel distal}

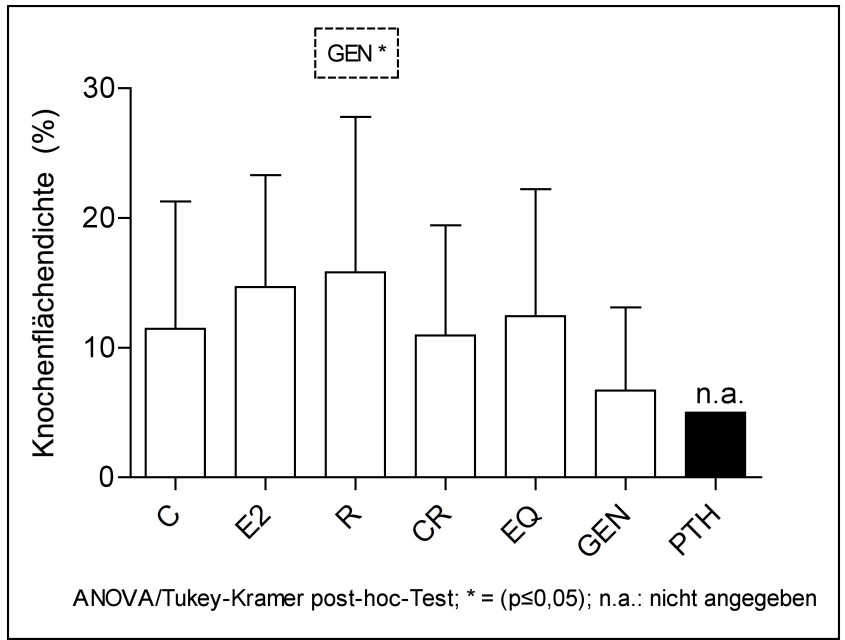

Abbildung 32: Messergebnisse für den Parameter 'Knochenflächendichte Trabekel distal'

$\mathrm{R}$ zeigt eine signifikant höhere Knochenflächendichte der distalen Trabekel als GEN. E2 reicht fast an den Wert von $\mathrm{R}$ heran. Dieser Messwert konnte für PTH nicht ermittelt werden (vgl. 3.4.1. S. 59). 


\subsubsection{Anzahl Trabekelkreuzungen absolut}

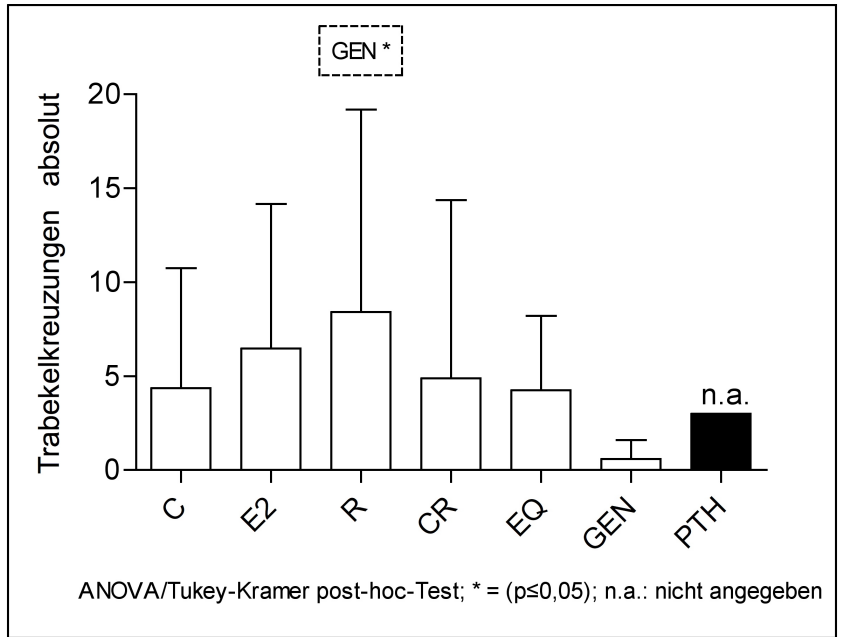

Abbildung 33: Messergebnisse für den Parameter 'Anzahl Trabekelkreuzungen absolut'

In der Testgruppe $R$ zeigt sich eine signifikant höhere Anzahl von Trabekelkreuzungen als in GEN. Bei hoher Standardabweichung erreicht E2 wiederum fast den Wert von R. Dieser Messwert konnte für PTH nicht ermittelt werden (vgl. 3.4.1, S. 59).

\subsubsection{Dichte Trabekelkreuzungen}

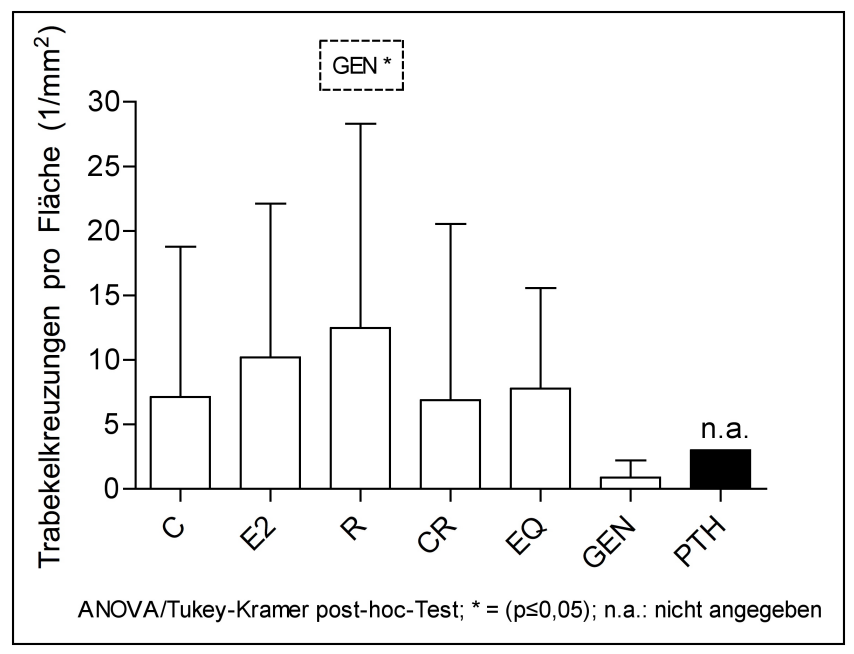

Abbildung 34: Messergebnisse für den Parameter 'Dichte Trabekelkreuzungen'

Die höchste Dichte an Trabekelkreuzungen im Bereich der distalen Trabekelfläche zeigt R, die geringste GEN. Auch hier besteht ein signifikanter Unterschied zwischen den Ergeb- 
nissen beider Testgruppen. Dieser Messwert konnte für PTH nicht ermittelt werden (vgl. 3.4.1. S. 59.

\subsubsection{Mittlere Trabekeldicke}

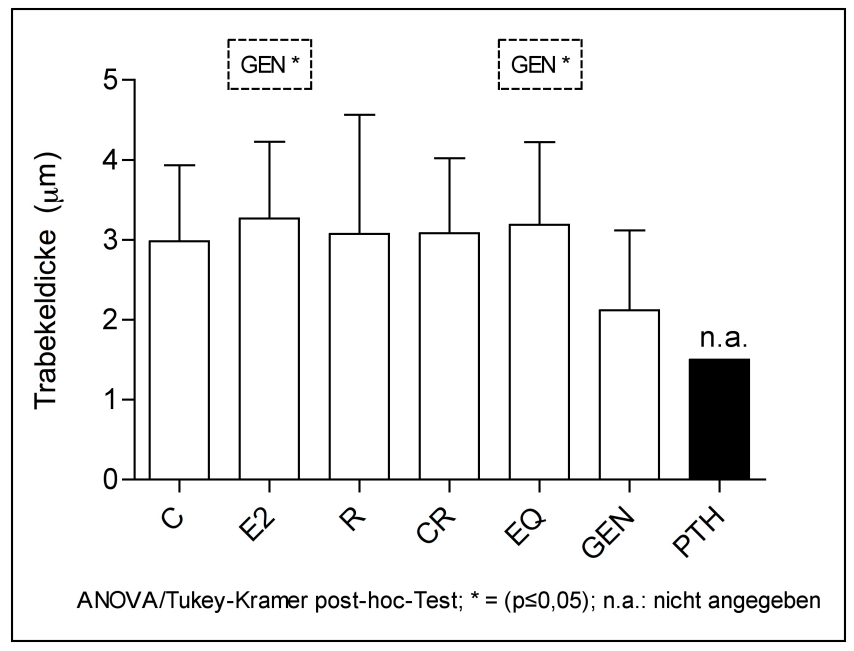

Abbildung 35: Messergebnisse für den Parameter 'Mittlere Trabekeldicke'

E2 und EQ zeigen im Bereich der distalen Trabekelfläche signifikant größere Trabekeldurchmesser als GEN. Ansonsten variiert die Trabekeldicke nur gering. Dieser Meßwert konnte für PTH nicht ermittelt werden (vgl. 3.4.1, S. 59). 


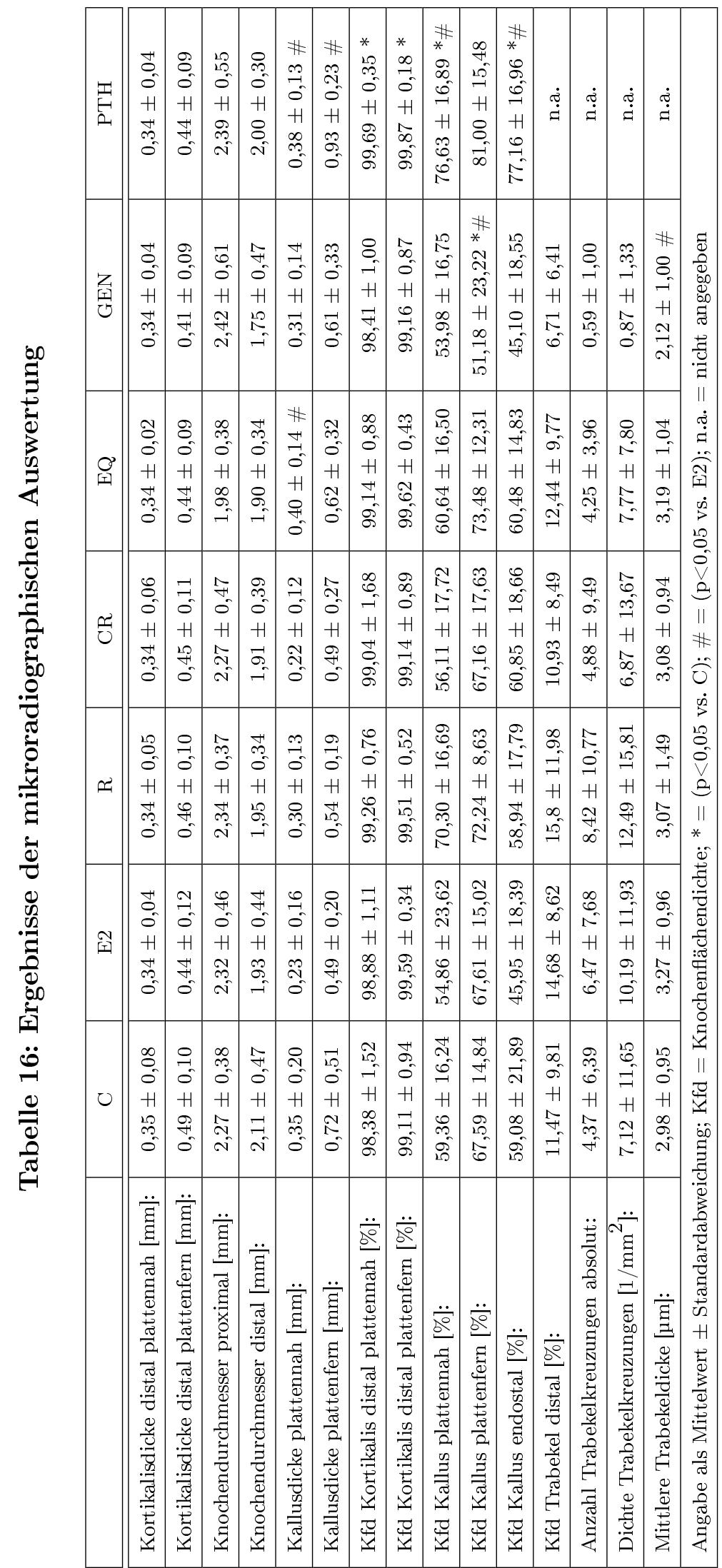




\subsection{Polychrome Sequenzmarkierung}

\subsubsection{Auswertung und Ergebnispräsentation der Polychromen Sequenzmar- kierung}

In Abb. 36 und 37 werden repräsentative Fluoreszenz-mikroskopische Bilder der einzelnen Versuchsgruppen dargestellt. Die korrespondierenden mikroradiographischen Bilder finden sich unter 3.4.1 (S. 59). Nachstehend werden die Ergebnisse der polychromen Sequenzmarkierung aufgeführt. Hierbei erfolgt zunächst eine Präsentation in Form von Säulendiagrammen unter Angabe der Mittelwerte, Standardabweichungen und Signifikanzen (vgl. 3.3.1, S. 56). Am Ende des Kapitels findet sich eine tabellarische Zusammenfassung aller ermittelter Ergebnisse (siehe Tab. 17, 18, 19 und 20, S. 79 und 80).

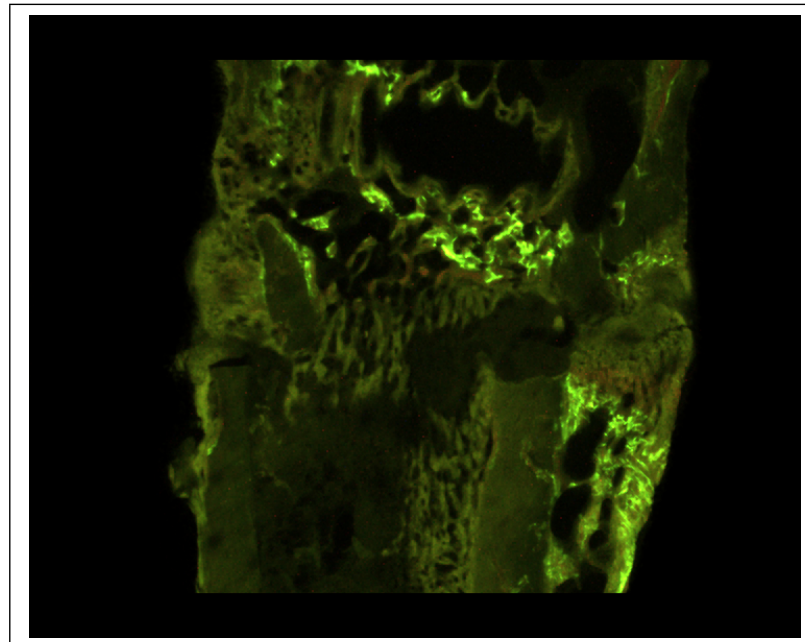

(a) Fluoreszenz-mikroskopisches Bild aus der Testgruppe C; Ratte Nr. 4; 16-fache Vergrößerung

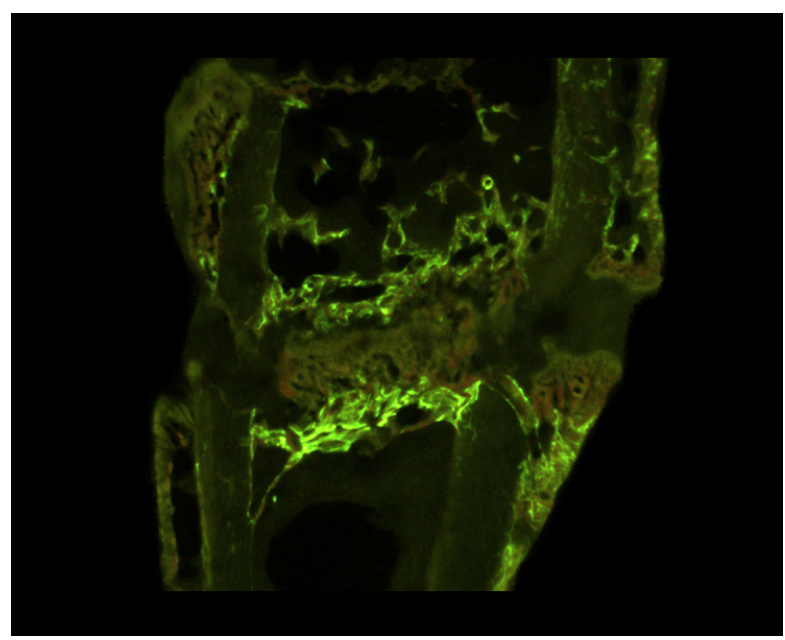

(c) Fluoreszenz-mikroskopisches Bild aus der Testgruppe R; Ratte Nr. 32; 16-fache Vergrößerung

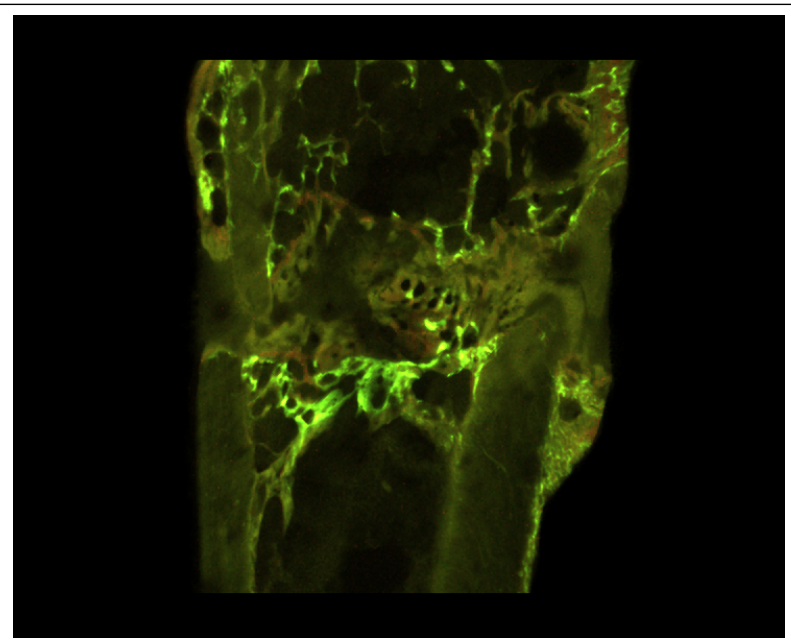

(b) Fluoreszenz-mikroskopisches Bild aus der Testgruppe E2; Ratte Nr. 16; 16-fache Vergrößerung

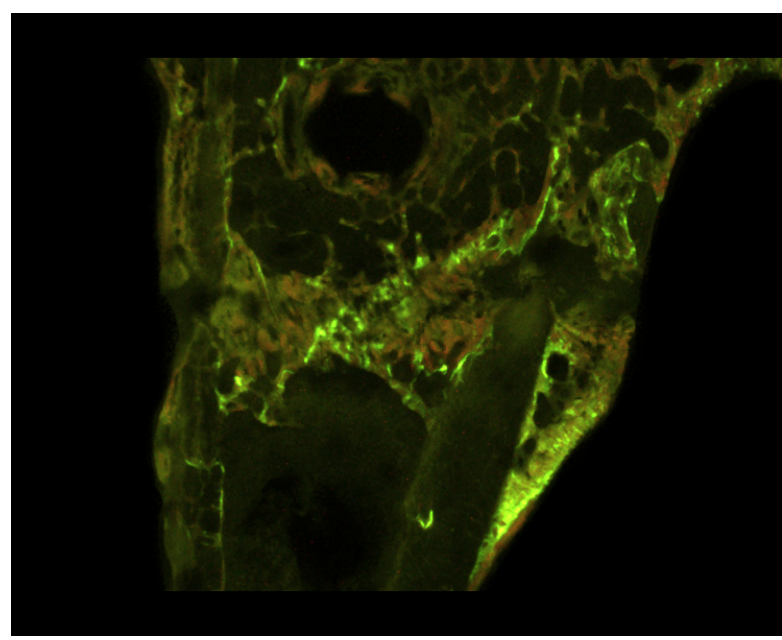

(d) Fluoreszenz-mikroskopisches Bild aus der Testgruppe CR; Ratte Nr. 37; 16-fache Vergrößerung

Abbildung 36: Repräsentative Fluoreszenz-mikroskopische Bilder der Testgruppen $\mathrm{C}, \mathrm{E} 2, \mathrm{R}$ und $\mathrm{CR}$ 


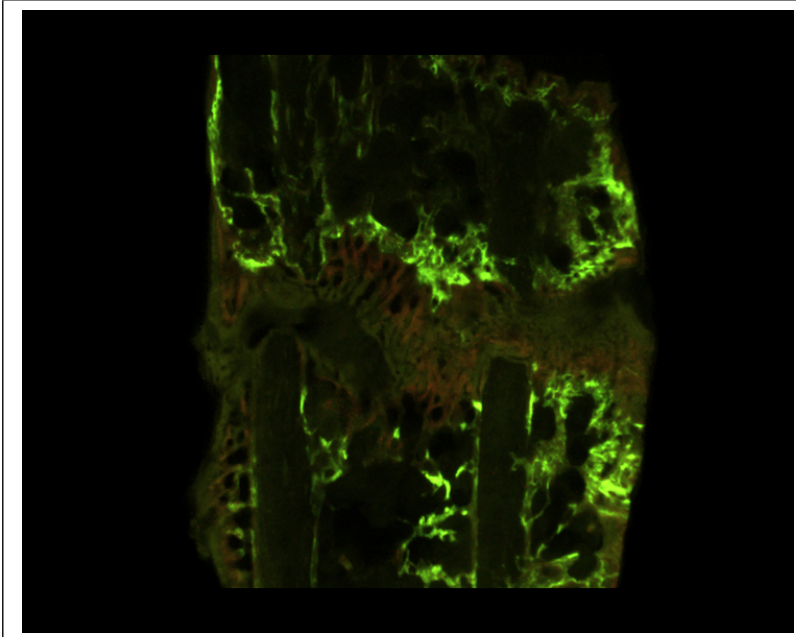

(a) Fluoreszenz-mikroskopisches Bild aus der Testgruppe EQ; Ratte Nr.57; 16-fache Vergrößerung

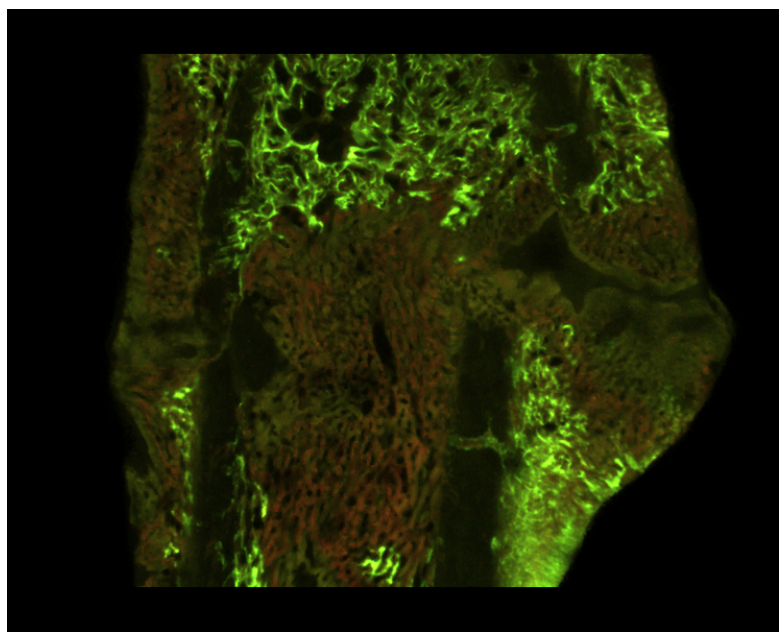

(c) Fluoreszenz-mikroskopisches Bild aus der Testgruppe PTH; Ratte Nr. 76; 16-fache Vergrößerung

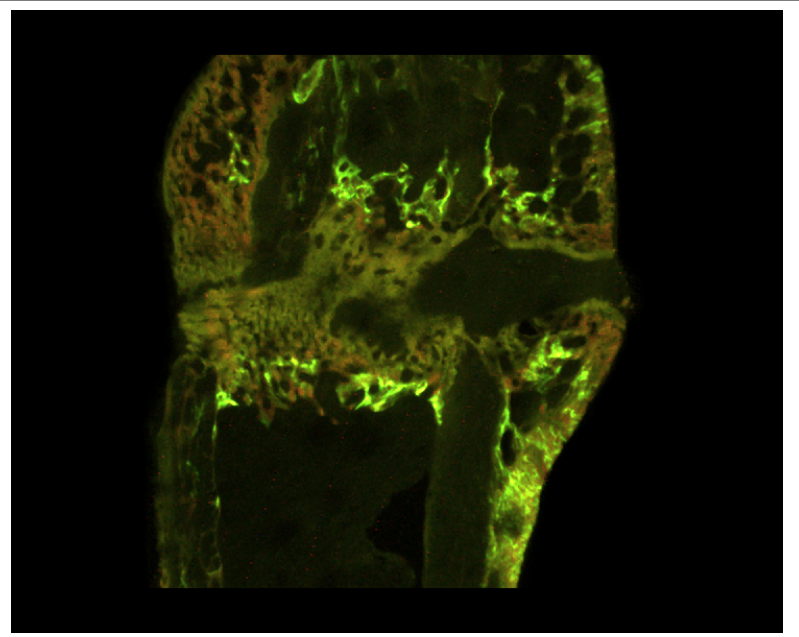

(b) Fluoreszenz-mikroskopisches Bild aus der Testgruppe GEN; Ratte Nr.67; 16-fache Vergrößerung

Abbildung 37: Repräsentative Fluoreszenz-mikroskopische Bilder der Testgruppen EQ, GEN und PTH 


\subsubsection{Gesamtfläche Kallus plattennah}

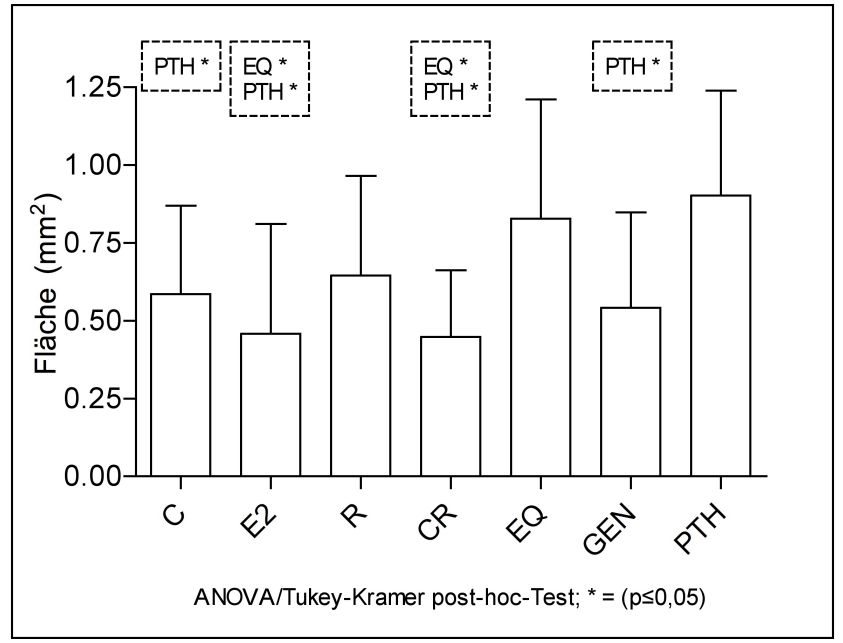

Abbildung 38: Messergebnisse für den Parameter 'Gesamtfläche Kallus plattennah'

Die Gesamtfläche des plattennahen Kallus umfasst alle drei polychrom-gefärbten Kallusareale (CG, AK und TC) an dieser Stelle. PTH erreicht die größte plattennahe Kallusfläche. Es besteht ein signifikanter Unterschied zu C, E2, CR und GEN. Außerdem zeigt EQ eine signifikant größere plattennahe Kallusfläche als E2 und CR.

\subsubsection{CG-Fläche Kallus plattennah}

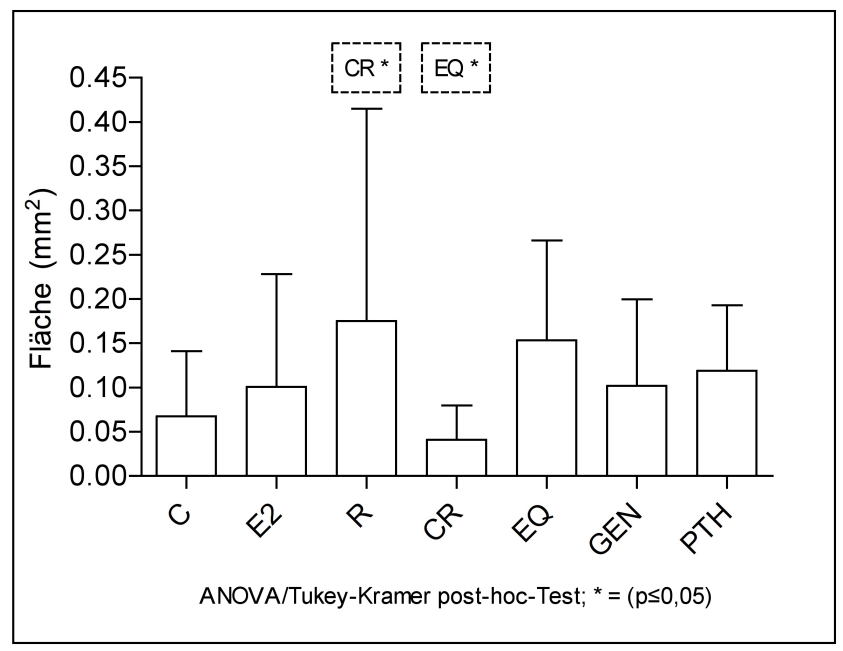

Abbildung 39: Messergebnisse für den Parameter 'CG-Fläche Kallus plattennah'

Bezüglich der plattennahen CG-Fläche werden in der Testgruppe CR signifikant kleinere Werte erreicht als in $\mathrm{R}$ und EQ. Weitere signifikante Unterschiede bestehen nicht. 


\subsubsection{AK-Fläche Kallus plattennah}

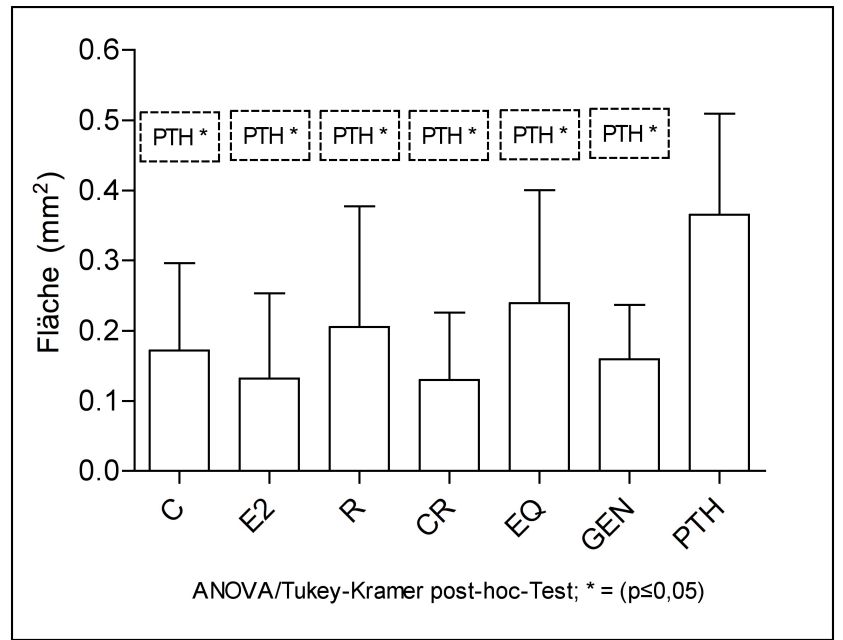

Abbildung 40: Messergebnisse für den Parameter 'AK-Fläche Kallus plattennah'

Die größte plattennahe AK-Fläche wird von der Testgruppe PTH erreicht. Diese ist signifikant größer als bei allen anderen Gruppen.

\subsubsection{TC-Fläche Kallus plattennah}

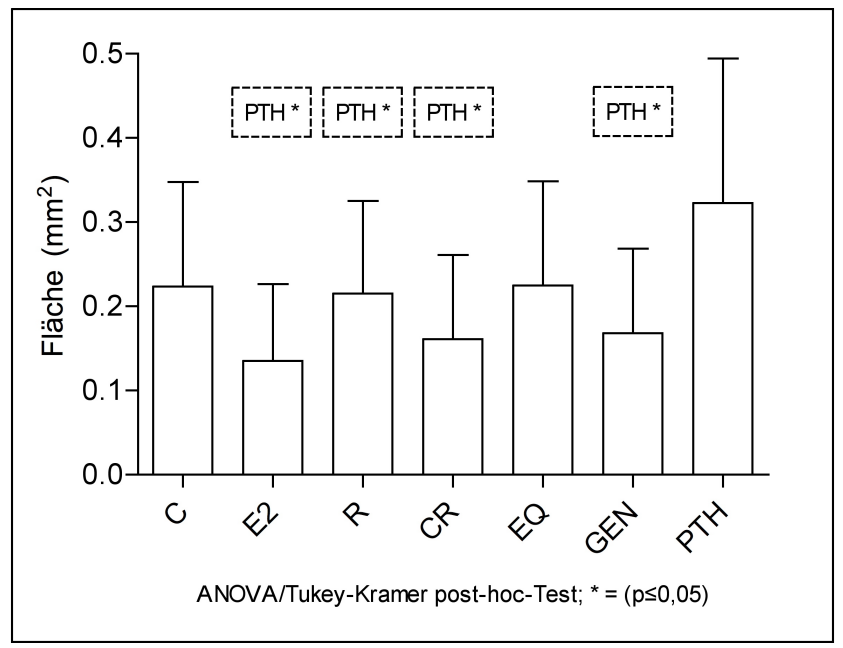

Abbildung 41: Messergebnisse für den Parameter 'TC-Fläche Kallus plattennah'

Unter PTH wird die größte plattennahe TC-fläche erreicht. Gegenüber E2, R, CR und GEN zeigt sich ein signifikanter Größenunterschied. 


\subsubsection{Gesamtfläche Kallus plattenfern}

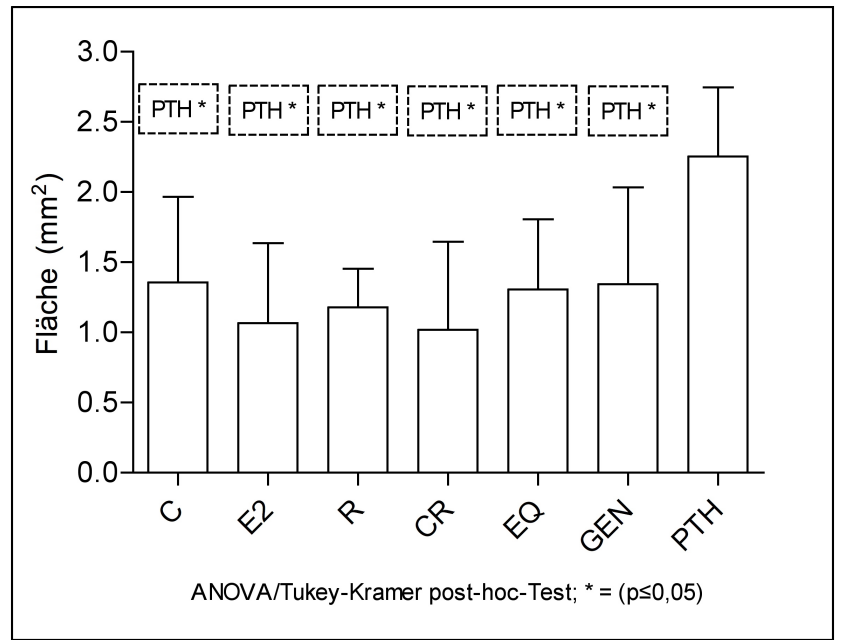

Abbildung 42: Messergebnisse für den Parameter 'Gesamtfläche Kallus plattenfern'

Die Gesamtfläche des plattenfernen Kallus umfasst alle drei polychrom-gefärbten Kallusareale (CG, AK und TC) an dieser Stelle. Die mit Abstand größte plattenferne GesamtKallusfläche erreicht die Testgruppe PTH. Zu allen Vergleichsgruppen besteht ein signifikanter Flächenunterschied.

\subsubsection{CG-Fläche Kallus plattenfern}

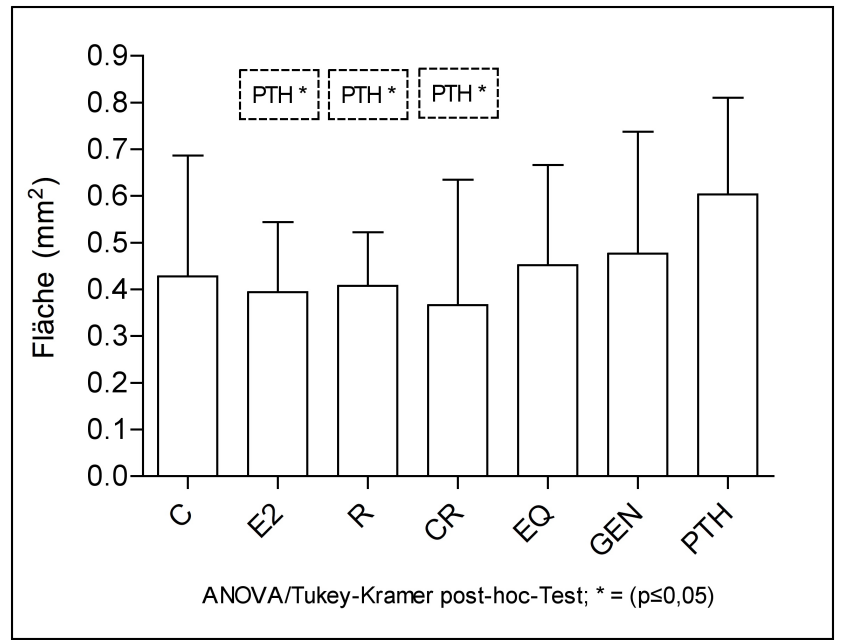

Abbildung 43: Messergebnisse für den Parameter 'CG-Fläche Kallus plattenfern' 
Die CG-Fläche im Bereich des plattenfernen Kallus ist unter PTH am größten. E2, R und CR erreichen signifikant kleinere Werte als PTH. Weitere signifikante Unterschiede bestehen nicht.

\subsubsection{AK-Fläche Kallus plattenfern}

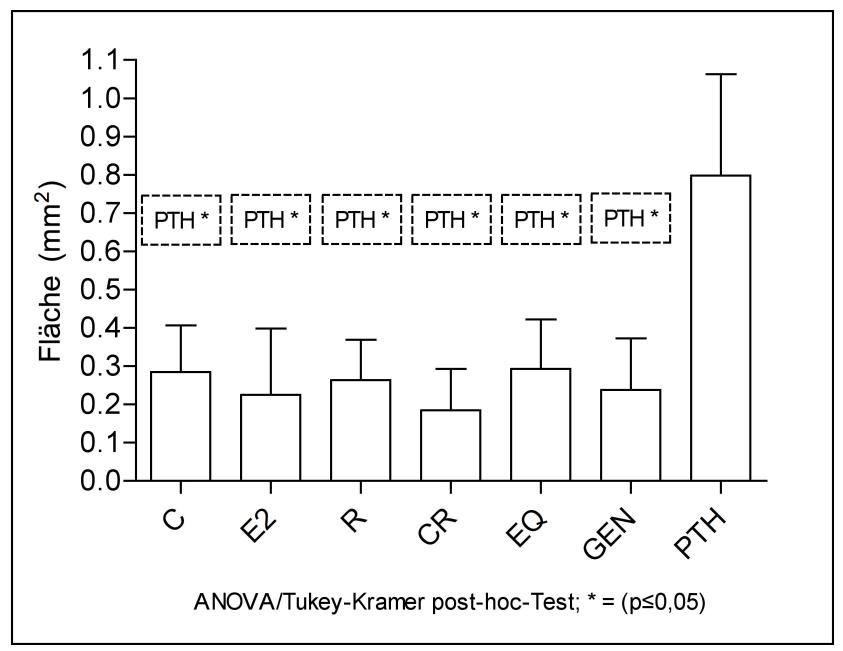

Abbildung 44: Messergebnisse für den Parameter 'AK-Fläche Kallus plattenfern'

Erneut erreicht PTH die mit Abstand größte Kallusfläche. Zu allen Vergleichsgruppen besteht ein signifikanter Unterschied. Die Ergebnisse der anderen Gruppen unterscheiden sich nur wenig.

\subsubsection{TC-Fläche Kallus plattenfern}

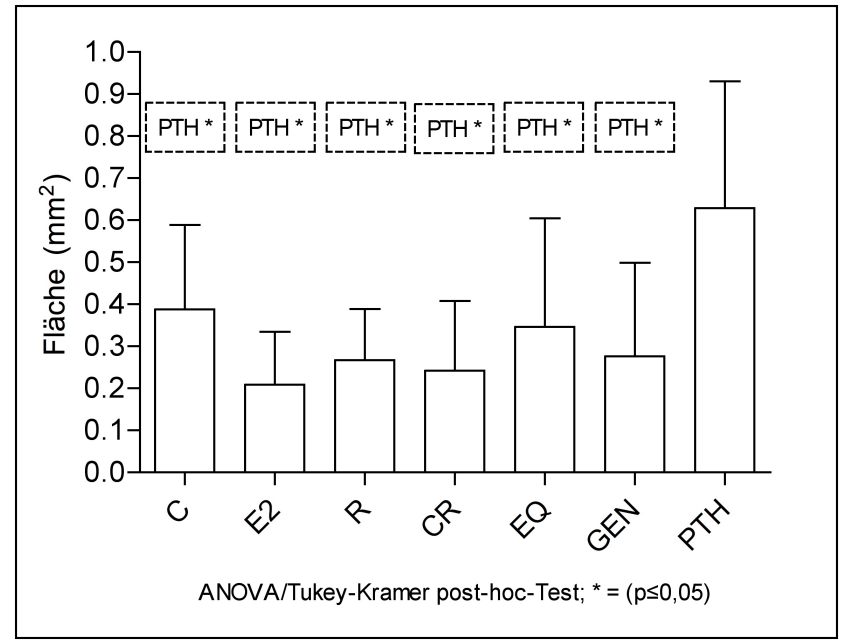

Abbildung 45: Messergebnisse für den Parameter 'TC-Fläche Kallus plattenfern' 
Auch dieser Parameter wird eindeutig von PTH dominiert. C, E2, R, CR, EQ und GEN weisen signifikant kleinere TC-Flächen im plattenfernen Kallus auf.

\subsubsection{Gesamtfläche Kallus endostal}

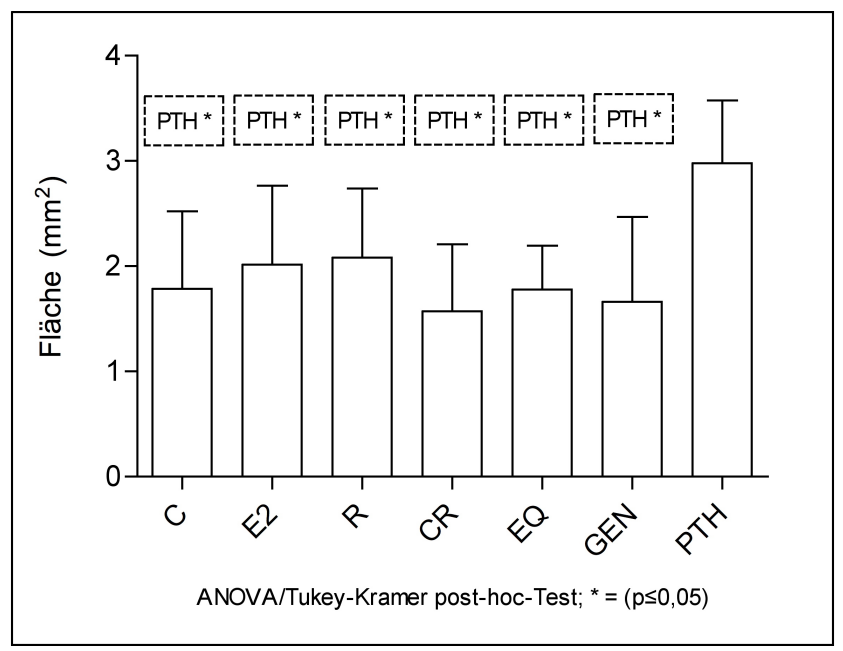

Abbildung 46: Messergebnisse für den Parameter 'Gesamtfläche Kallus endostal'

Die Gesamtfläche des endostalen Kallus umfasst alle drei polychrom-gefärbten Kallusareale (CG, AK und TC) an dieser Stelle. PTH zeigt die mit Abstand größte endostale Kallusfläche. Zu allen anderen Testgruppen besteht ein signifikanter Größenunterschied. Weitere Signifikanzen bestehen nicht.

\subsubsection{CG-Fläche Kallus endostal}

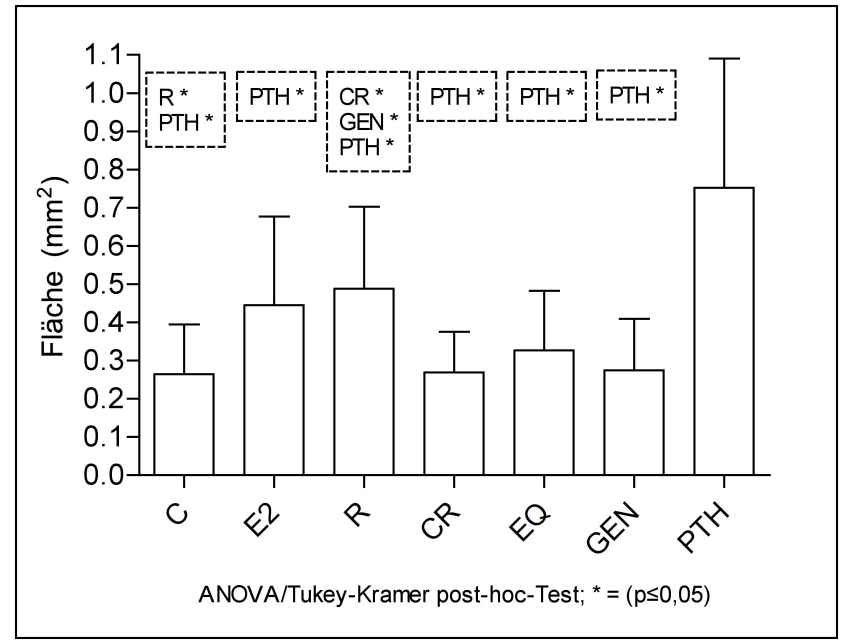

Abbildung 47: Messergebnisse für den Parameter 'CG-Fläche Kallus endostal' 
C, E2, R, CR, EQ und GEN zeigen eine signifikant kleinere Kallusflächen als PTH. In der Testgruppe R werden signifikant höhere Werte als in CR, GEN und der Negativkontrolle C erreicht.

\subsubsection{AK-Fläche Kallus endostal}

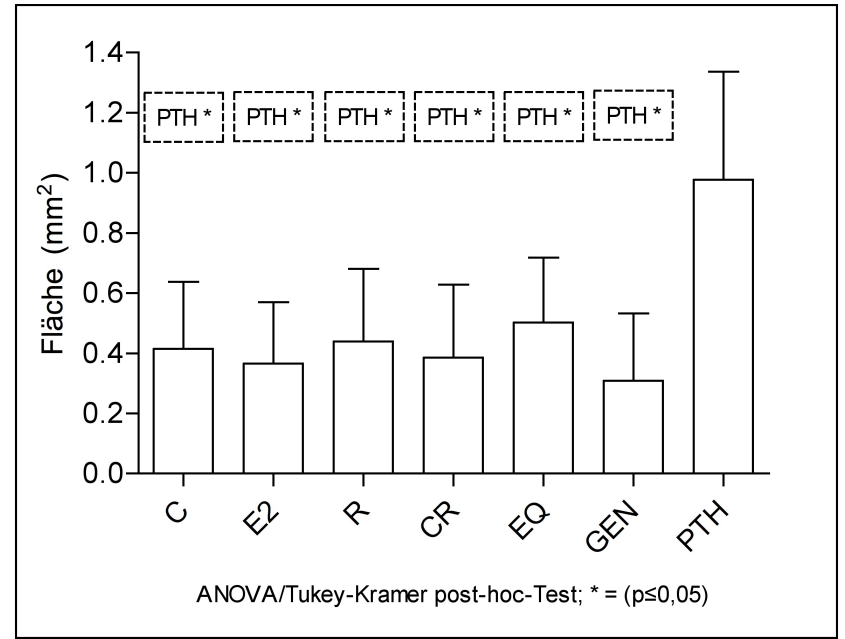

Abbildung 48: Messergebnisse für den Parameter 'AK-Fläche Kallus endostal'

PTH zeigt die mit Abstand größte endostale AK-Kallusfläche. Zu allen anderen Testgruppen besteht ein signifikanter Größenunterschied.

\subsubsection{TC-Fläche Kallus endostal}

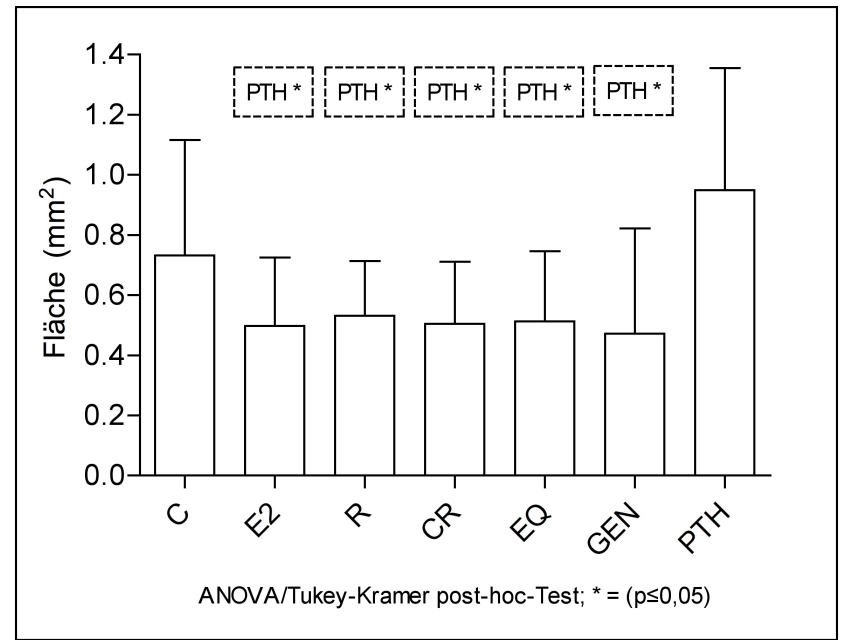

Abbildung 49: Messergebnisse für den Parameter 'TC-Fläche Kallus endostal' 
Der höchste Wert wird erneut von PTH erreicht. E2, R, CR, EQ und GEN weisen eine signifikant kleinere endostale TC-Fläche auf. Zwischen der Kontrollgruppe C und PTH besteht kein signifikanter Unterschied.

\subsubsection{Additivkallus}

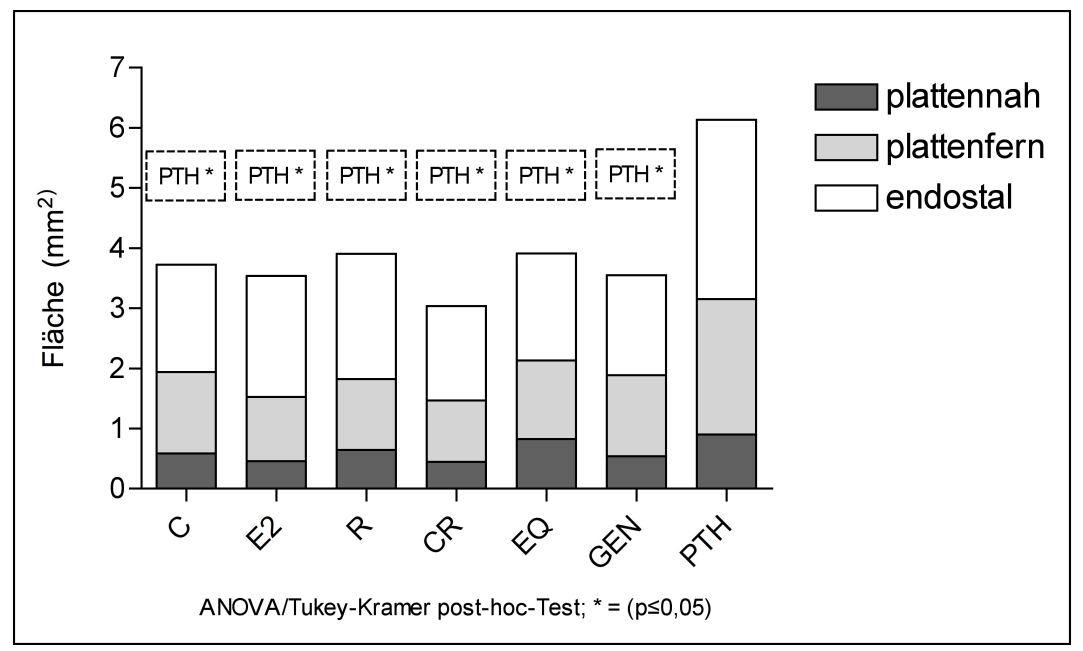

Abbildung 50: Messergebnisse für den Parameter 'Additivkallus'

Als Additivkallus wird der gesamte Kallus ventral, dorsal und endostal einer Testsubstanz bezeichnet. PTH erreicht die mit Abstand größte Additivkallus-Fläche. Alle anderen Testgruppen zeigen signifikant niedrigere Werte. R und EQ induzieren deutlich mehr Kallus als C, E2, CR und GEN, wenn auch der Unterschied nicht signifikant ist.

Tabelle 17: Ergebnisse der Polychromen Sequenzmarkierung (plattennaher Kallus)

\begin{tabular}{ccccc}
\hline & Gesamt pn $\left[\mathrm{mm}^{2}\right]$ & CG pn $\left[\mathrm{mm}^{2}\right]$ & AK pn $\left[\mathrm{mm}^{2}\right]$ & TC pn $\left[\mathrm{mm}^{2}\right]$ \\
\hline \hline C & $0,59 \pm 0,28$ & $0,07 \pm 0,07$ & $0,17 \pm 0,12$ & $0,22 \pm 0,12$ \\
E2 & $0,46 \pm 0,35$ & $0,10 \pm 0,13$ & $0,13 \pm 0,12$ & $0,14 \pm 0,09$ \\
R & $0,65 \pm 0,32$ & $0,18 \pm 0,24$ & $0,21 \pm 0,17$ & $0,22 \pm 0,11$ \\
CR & $0,45 \pm 0,21$ & $0,04 \pm 0,04$ & $0,13 \pm 0,10$ & $0,16 \pm 0,10$ \\
EQ & $0,83 \pm 0,38 \#$ & $0,15 \pm 0,11$ & $0,24 \pm 0,16$ & $0,22 \pm 0,12$ \\
GEN & $0,54 \pm 0,31$ & $0,10 \pm 0,10$ & $0,16 \pm 0,08$ & $0,17 \pm 0,10$ \\
PTH & $0,90 \pm 0,34^{*} \#$ & $0,12 \pm 0,07$ & $0,37 \pm 0,14^{*} \#$ & $0,32 \pm 0,17 \#$ \\
\hline
\end{tabular}

Angabe als Mittelwert \pm Standardabweichung; Gesamt pn = Gesamtfläche Kallus plattennah;

CG pn $=$ CG-Fläche Kallus plattennah; AK pn = AK-Fläche Kallus plattennah;

TC pn $=$ TC-Fläche Kallus plattennah; $*=(p<0,05$ vs. C); \# = (p<0,05 vs. E2) 
Tabelle 18: Ergebnisse der Polychromen Sequenzmarkierung (plattenferner Kallus)

\begin{tabular}{ccccc}
\hline & Gesamt pf $\left[\mathrm{mm}^{2}\right]$ & CG pf $\left[\mathrm{mm}^{2}\right]$ & AK pf $\left[\mathrm{mm}^{2}\right]$ & TC pf $\left[\mathrm{mm}^{2}\right]$ \\
\hline \hline C & $1,36 \pm 0,61$ & $0,43 \pm 0,26$ & $0,28 \pm 0,12$ & $0,39 \pm 0,20$ \\
E2 & $1,07 \pm 0,57$ & $0,39 \pm 0,15$ & $0,23 \pm 0,17$ & $0,21 \pm 0,13$ \\
R & $1,18 \pm 0,28$ & $0,41 \pm 0,11$ & $0,26 \pm 0,11$ & $0,27 \pm 0,12$ \\
CR & $1,02 \pm 0,63$ & $0,37 \pm 0,27$ & $0,19 \pm 0,11$ & $0,24 \pm 0,17$ \\
EQ & $1,31 \pm 0,50$ & $0,45 \pm 0,21$ & $0,29 \pm 0,13$ & $0,35 \pm 0,26$ \\
GEN & $1,34 \pm 0,69$ & $0,48 \pm 0,26$ & $0,24 \pm 0,13$ & $0,28 \pm 0,22$ \\
PTH & $2,25 \pm 0,49^{*} \#$ & $0,60 \pm 0,21 \#$ & $0,80 \pm 0,27^{*} \#$ & $0,63 \pm 0,30^{*} \#$ \\
\hline
\end{tabular}

Angabe als Mittelwert \pm Standardabweichung; Gesamt pf = Gesamtfläche Kallus plattenfern;

$\mathrm{CG}$ pf = CG-Fläche Kallus plattenfern; AK pf = AK-Fläche Kallus plattenfern;

TC pf $=$ TC-Fläche Kallus plattenfern; ${ }^{*}=(p<0,05$ vs. $\mathrm{C}) ; \#=(\mathrm{p}<0,05$ vs. E2 $)$

Tabelle 19: Ergebnisse der Polychromen Sequenzmarkierung (endostaler Kallus)

\begin{tabular}{ccccc}
\hline & Gesamt en $\left[\mathrm{mm}^{2}\right]$ & CG en $\left[\mathrm{mm}^{2}\right]$ & AK en $\left[\mathrm{mm}^{2}\right]$ & TC en $\left[\mathrm{mm}^{2}\right]$ \\
\hline \hline C & $1,78 \pm 0,74$ & $0,26 \pm 0,13$ & $0,42 \pm 0,22$ & $0,73 \pm 0,38$ \\
E2 & $2,02 \pm 0,75$ & $0,45 \pm 0,23$ & $0,37 \pm 0,20$ & $0,50 \pm 0,23$ \\
R & $2,08 \pm 0,66$ & $0,49 \pm 0,21$ & $0,44 \pm 0,24$ & $0,53 \pm 0,18$ \\
CR & $1,57 \pm 0,64$ & $0,27 \pm 0,11$ & $0,39 \pm 0,24$ & $0,50 \pm 0,21$ \\
EQ & $1,78 \pm 0,42$ & $0,33 \pm 0,16$ & $0,50 \pm 0,22$ & $0,51 \pm 0,23$ \\
GEN & $1,66 \pm 0,81$ & $0,27 \pm 0,13$ & $0,31 \pm 0,22$ & $0,47 \pm 0,35$ \\
PTH & $2,98 \pm 0,60^{*} \#$ & $0,75 \pm 0,34^{*} \#$ & $0,98 \pm 0,36^{*} \#$ & $0,95 \pm 0,41 \#$ \\
\hline
\end{tabular}

Angabe als Mittelwert \pm Standardabweichung; Gesamt en = Gesamtfläche Kallus endostal;

CG en $=$ CG-Fläche Kallus endostal; AK en = AK-Fläche Kallus endostal;

TC en $=$ TC-Fläche Kallus endostal; * $=(p<0,05$ vs. $C) ; \#=(p<0,05$ vs. E2)

Tabelle 20: Ergebnisse der Polychromen Sequenzmarkierung (Additivkallus)

\begin{tabular}{cc}
\hline & Additivkallus $\left[\mathrm{mm}^{2}\right]$ \\
\hline \hline $\mathrm{C}$ & $3,87 \pm 1,02$ \\
$\mathrm{E} 2$ & $3,68 \pm 1,02$ \\
$\mathrm{R}$ & $3,90 \pm 0,42$ \\
$\mathrm{CR}$ & $3,14 \pm 1,01$ \\
$\mathrm{EQ}$ & $3,91 \pm 0,30$ \\
$\mathrm{GEN}$ & $3,55 \pm 0,60$ \\
$\mathrm{PTH}$ & $6,06 \pm 0,61^{*} \#$ \\
\hline
\end{tabular}

Angabe als Mittelwert \pm Standardabweichung;

$*=(\mathrm{p}<0,05$ vs. $\mathrm{C}) ; \#=(\mathrm{p}<0,05$ vs. $\mathrm{E} 2)$ 


\subsection{Zusammenfassung der Ergebnisse}

In der nachstehenden Tab. 21 sind die Ergebnisse aus 3.3, 3.4 und 3.5 vereinfacht zusammengefasst. Dabei werden nur die signifikanten Unterschiede der einzelnen Testgruppen zur Kontrollgruppe C aufgeführt.

Tabelle 21: Zusammenfassung der Ergebnisse

\begin{tabular}{|c|c|c|c|c|c|c|}
\hline Messparameter & E2 & $\mathbf{R}$ & CR & EQ & GEN & PTH \\
\hline Elastizität & $\leftrightarrow$ & $\leftrightarrow$ & $\leftrightarrow$ & $\leftrightarrow$ & $\leftrightarrow$ & $\Uparrow$ \\
\hline Elastizität in Bezug auf das KG & $\leftrightarrow$ & $\leftrightarrow$ & $\leftrightarrow$ & $\leftrightarrow$ & $\leftrightarrow$ & $\Uparrow$ \\
\hline Streckgrenze & $\leftrightarrow$ & $\leftrightarrow$ & $\leftrightarrow$ & $\leftrightarrow$ & $\leftrightarrow$ & $\Uparrow$ \\
\hline Streckgrenze in Bezug auf das KG & $\leftrightarrow$ & $\Uparrow$ & $\leftrightarrow$ & $\Uparrow$ & $\leftrightarrow$ & $\Uparrow$ \\
\hline Kortikalisdicke distal plattennah & $\leftrightarrow$ & 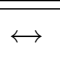 & 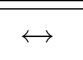 & $\leftrightarrow$ & $\leftrightarrow$ & 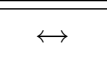 \\
\hline Kortikalisdicke distal plattenfern & $\leftrightarrow$ & $\leftrightarrow$ & $\leftrightarrow$ & $\leftrightarrow$ & $\leftrightarrow$ & $\leftrightarrow$ \\
\hline Knochendurchmesser proximal & $\leftrightarrow$ & $\leftrightarrow$ & $\leftrightarrow$ & $\leftrightarrow$ & $\leftrightarrow$ & $\leftrightarrow$ \\
\hline Knochendurchmesser distal & $\leftrightarrow$ & $\leftrightarrow$ & $\leftrightarrow$ & $\leftrightarrow$ & $\leftrightarrow$ & $\leftrightarrow$ \\
\hline Kallusdicke plattennah & $\leftrightarrow$ & $\leftrightarrow$ & $\leftrightarrow$ & $\leftrightarrow$ & $\leftrightarrow$ & $\leftrightarrow$ \\
\hline Kallusdicke plattenfern & $\leftrightarrow$ & $\leftrightarrow$ & $\leftrightarrow$ & $\leftrightarrow$ & $\leftrightarrow$ & $\leftrightarrow$ \\
\hline Knochenflächendichte Kortikalis distal plattennah & $\leftrightarrow$ & $\leftrightarrow$ & $\leftrightarrow$ & $\leftrightarrow$ & $\leftrightarrow$ & $\Uparrow$ \\
\hline Knochenflächendichte Kortikalis distal plattenfern & $\leftrightarrow$ & $\leftrightarrow$ & $\leftrightarrow$ & $\leftrightarrow$ & $\leftrightarrow$ & $\Uparrow$ \\
\hline Knochenflächendichte Kallus plattennah & $\leftrightarrow$ & $\leftrightarrow$ & $\leftrightarrow$ & $\leftrightarrow$ & $\leftrightarrow$ & $\Uparrow$ \\
\hline Knochenflächendichte Kallus plattenfern & $\leftrightarrow$ & $\leftrightarrow$ & $\leftrightarrow$ & $\leftrightarrow$ & $\Downarrow$ & $\leftrightarrow$ \\
\hline Knochenflächendichte Kallus endostal & $\leftrightarrow$ & $\leftrightarrow$ & $\leftrightarrow$ & $\leftrightarrow$ & $\leftrightarrow$ & $\Uparrow$ \\
\hline Knochenflächendichte Trabekel distal & $\leftrightarrow$ & $\leftrightarrow$ & $\leftrightarrow$ & $\leftrightarrow$ & $\leftrightarrow$ & n.a. \\
\hline Anzahl Trabekelkreuzungen absolut & $\leftrightarrow$ & $\leftrightarrow$ & $\leftrightarrow$ & $\leftrightarrow$ & $\leftrightarrow$ & n.a. \\
\hline Dichte Trabekelkreuzungen & $\leftrightarrow$ & $\leftrightarrow$ & $\leftrightarrow$ & $\leftrightarrow$ & $\leftrightarrow$ & n.a. \\
\hline Mittlere Trabekeldicke & $\leftrightarrow$ & $\leftrightarrow$ & $\leftrightarrow$ & $\leftrightarrow$ & $\leftrightarrow$ & n.a. \\
\hline Gesamtfläche Kallus plattennah & $\leftrightarrow$ & 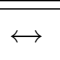 & $\leftrightarrow$ & $\leftrightarrow$ & $\leftrightarrow$ & 个 \\
\hline CG-Fläche Kallus plattennah & $\leftrightarrow$ & $\leftrightarrow$ & $\leftrightarrow$ & $\leftrightarrow$ & $\leftrightarrow$ & $\leftrightarrow$ \\
\hline AK-Fläche Kallus plattennah & $\leftrightarrow$ & $\leftrightarrow$ & $\leftrightarrow$ & $\leftrightarrow$ & $\leftrightarrow$ & $\Uparrow$ \\
\hline TC-Fläche Kallus plattennah & $\leftrightarrow$ & $\leftrightarrow$ & $\leftrightarrow$ & $\leftrightarrow$ & $\leftrightarrow$ & $\leftrightarrow$ \\
\hline Gesamtfläche Kallus plattenfern & $\leftrightarrow$ & $\leftrightarrow$ & $\leftrightarrow$ & $\leftrightarrow$ & $\leftrightarrow$ & $\Uparrow$ \\
\hline CG-Fläche Kallus plattenfern & $\leftrightarrow$ & $\leftrightarrow$ & $\leftrightarrow$ & $\leftrightarrow$ & $\leftrightarrow$ & $\leftrightarrow$ \\
\hline AK-Fläche Kallus plattenfern & $\leftrightarrow$ & $\leftrightarrow$ & $\leftrightarrow$ & $\leftrightarrow$ & $\leftrightarrow$ & $\Uparrow$ \\
\hline TC-Fläche Kallus plattenfern & $\leftrightarrow$ & $\leftrightarrow$ & $\leftrightarrow$ & $\leftrightarrow$ & $\leftrightarrow$ & $\Uparrow$ \\
\hline Gesamtfläche Kallus endostal & $\leftrightarrow$ & $\leftrightarrow$ & $\leftrightarrow$ & $\leftrightarrow$ & $\leftrightarrow$ & $\Uparrow$ \\
\hline CG-Fläche Kallus endostal & $\leftrightarrow$ & $\leftrightarrow$ & $\leftrightarrow$ & $\leftrightarrow$ & $\leftrightarrow$ & $\Uparrow$ \\
\hline AK-Fläche Kallus endostal & $\leftrightarrow$ & $\leftrightarrow$ & $\leftrightarrow$ & $\leftrightarrow$ & $\leftrightarrow$ & $\Uparrow$ \\
\hline TC-Fläche Kallus endostal & $\leftrightarrow$ & $\leftrightarrow$ & $\leftrightarrow$ & $\leftrightarrow$ & $\leftrightarrow$ & $\leftrightarrow$ \\
\hline Additivkallus & $\leftrightarrow$ & $\leftrightarrow$ & $\leftrightarrow$ & $\leftrightarrow$ & $\leftrightarrow$ & $\Uparrow$ \\
\hline
\end{tabular}

$\leftrightarrow=$ kein signifikanter Unterschied zur Kontrollgruppe $(\mathrm{C})$; $\Uparrow=$ signifikant höherer Wert als $\mathrm{C}(\mathrm{p}<0,05)$;

$\Downarrow=$ signifikant niedrigerer Wert als $\mathrm{C}(\mathrm{p}<0,05) ; \mathrm{KG}=$ Körpergewicht; n.a. $=$ nicht angegeben 


\section{Diskussion}

Die Therapie osteoporotischer Frakturen stellt ein bislang ungelöstes Problem dar. Durch die veränderte Knochenstruktur lassen sich Implantate nur schwer fixieren. Außerdem ist der Heilungsprozess verlangsamt und qualitativ beeinträchtigt [Lill et al. 2002 a, b; Namkung-Matthai et al. 2001; Wang et al. 2005 a]. Häufige Komplikationen sind Implantatversagen, verzögerte Frakturheilung und die Ausbildung von Pseudarthrosen mit entsprechenden Konsequenzen für die betroffenen Patienten. Als Folge der zu erwartenden demographischen Entwicklung wird dieses Problem innerhalb der nächsten 10 - 20 Jahre exponentiell wachsen und mit ihm die Kosten für das Gesundheitssystem [Weinstein 2009]. Um eine Verbesserung der Therapie osteoporotischer Frakturen zu erreichen, gibt es im Wesentlichen zwei Herangehensweisen. Zum einen die Entwicklung spezieller Implantate, zum anderen die medikamentöse Verbesserung der Knochenqualität, um die schnelle Ausbildung eines suffizienten Kallus zu erreichen und auf biologischem Wege die Implantatfixierung zu fördern. Letztere Option stand im Zentrum der vorliegenden Arbeit. Hierbei wurden die Auswirkungen verschiedener potentiell antiosteoporotischer Substanzen (E2, R, CR, EQ, GEN, PTH) auf die metaphysäre Frakturheilung der osteoporotisch veränderten Rattentibia untersucht.

\subsection{Metaphysäres Frakturmodell}

Der Knochenabbau unter Osteoporose und die daraus folgende erhöhte Frakturgefahr betreffen vorrangig den metaphysären Knochen, beim Menschen insbesondere im Bereich der Hüfte, des proximalen Humerus und des distalen Radius. Trotz dieser Tatsache wurden experimentelle Untersuchungen zur Frakturheilung unter Osteoporose fast ausnahmslos an diaphysären Frakturmodellen (Tibia [Melhus et al. 2007; Nakajima et al. 2002; Xu et al. 2004] und Femur [Cao et al. 2002; Kubo et al. 1999; Xu et al. 2003]) durchgeführt. Hierbei gilt zu beachten, dass sich dieses Frakturmodell in zwei wesentlichen Punkten von einem metaphysären Modell unterscheidet. Zum einen hinsichtlich des prinzipiellen Mechanismus der Frakturheilung. So heilt diaphysärer Knochen indirekt mit ausgeprägter periostaler Kallusbildung. Nur unter absolut stabilen Verhältnissen kommt es zur direkten Frakturheilung mit lamellärem Knochen (vgl. 1.2.2.2, S. 7). Metaphysäre Frakturen heilen dahingegen gewöhnlicherweise direkt durch endostale Frakturspaltüberbrückung, ohne signifikante periostale Kallusbildung. Ein zweiter wichtiger Unterschied ist, dass der metaphysäre Knochen von Osteoporose in erheblichem Maße mehr beeinträchtigt wird als diaphysärer Knochen. So zeigt sich in der proximalen Tibiametaphyse von Ratten drei Monate nach Ovarektomie ein Knochenmasseverlust von ca. $50 \%$, der vorrangig auf einem Abbau trabekulärer Strukturen beruht. Die Verluste im diaphysären Bereich sind 
niedriger. Hier finden sich keine Trabekel [Iwaniec et al. 2007; Seidlová-Wuttke et al. 2003; Wronski et al. 1985].

Aus den genannten Gründen wurde für die vorliegende Arbeit ein von Stürmer et al. [2008] an Ratten entwickeltes metaphysäres Frakturmodell gewählt. Bei diesem wird die Osteotomie im Bereich der proximalen Tibiametaphyse gesetzt und mit einer 5-LochLeibinger-Platte osteosynthetisch stabil versorgt. Durch das Bohren der Schraubenkanäle vor Durchtrennung des Knochens entsteht ein standardisierter, 0,5 mm breiter Osteotomiespalt zwischen den Tibiafragmenten (vgl. 2.4. S. 33), in dem später die substanzspezifische endostale Kallusbildung gut morphometrisch ausgewertet werden kann. Der relativ kleine Osteotomiespalt führt zu einem verbesserten Heilungsprozess, wohingegen größere Abstände (>2 mm) die Frakturheilung beeinträchtigen würden [Claes et al. 1997].

Die gewählte Plattenosteosynthese und der Frakturspalt erlauben Mikrobewegungen zwischen den Tibiafragmenten, die zu einer Stimulation der periostalen Kallusbildung führen. So kommt es im vorliegenden metaphysären Frakturmodell bei regelrechtem Heilungsverlauf zu einer endostalen Frakturüberbrückung mit zusätzlicher Ausbildung eines kleinen periostalen Kallus an der der Platte gegenüberliegenden Seite.

Wie bereits von Stürmer et al. [2008] beschrieben, ist die intakte Fibula essentiell wichtig für die Stabilität der Osteosynthese. Eine akzessorische, intravitale Fibulafraktur führt zu einer primär hohen Instabilität mit gesteigerter interfragmentärer Beweglichkeit. Diese hat wiederum starken Einfluss auf die Kallusbildung. Im Falle einer solchen Instabilität kann davon ausgegangen werden, dass diese biomechanische Komponente die Frakturheilung in wesentlichem Maße beeinflusst und den Effekt der untersuchten antiosteoporotischen Substanzen überlagert. Eine klare Abgrenzung zwischen biomechanischer und substanzspezifischer Wirkung kann bei zusätzlicher Fibulafraktur somit nicht erfolgen. Aus diesem Grund mussten in der vorliegenden Arbeit einige Tibiae ausgeschlossen werden, obwohl bei diesen eine knöcherne Heilung eingetreten war.

\subsection{Analyse der Ergebnisse}

\subsubsection{Estradiol}

Estradiol, das im Rahmen der HRT viele Jahre zur Behandlung der postmenopausalen Osteoporose verwendet wurde, aufgrund seines ungünstigen Risikoprofils heute aber nur noch unter strenger Indikationsstellung eingesetzt wird, diente in der vorliegenden Arbeit als positive Kontrollsubstanz. Für diese ist belegt, dass sie osteoanabole Effekte zeigt und die Frakturheilung fördert [Kolios et al. 2009; Ouyang et al. 2004; Rossouw et al. 2002; Spelsberg et al. 1999; Stürmer et al. 2008; Tian et al. 2006].

Der Prozess der Frakturheilung ist bei osteoporotischem Knochen verlangsamt [Lill et al. 2002 a, b]. Analog dazu zeigte sich in der Kontrollgruppe C der vorliegenden Arbeit über 
den gesamten Untersuchungszeitraum von 35 Tagen eine kontinuierliche Zunahme der periostalen Kallusbildung. Dies ist so zu interpretieren, dass sich der Kallus am Ende des Beobachtungszeitraums in der osteoporotischen Kontrollgruppe noch in der Aufbauphase befand. Die Frakturheilung war somit bei weitem noch nicht abgeschlossen. Erwartungsgemäß führte E2 gegenüber der Kontrollgruppe zu einer Beschleunigung des Heilungsprozesses [Ouyang et al. 2004, Tian et al. 2006]. So war unter Estradioleinfluss im TC-markierten Zeitraum (Tag 27 bis 35) kein weiterer Anstieg der periostalen Kallusbildung festzustellen. Dies spricht für ein bereits fortgeschrittenes Stadium der Frakturheilung.

In der histomorphometrischen Untersuchung fanden sich keine signifikanten Unterschiede zur Kontrollgruppe, dennoch waren Tendenzen unter Estradioleinfluss zu erkennen. E2 hat den Heilungsprozess hauptsächlich durch Förderung der primären, endostalen Frakturüberbrückung positiv beeinflusst, wie sie typisch für die metaphysäre Frakturheilung ist. Diese Stabilisierung im Inneren des Knochens machte eine zusätzliche Stabilisierung durch periostalen Kallus weniger bedeutsam. Folglich fiel die periostale Kallusbildung gering aus. Die Knochenflächendichte des Kallus erreichte in der vorliegenden Arbeit niedrigere Werte als von Stürmer et al. [2008] beschrieben. So zeigte E2 anders als erwartet keine Verbesserung der Knochenflächendichte des Kallus gegenüber der Kontrollgruppe. Insbesondere endostal wurden deutlich niedrigere Werte festgestellt. Die angrenzende metaphysäre Kortikalis blieb hinsichtlich des Durchmessers und der Knochenflächendichte von E2 weitgehend unbeeinflusst. Hier ergaben sich ähnliche Ergebnisse wie in der Kontrollgruppe. Als mögliche Ursachen kommen unter anderem der verlangsamte Remodelingprozess (vgl. 1.2.1.4 S. 5 oder eine geringere Dichte von Östrogenrezeptoren in kortikalem Knochen in Frage. Außerdem ist zu berücksichtigen, dass bei dem verwendeten Frakturmodell der vergleichsweise geringe metaphysäre kortikale Knochen, nicht die dicke und knochendichte diaphysäre Kortikalis analysiert wurde.

E2 hat erwartungsgemäß zu einer deutlichen, wenn auch nicht signifikanten Verbesserung der trabekulären Strukturen im metaphysären Knochen geführt. Dies zeigte sich in einer höheren Knochenflächendichte der distalen Trabekel, einer Zunahme der Trabekelkreuzungen und einer gesteigerten Trabekeldicke. Veränderungen des trabekulären Knochens dieser Art sind bereits in verschiedenen Arbeiten beschrieben [Bain et al. 1993; Stürmer et al. 2009; Stürmer et al. 2008; Stürmer et al. 2006]. Im Rahmen der chirurgischen Therapie osteoporotischer Frakturen kommt diesen Veränderungen eine besondere Bedeutung zu, da sie mit einer Kräftigung des Knochens einhergehen und somit einen verbesserten Halt von Implantaten ermöglichen.

Im biomechanischen Versuch erzielte E2 eine höhere Elastizität und Streckgrenze als die Kontrollgruppe, auch in Bezug auf das Körpergewicht. Ein signifikanter Unterschied konnte jedoch aufgrund der hohen Standardabweichung auch hier für keinen der Parameter ermittelt werden. 
Zusammenfassend ist festzuhalten, dass die E2-Kurzzeittherapie über fünf Wochen tendenziell den metaphysären Frakturheilungsprozess bei schwerer Osteoporose beschleunigt, zur Ausbildung eines kleinen, stabilen Kallus führt und den trabekulären Knochen außerhalb der Frakturregion qualitativ und quantitativ verbessert. Signifikante Unterschiede zur Kontrollgruppe konnten in der vorliegenden Arbeit jedoch nicht nachgewiesen werden.

\subsubsection{Raloxifen}

Raloxifen, eine Substanz aus der Gruppe der selektiven Östrogen-Rezeptor-Modulatoren, wird bereits seit Jahren von der DVO-Leitlinie zur Therapie der postmenopausalen Osteoporose mit höchster Evidenzklasse empfohlen. Durch verschiedene Untersuchungen und Studien konnte die antiosteoporotische Wirkung dieser Substanz belegt werden [Ettinger et al. 1999; Stürmer et al. 2006; Stürmer et al. 2009]. In Versuchen zur Auswirkung einer Raloxifentherapie auf die Frakturheilung liegen bislang nur wenige Ergebnisse vor, die allerdings auf eine positive Beeinflussung des Heilungsverlaufs hindeuten [Cao et al. 2002; Stürmer et al. 2008].

In der vorliegenden Arbeit wurde unter Raloxifentherapie in allen Parametern des biomechanischen Tests bessere Ergebnisse als in der Kontrollgruppe erreicht. Hinsichtlich der „Streckgrenze in Bezug auf das Körpergewicht“ ergab sich sogar ein signifikanter Unterschied. Dies besagt, dass nach Raloxifentherapie eine signifikant höhere Kraft nötig war als in der Kontrollgruppe, um eine irreversible plastische Deformierung des Kallus zu bewirken. Gegenüber E2 erreichte $\mathrm{R}$ im biomechanischen Test geringfügig bessere Werte. Somit hat $\mathrm{R}$ in der vorliegenden Arbeit besser abgeschnitten als in einer vorausgehenden Untersuchung dieser Arbeitsgruppe, bei der R während der Osteoporoseentwicklung gegeben wurde [Stürmer et al. 2008]. In diesen ließ sich kein signifikanter Unterschied zur Kontrollgruppe ausmachen. Zudem lagen die Ergebnisse bezüglich der Streckgrenze niedriger als unter Estradioleinfluss.

Die histomorphometrische Untersuchung zeigte eine relativ große Kallusgesamtfläche. Hierbei fiel eine ausgeprägte endostale Kallusbildung bei geringer periostaler Kallusdicke auf, wie sie bereits für die Estradiolgruppe typisch war. Erwartungsgemäß erreichte R eine höhere Knochenflächendichte im plattennahen, plattenfernen und endostalen Kallus als E2 und die Kontrollgruppe [Stürmer et al. 2008]. Gegenüber E2 fiel dieser Unterschied recht deutlich aus. Signifikante Unterschiede ließen sich zwischen diesen Testgruppen allerdings nicht feststellen. Hinsichtlich der Parameter „Knochenflächendichte Trabekel distal“, „Anzahl der Trabekelkreuzungen absolut" und „Dichte Trabekelkreuzungen“ erreichte R die besten Ergebnisse im Versuch, ohne dabei aufgrund der hohen Standardabweichung einen signifikanten Unterschied zu E2 oder der Kontrollgruppe zu zeigen. Die mittlere Trabekeldicke und die metaphysäre Kortikalis blieben weitgehend unbeeinflusst. 
$\mathrm{R}$ hat zu einer Beschleunigung des Heilungsverlaufs geführt. So zeigte sich im letzten Markierungszeitraum der Fluoreszenz-mikroskopischen Untersuchung kein weiterer Anstieg der periostalen Kallusbildung, wie er charakteristisch für den verzögerten Heilungsprozess der Kontrollgruppe war.

Zusammenfassend ist festzustellen, dass die Kurzzeittherapie mit $\mathrm{R}$ die Frakturheilung des schwer osteoporotischen Knochen beschleunigt, die Kallusqualität verbessert und den trabekulären Knochen stärkt. Insbesondere die mechanische Belastbarkeit des Kallus unter Berücksichtigung des Körpergewichts konnte durch die Therapie signifikant verbessert werden. $\mathrm{R}$ zeigte bezüglich des Heilungsverlaufs diverse Parallelen zur Muttersubstanz E2 und erreichte im vorliegenden Versuch hinsichtlich fast aller Parameter gering bessere Ergebnisse als diese. Signifikante Unterschiede zwischen beiden Substanzen ließen sich allerdings nicht feststellen. Unter Berücksichtigung der gering verbesserten Heilungstendenzen und des günstigeren Nebenwirkungsprofils (thromboembolische Komplikationenen; Mammakarzinomrate) ist in weiterführenden Untersuchungen zur Frakturheilung unter Osteoporose R gegenüber E2 zu bevorzugen.

Die Ergebnisse sind derzeit zur Publikation in der Zeitschrift "Journal of Orthopaedic Trauma" eingereicht.

\subsubsection{Cimicifuga racemosa}

Der Cimicifuga-racemosa-Extrakt BNO 1055 hat bereits in verschiedenen Untersuchungen an Ratten gezeigt, dass es den Knochenmasseverlust nach Ovarektomie reduzieren kann, ohne hierbei uterotrope Effekte zu zeigen [Seidlova-Wuttke et al. 2003 a; Wuttke et al. 2003]. In einer doppelt verblindeten, placebokontrollierten klinischen Studie an 62 postmenopausalen Frauen von Wuttke et al. [2006] wurde laborchemisch eine Steigerung der Osteoblastenaktivität mit konsekutiver Steigerung des Knochenremodelings nachgewiesen. Die Wirkung wird nicht über den Östrogenrezeptor, sondern über eine bislang unbekannte Bindungsstelle vermittelt [Jarry et al. 2003]. Daten zur Frakturheilung liegen bislang nicht vor.

Im vorliegenden Versuch konnte die biomechanische Qualität der Frakturüberbrückung durch die Kurzzeitapplikation von CR anders als bei früher Osteoporose nicht verbessert werden. Im Vergleich zur Kontrollgruppe wurden nur geringfügig höhere Werte bei schwerer Osteoporose ermittelt.

CR erreichte in der histomorphometrischen Auswertung die geringste Additivkallusfläche aller Testgruppen. Die plattennahe und plattenferne Kallusdicke zeigte ähnlich niedrige Werte wie unter Estradioltherapie. Plattennaher, plattenferner und endostaler Kallus wiesen hinsichtlich ihrer Knochenflächendichte keinen bedeutsamen Unterschied zur Kontrollgruppe auf. Auch der trabekuläre Knochen und die angrenzende metaphysäre Kortikalis blieben weitestgehend unbeeinflusst. Es zeigte sich kein anaboler Effekt. 
CR zeigte im letzen Markierungszeitraum der polychromen Sequenzmarkierung eine weitere Zunahme der periostalen Kallusbildung. Dies deutet darauf hin, dass CR keine Beschleunigung des Heilungsprozesses gegenüber der Kontrollgruppe bewirken konnte, sondern eher zu einer Verzögerung desselben geführt hat.

Zusammenfassend hat die Kurzzeitapplikation von CR in keiner Hinsicht eine Verbesserung der Frakturheilung des manifest osteoporotischen Knochens bewirkt. Bemerkenswert ist allerdings die Tatsache, dass trotz der relativ kleinen Kallusfläche, die etwa $12 \%$ kleiner als die der Kontrollgruppe ist, eine gleiche biomechanische Qualität wie in der Kontrollgruppe erreicht wurde. Abgesehen von der relativ geringen Kallusfläche und Kallusdicke liegen alle ermittelten Parameter im Bereich der Kontrollgruppe. Als Grund für die geringe Wirksamkeit kommt eine im Vergleich zu Versuchen anderer Forschungsgruppen relativ kurze Therapiedauer in Frage. CR scheint sein Wirkpotenzial erst nach 6 - 8 Wochen vollständig zu entwickeln. Aus den Daten dieser Arbeit ergibt sich somit kein Hinweis darauf, dass die therapeutische Kurzzeitapplikation von CR nach einer osteoporotischen Fraktur den Heilungsprozess positiv beeinflussen kann.

Die Ergebnisse sind derzeit zur Publikation in der Zeitschrift "Phytotherapy Research" eingereicht.

\subsubsection{Equol}

In verschiedenen vorausgehenden Untersuchungen konnte gezeigt werden, dass Equol, der aktive Metabolit des Daidzeins, einen protektiven Effekt auf osteoporotischen Knochen zeigt [Fujioka et al. 2004; Mathey et al. 2007; Tezval et. al 2009 a]. Als Wirkmechanismus wird eine Hemmung der Osteoklastenformation angenommen [Ohtomo et al. 2008]. Daten zur Frakturheilung liegen derzeit nicht vor.

EQ hat in der vorliegenden Arbeit zu einer Verbesserung der biomechanischen Eigenschaften des Frakturkallus geführt. In allen Messparametern erreichte EQ gegenüber der Kontrollgruppe bessere Ergebnisse. Diese liegen in etwa auf dem Level der Raloxifentherapie. Hinsichtlich der Streckgrenze in Bezug auf das Körpergewicht ergab sich sogar ein signifikanter Unterschied zur Kontrollgruppe. EQ erreichte die besten Werte aller getesteter Phytoextrakte.

Die Ergebnisse des biomechanischen Tests wurden in der histomorphometrischen Untersuchung weitestgehend bestätigt. Unter EQ weist der Kallus in allen drei Anteilen eine höhere Knochenflächendichte als die Kontroll- und die Estradiolgruppe auf. Signifikante Unterschiede konnten aufgrund der hohen Standardabweichung allerdings nicht ermittelt werden. Die ausgeprägte plattennahe und plattenferne Kallusbildung spricht dafür, dass EQ im Gegensatz zu E2 insbesondere die periostale Frakturheilung gefördert hat. Im trabekulären Knochen erreichte EQ ähnliche Ergebnisse wie die Kontrollgruppe C und erzielte damit auch hier die besten Ergebnisse unter den Phytoextrakten. Die metaphysäre 
Kortikalis blieb weitestgehend unbeeinflusst. So ergaben sich hinsichtlich der Knochenflächendichte und Kortikalisdicke keine bedeutsamen Unterschiede zur Kontrollgruppe.

In der Fluoreszenz-mikroskopischen Untersuchung zeigte sich im letzten Markierungszeitraum eine weitere Zunahme der periostalen Kallusbildung. Dies deutet darauf hin, dass die Frakturheilung am 35. Heilungstag noch nicht abgeschlossen war. Der Additivkallus ist deutlich größer als unter Estradioleinfluss und erreicht einen Wert, der nur geringfügig über dem der Kontrollgruppe liegt.

Zusammenfassend ist festzuhalten, dass die Kurzzeitapplikation von EQ den Heilungsprozess positiv beeinflusst hat. Insbesondere im biomechanischen Test wurde ein signifikant besseres Ergebnis als in der Kontrollgruppe erreicht. EQ erzielte die besten Ergebnisse der getesteten Phytoextrakte. Als Ursache hierfür ist die relativ hohe Affinität dieser Substanz zum Östrogenrezeptor anzunehmen [Picherit et al. 2000; Morito et al. 2001]. Im Vergleich zu E2 wurde unter Equoltherapie mehr Kallusvolumen benötigt, um eine ähnliche biomechanische Qualität der Frakturüberbrückung zu erreichen. Hieran ist zu sehen, dass ein höheres Kallusvolumen nicht zwangsläufig mit einer besseren Kallusstabilität einhergeht. Der Heilungsprozess unter Equoltherapie verlief somit im Verhältnis zu E2 weniger effektiv und wurde im Gegensatz zu E2 voranging über periostale Kallusbildung erreicht. Hinsichtlich der systemischen Effekte beider Testsubstanzen scheint EQ überlegen zu sein. So werden Uterus, die Brustdrüse und das Körpergewicht durch EQ deutlich geringer beeinflusst als durch E2 [Rachon et al. 2008, 2007 b]. Das hier beschriebene Wirkprofil von EQ lässt vermuten, dass sich eine entsprechende Therapie auch beim Menschen positiv auf die Heilung osteoporotischer Frakturen auswirkt, und legt somit die Empfehlung nahe, weiterführende Untersuchungen $\mathrm{zu}$ veranlassen.

Die Ergebnisse sind in der Zeitschrift "Planta Medica" publiziert [Kolios et al. 2009].

\subsubsection{Genistein}

In verschiedenen Untersuchungen an Tieren und Menschen zur Therapie der postmenopausalen Osteoporose konnte Genistein ein osteoprotektiver Effekt nachgewiesen werden [Mathey et al. 2007; Marini et al. 2007; Morabito et al. 2002; Picherit et al. 2000; Sehmisch et al. 2008]. GEN wirkt durch Stimulation der Knochenneubildung und gleichzeitige Hemmung der Osteoblasten-vermittelten Knochenresorption [Li und Yu 2003]. Daten zur Frakturheilung liegen derzeit nicht vor.

Im biomechanischen Test der vorliegenden Arbeit erreichte die Kurzzeitapplikation von GEN keine Verbesserung der Kallusqualität. So wurden im Vergleich zur Kontrollgruppe nur geringfügig höhere Werte erzielt.

Die histomorphometrische Untersuchung zeigte bezüglich der Kallusgröße und -dicke keine größeren Abweichungen von der osteoporotischen Kontrollgruppe. Deutliche Unterschiede ergaben sich hinsichtlich der Knochenflächendichte des Kallus. Hier erreichte GEN platten- 
nah, plattenfern und endostal geringere Werte. Insbesondere im plattenfernen Kallus war die Knochenflächendichte signifikant niedriger als in der osteoporotischen Kontrollgruppe. GEN hat im trabekulären Knochen unerwartet zu einem vermehrten Abbau von Knochensubstanz geführt und erreichte hier die niedrigsten Werte im Versuch. Diese liegen deutlich unter denen der Kontrollgruppe. Hinsichtlich der trabekulären Knochenflächendichte und Anzahl der Trabekelkreuzungen zeigte sich ein signifikanter Unterschied zu R. Bezüglich der mittleren Trabekeldicke wurden signifikant niedrigere Ergebnisse als unter E2 und EQ erreicht. Die metaphysäre Kortikalis blieb von GEN weitgehend unbeeinflusst.

In der Fluoreszenz-mikroskopischen Untersuchung zeigte sich auch im letzten Markierungszeitraum eine weitere Zunahme der periostalen Kallusbildung. Dies ist sicherlich im Wesentlichen durch die Osteoklastenhemmung bedingt. Es deutet darauf hin, dass die Frakturheilung gegenüber der Kontrollgruppe nicht wesentlich beschleunigt werden konnte.

Zusammenfassend ist festzuhalten, dass die Genisteinkurzzeittherapie in der vorliegenden Arbeit einen inhibierenden Effekt auf die Frakturheilung zeigte [Kolios et al. 2009]. Der Heilungsprozess verlief zeitlich verzögert. Ein effektives Remodeling fehlte. Der Kallus und das angrenzende metaphysäre Trabekelwerk wiesen gegenüber den anderen Testgruppen qualitative und quantitative Defizite auf. Es ist anzunehmen, dass der von Gao und Yamaguchi [2000] beschriebene osteoklastenhemmende Effekt Grund für das schlechte Abschneiden von GEN ist. Dieser hat vermutlich den Remodelingprozess im Rahmen der Frakturheilung, dessen wichtiger Bestandteil die osteoklastenvermittelte Knochenresorption ist, gestört. Dieser Effekt ist auch für andere Osteoklasteninhibitoren, wie beispielsweise Bisphosphonate, beschrieben [Cao et al. 2002]. Ob sich Osteoklasteninhibitoren generell durch Hemmung des Remodelings negativ auf die frühe Phase der Frakturheilung auswirken oder der Nutzen des verminderten Knochenabbaus überwiegt, ist derzeit noch unklar. Die Ergebnisse von Sehmisch et al. [2008] und Picherit et al. [2000] an intakten Knochen, nach denen GEN einen osteoprotektiven Effekt aufweist, scheinen hier im Widerspruch zu dem im vorliegenden Versuch beobachteten Abbau trabekulären Knochens zu stehen. Dabei ist jedoch zu berücksichtigen, dass GEN in diesen Untersuchungen über einen längeren Zeitraum von drei Monaten verabreicht wurde. Zudem unterscheidet sich der Knochenmetabolismus unter Frakturheilung wesentlich von dem des intakten Knochens.

Nach den vorliegenden Ergebnissen ist somit die Kurzzeitapplikation von GEN nicht zur therapeutischen Unterstützung der Frakturheilung unter Osteoporose zu empfehlen.

Die Ergebnisse sind in der Zeitschrift "Planta Medica" publiziert [Kolios et al. 2009].

\subsubsection{Parathormon}

Aus Untersuchungen ist bekannt, dass die pulsatile Applikation von Parathormon einen osteoanabolen Effekt bei Tieren und Menschen zeigt. Sowohl die Mikroarchitektur und 
Knochenmineraldichte des intakten Knochengewebes als auch die Frakturheilung werden deutlich positiv beeinflusst [Alkhiary et al. 2005; Andreassen et al. 2001; Dempster et al. 2001; Greenspan et al. 2007; Jiang et al. 2003; Kim und Jahng 1999; Neer et al. 2001; Zhang et al. 2002]. Derzeit findet PTH bereits Einsatz zur Therapie der postmenopausalen Osteoporose mit hohem bis sehr hohem Frakturrisiko.

In der vorliegenden Arbeit konnte deutlich gezeigt werden, dass PTH über den gesamten Beobachtungszeitraum von fünf Wochen die metaphysäre Frakturheilung fördert. Hinsichtlich fast aller untersuchter Parameter erreichte PTH mit Abstand die besten Ergebnisse, die sich zu einem überwiegenden Anteil signifikant von den Vergleichsgruppen unterschieden.

Besonders bemerkenswert ist der osteoanabole Effekt, den PTH auf die osteotomierte Tibiametaphyse zeigte. Durch diesen kam es zu einer enormen Zunahme der Kallusfläche, der Kallusdichte und der Trabekeldicke. Das hat dazu geführt hat, dass eine Differenzierung zwischen neugebildetem knöchernem Kallus und neugebildeten metaphysären Trabekeln durch die computerassistierte histomorphometrische Flächendetektion nicht mehr möglich war.

Im Gegensatz zu Ergebnissen von Ejersted et al. [1994] und Okimoto et al. [1998] führte PTH im vorliegenden Versuch zwar zu einem signifikanten Anstieg der kortikalen Knochenflächendichte, zeigte jedoch keine bedeutsame Zunahme des metaphysären Kortikalisund Knochendurchmessers. Bezüglich dieser Parameter ergaben sich ähnliche Werte wie unter E2.

Die hohe osteoanabole Wirkung und verbesserte Mikroarchitektur unter PTH-Applikation spiegelt sich auch in den Ergebnissen des biomechanischen Tests wider. So erreichte der Kallus die höchsten Werte für die Parameter Elastizität und Streckgrenze, auch in Bezug auf das Körpergewicht. Diese liegen fast doppelt so hoch, wie die der Kontrollgruppe und unterscheiden sich von dieser signifikant.

In der Fluoreszenz-mikroskopischen Untersuchung zeigte PTH als einzige Testgruppe einen deutlichen Rückgang der Kallusbildung im letzten Beobachtungszeitraum. Dies deutet darauf hin, dass der Prozess der Frakturheilung hier am 35. Tag nach der Osteotomie von allen Testgruppen am weitesten fortgeschritten war.

Es ist zusammenfassend festzustellen, dass in der vorliegenden Untersuchung die pulsatile Verabreichung von PTH hinsichtlich fast aller untersuchter Parameter, abgesehen vom metaphysären Kortikalisdurchmesser und der plattennahen Kallusdicke, Bestwerte erreicht hat. PTH hält nicht nur das Fortschreiten der Osteoporose auf, sondern fördert sogar die Regeneration des geschwächten Knochens und die frühe Bildung eines belastbaren Kallus im Rahmen der metaphysären Frakturheilung. Es ist zu erwarten, dass diese Therapie auch beim Menschen positive Effekte auf den Heilungsverlauf, die Patientenmobilität und 
die Rehabilitation zeigt. Um hier letztendlich Klarheit zu gewinnen, sind weitere Untersuchungen an größeren Tieren und später am Menschen erforderlich.

Die Ergebnisse sind derzeit zur Publikation in der Zeitschrift "Journal of Orthopaedic Trauma" eingereicht. 


\subsection{Schlussfolgerung}

In der vorliegenden Arbeit haben die osteoporotische Kontrollgruppe (Negativkontrolle) und die Estradiolgruppe (Positivkontrolle) die Ergebnisse vorausgehender Veröffentlichungen bestätigt. Obwohl sich zwischen beiden Testgruppen keine signifikanten Unterschiede ergaben, so waren doch deutliche Tendenzen zu erkennen. In der Negativkontrolle führte der Östrogenmangel zu einer verzögerten Heilung. Zudem zeigte die Frakturüberbrückung qualitative und quantitative Defizite. Diese Veränderungen waren durch die Estradiolsubstitution auf physiologischem Niveau reversibel. Hier verlief die Heilung beschleunigt und es zeigte sich fünf Wochen nach der Osteotomie ein kleiner, stabiler, hauptsächlich endostal lokalisierter Kallus.

Als auffälligster und potentester Wirkstoff im Versuch ist Parathormon zu nennen. Es beschleunigte den Heilungsprozess, induzierte die höchste Kallusbildung und führte zu einer deutlich besseren Kallusqualität als die übrigen getesteten Substanzen. Zudem zeigte es als einziger Wirkstoff im Versuch eine signifikante Steigerung der kortikalen Knochenflächendichte.

Die bereits in vorhergehenden Versuchen beschriebenen positiven Effekte von Raloxifen auf den früh-osteoporotischen Knochen und die Frakturheilung wurden durch die vorliegende Arbeit in Bezug auf den schwer osteoporotischen Knochen bestätigt. So erreichte die Raloxifentherapie insbesondere eine gesteigerte biomechanische Belastbarkeit der Frakturüberbrückung. Die Ergebnisse bekräftigen somit die Therapieempfehlung der DVO-Leitlinie und stellen zudem einen zukünftigen Einsatz von Raloxifen im Rahmen der Frakturtherapie in Aussicht.

In der Wirksamkeit der drei getesteten Phytoextrakte auf die Frakturheilung ließ sich eine klare Abstufung erkennen. Die besten Ergebnisse erreichte Equol, das die mechanische Qualität des Kallus verbessern konnte. Cimicifuga racemosa hatte dahingegen keinen Einfluss auf den Heilungsprozess. Die Applikation von Genistein führte sogar zu einer Verschlechterung des Heilungsverlaufs, was mit hoher Wahrscheinlichkeit auf dessen Hauptwirkmechanismus, die Hemmung der Osteoklasten mit konsekutiver Hemmung der Remodelingprozesse, zurückzuführen ist. Die Auswirkungen der Genisteintherapie haben in der vorliegenden Arbeit deutlich gezeigt, dass sich Substanzen, denen eine osteoprotektive Wirkung nachgewiesen ist, nicht zwangsläufig positiv auf die Frakturheilung auswirken und diese sogar beeinträchtigen können. Die gewonnenen Ergebnisse legen die Empfehlung nahe, während der ersten Wochen nach einer Fraktur keine Therapie mit Genistein zu beginnen bzw. eine laufende Therapie auszusetzen.

Durch die vorliegende Untersuchung ließ sich des Weiteren feststellen, dass sich die Osteoporose und die getesteten Substanzen insbesondere auf die metaphysäre Spongiosa und den neugebildeten Kallus auswirken. Der metaphysäre kortikale Knochen wurde vergleichsweise wenig beeinflusst. 
Zusammenfassend hat sich in der vorliegenden Arbeit gezeigt, dass die therapeutische Kurzzeitapplikation von Parathormon, Raloxifen oder Equol nach einer osteoporotischen Fraktur den Heilungsprozess verbessern kann. Hierbei ist allerdings zu berücksichtigen, dass diese Untersuchungen am Osteoporosemodell Ratte durchgeführt wurden. Daher sind weiterführende Untersuchungen an Großtiermodellen und spätere Studien am Menschen indiziert, um hier letztendlich Klarheit über den Nutzen dieser Substanzen zu gewinnen. 


\section{Zusammenfassung}

Osteoporose ist nach Einstufung der WHO eine der zehn gravierendsten Volkskrankheiten mit weltweit ca. 200 Millionen betroffenen Menschen. Zentrales Problem dieser systemischen Skeletterkrankung, die zu verminderter Knochenmineraldichte und einer gestörten Mikroarchitektur führt, ist die Fraktur des geschwächten Knochens. Ein Großteil der Patienten erleidet die erste Fraktur zu einem Zeitpunkt, an dem ihre Erkrankung weder diagnostiziert noch therapiert ist. Aus diesem Grund kommt es im Rahmen der chirurgischen Therapie häufig zu Implantatversagen und einer gestörten Frakturheilung. In der vorliegenden Arbeit wurde untersucht, in welcher Weise die therapeutische Kurzzeitapplikation der potentiell antiosteoporotischen Substanzen Estradiol, Raloxifen, Parathormon und der Phytoextrakte Cimicifuga racemosa, Genistein und Equol Einfluss auf den Heilungsverlauf manifest osteoporotischen Knochens nehmen und ob diese eine Verbesserung der Frakturheilung bewirken können.

84 Ratten wurden im Alter von drei Monaten ovarektomiert und entwickelten innerhalb der folgenden neun Wochen eine ausgeprägte Osteoporose. Anschließend wurde im Bereich der proximalen Tibiametaphyse eine standardisierte Osteotomie durchgeführt und mit einer T-Platte versorgt. Während des Heilungsprozesses wurden die Ratten in sieben Gruppen unterteilt, die Estradiol, Raloxifen, Cimicifuga racemosa, Genistein oder Equol oral, Parathormon subkutan oder sojafreies Futter erhielten. Nach einer Heilungszeit von fünf Wochen erfolgte die Bewertung des Kallus und der angrenzenden metaphysären Strukturen anhand radiologischer, biomechanischer und histomorphometrischer Kriterien. Eine während der Heilung durchgeführte Polychrome Sequenzmarkierung ermöglichte außerdem die Untersuchung des zeitlichen Verlaufs der Konsolidierung.

Parathormon hat die Frakturheilung biomechanisch und morphologisch deutlich verbessert und zeigte zudem ausgeprägte positive Effekte auf die angrenzende metaphysäre Kortikalis und den trabekulären Knochen. Raloxifen und Equol führten zu einer gesteigerten biomechanischen Belastbarkeit des Frakturkallus und zu einer tendentiellen Verbesserung der Kallusstruktur. Estradiol und Cimicifuga racemosa wiesen keine signifikanten Unterschiede zur Kontrollgruppe auf. Als einzige Testsubstanz hatte das Phytoextrakt Genistein eine inhibierende Wirkung auf den Verlauf der Frakturheilung. Es ist durch weiterführende Versuche zu prüfen, ob die Kurzzeitapplikation von Parathormon, Raloxifen und Equol auch beim Menschen die hier beschriebenen positiven Effekte auf die Frakturheilung erreichen kann. 


\section{$6 \quad$ Literaturverzeichnis}

[Alkhiary et al. 2005] = Alkhiary YM, Gerstenfeld LC, Krall E, Westmore M, Sato M, Mitlak BH, Einhorn TA (2005): Enhancement of experimental fracture-healing by systemic administration of recombinant human parathyroid hormone (PTH 1-34). J Bone Joint Surg Am 87(4): 731-41

[Anderson et al. 2004] = Anderson GL, Limacher M, Assaf AR, Bassford T, Beresford SA, Black H, Bonds D, Brunner R, Brzyski R, Caan B (2004): Effects of conjugated equine estrogen in postmenopausal women with hysterectomy: the Women's Health Initiative randomized controlled trial. JAMA 291(14): 1701-12

[Andreassen et al. 2001] = Andreassen TT, Fledelius C, Ejersted C, Oxlund H (2001): Increases in callus formation and mechanical strength of healing fractures in old rats treated with parathyroid hormone. Acta Orthop Scand 72(3): 304-7

[Asarian und Geary 2006] = Asarian L, Geary N (2006): Modulation of appetite by gonadal steroid hormones. Philos Trans R Soc Lond B Biol Sci 361(1471): 1251-63

[Atkinson et al 2005] = Atkinson C, Frankenfeld CL, Lampe JW (2005): Gut bacterial metabolism of the soy isoflavone daidzein: exploring the relevance to human health. Exp Biol Med (Maywood) 230(3): 155-70

[Augat et al. 1998] = Augat P, Fuerst T, Genant HK (1998): Quantitative bone mineral assessment at the forearm: a review. Osteoporos Int 8(4): 299-310

[Bain et al. 1993] = Bain SD, Bailey MC, Celino DL, Lantry MM, Edwards MW (1993): High-dose estrogen inhibits bone resorption and stimulates bone formation in the ovariectomized mouse. J Bone Miner Res $\underline{8(4): 435-42}$

[Banse et al. 2001] = Banse X, Devogelaer JP, Munting E, Delloye C, Cornu O, Grynpas M (2001): Inhomogeneity of human vertebral cancellous bone: systematic density and structure patterns inside the vertebral body. Bone 28(5): 563-71

[Bartl R und Bartl C 2008] = Bartl R, Bartl C: Osteoporose - Prävention, Diagnostik, Therapie; 3. Auflage; Georg Thieme Verlag KG, Stuttgart 2008

[Bartl R et al. 2003] = Bartl R, Bartl C, Mutschler W (2003): [Diagnosis and therapy of osteoporosis. Strategy for effective treatment after fragility fractures]. Unfallchirurg 106(7): 526-41 
[Beral 2003] = Beral V (2003): Breast cancer and hormone-replacement therapy in the Million Women Study. Lancet 362(9382): 419-27

[Beral et al. 2005] = Beral V, Bull D, Reeves G (2005): Endometrial cancer and hormonereplacement therapy in the Million Women Study. Lancet 365(9470): 1543-51

[Beral et al. 2007] = Beral V, Bull D, Green J, Reeves G (2007): Ovarian cancer and hormone replacement therapy in the Million Women Study. Lancet 369(9574): 1703-10

[Black et al. 1996] = Black DM, Cummings SR, Karpf DB, Cauley JA, Thompson DE, Nevitt MC, Bauer DC, Genant HK, Haskell WL, Marcus R (1996): Randomised trial of effect of alendronate on risk of fracture in women with existing vertebral fractures. Fracture Intervention Trial Research Group. Lancet 348(9041): 1535-41

[Blake und Fogelman 1997] = Blake GM, Fogelman I (1997): Technical principles of dual energy x-ray absorptiometry. Semin Nucl Med 27(3): 210-28

[Böcker et al. 2004] = Böcker W, Denk H, Heitz PU; Pathologie, 3. Auflage; Urban \& Fischer Verlag, München 2004, 1044-1046

[Borrelli und Ernst 2008] = Borrelli F, Ernst E (2008): Black cohosh (Cimicifuga racemosa) for menopausal symptoms: A systematic review of its efficacy. Pharmacol Res $\underline{58(1): 8-14}$

[Brzezinski und Debi 1999] = Brzezinski A, Debi A (1999): Phytoestrogens: the "natural" selective estrogen receptor modulators? Eur J Obstet Gynecol Reprod Biol 85, 47-51

[Cao et al. 2002] = Cao Y, Mori S, Mashiba T, Westmore MS, Ma L, Sato M, Akiyama T, Shi L, Komatsubara S, Miyamoto K (2002): Raloxifene, estrogen, and alendronate affect the processes of fracture repair differently in ovariectomized rats. J Bone Miner Res 17(12): 2237-46

[Chesnut et al. 2004] = Chesnut IC, Skag A, Christiansen C, Recker R, Stakkestad JA, Hoiseth A, Felsenberg D, Huss H, Gilbride J, Schimmer RC (2004): Effects of oral ibandronate administered daily or intermittently on fracture risk in postmenopausal osteoporosis. J Bone Miner Res 19(8): 1241-9

[Claes und Heigele 1998] = Claes LE, Heigele CA (1999): Magnitudes of local stress and strain along bony surfaces predict the course and type of fracture healing. J Biomech 32(3): 255-66 
[Claes et al. 1997] = Claes L, Augat P, Suger G, Wilke HJ (1997): Influence of size and stability of the osteotomy gap on the success of fracture healing. J Orthop Res 15(4): $577-84$

[Cooper et al. 1993] = Cooper C, Atkinson EJ, Jacobsen SJ, O'Fallon WM, Melton LJ, 3rd (1993): Population-based study of survival after osteoporotic fractures. Am J Epidemiol 137(9): 1001-5

[Cummings et al. 1998] = Cummings SR, Black DM, Thompson DE, Applegate WB, Barrett-Connor E, Musliner TA, Palermo L, Prineas R, Rubin SM, Scott JC (1998): Effect of alendronate on risk of fracture in women with low bone density but without vertebral fractures: results from the Fracture Intervention Trial. JAMA 280(24): 2077-82

[Cummings et al. 1999] = Cummings SR, Eckert S, Krueger KA, Grady D, Powles TJ, Cauley JA, Norton L, Nickelsen T, Bjarnason NH, Morrow M (1999): The effect of raloxifene on risk of breast cancer in postmenopausal women: results from the MORE randomized trial. Multiple Outcomes of Raloxifene Evaluation. JAMA 281(23): 2189-97

[D'Anna et al. 2007] = D'Anna R, Cannata ML, Atteritano M, Cancellieri F, Corrado F, Baviera G, Triolo O, Antico F, Gaudio A, Frisina N, Bitto A, Polito F, Minutoli L, Altavilla D, Marini H, Squadrito F (2007): Effects of the phytoestrogen genistein on hot flushes, endometrium, and vaginal epithelium in postmenopausal women: a 1-year randomized, double-blind, placebo-controlled study. Menopause 14(4): 648-55

[Dawson-Hughes et al. 1997] = Dawson-Hughes B, Harris SS, Krall EA, Dallal GE (1997): Effect of calcium and vitamin D supplementation on bone density in men and women 65 years of age or older. N Engl J Med $\underline{337(10): 670-6}$

[Decroos et al. 2005] = Decroos K, Vanhemmens S, Cattoir S, Boon N, Verstraete W (2005): Isolation and characterisation of an equol-producing mixed microbial culture from a human faecal sample and its activity under gastrointestinal conditions. Arch Microbiol 183(1): 45-55

[Dempster et al. 2001] = Dempster DW, Cosman F, Kurland ES, Zhou H, Nieves J, Woelfert L, Shane E, Plavetic K, Muller R, Bilezikian J (2001): Effects of daily treatment with parathyroid hormone on bone microarchitecture and turnover in patients with osteoporosis: a paired biopsy study. J Bone Miner Res 16(10): 1846-53

[Di Daniele et al. 2004] = Di Daniele N, Carbonelli MG, Candeloro N, Iacopino L, De Lorenzo A, Andreoli A (2004): Effect of supplementation of calcium and vitamin D on 
bone mineral density and bone mineral content in peri- and post-menopause women; a double-blind, randomized, controlled trial. Pharmacol Res 50(6): 637-41

[Dutertre und Smith 2000] = Dutertre M, Smith CL (2000): Molecular mechanisms of selective estrogen receptor modulator (SERM) action. J Pharmacol Exp Ther 295(2): $431-7$

[Einhorn 1995] = Einhorn TA (1995): Enhancement of fracture-healing. J Bone Joint Surg Am 77(6): 940-56

[Ejersted et al. 1994] = Ejersted C, Andreassen TT, Nilsson MH, Oxlund H (1994): Human parathyroid hormone(1-34) increases bone formation and strength of cortical bone in aged rats. Eur J Endocrinol 130(2): 201-7

[El Maghraoui et al. 2007] = El Maghraoui A, Mouinga Abayi DA, Rkain H, Mounach A (2007): Discordance in diagnosis of osteoporosis using spine and hip bone densitometry. J Clin Densitom 10(2): 153-6

[Ettinger et al. 1999] = Ettinger B, Black DM, Mitlak BH, Knickerbocker RK, Nickelsen T, Genant HK, Christiansen C, Delmas PD, Zanchetta JR, Stakkestad J (1999): Reduction of vertebral fracture risk in postmenopausal women with osteoporosis treated with raloxifene: results from a 3-year randomized clinical trial. Multiple Outcomes of Raloxifene Evaluation (MORE) Investigators. JAMA 282(7): 637-45

[Fanti et al. 1998] = Fanti P, Monier-Faugere MC, Geng Z, Schmidt J, Morris PE, Cohen D, Malluche HH (1998): The phytoestrogen genistein reduces bone loss in short-term ovariectomized rats. Osteoporos Int $\underline{8(3)}$ : 274-81

[Frost und Jee 1992] = Frost HM, Jee WS (1992): On the rat model of human osteopenias and osteoporoses. Bone Miner 18(3): 227-36

[Frost et al. 2001] = Frost ML, Blake GM, Fogelman I (2001): Does the combination of quantitative ultrasound and dual-energy X-ray absorptiometry improve fracture discrimination? Osteoporos Int 12(6): 471-7

[Fujioka et al. 2004] = Fujioka M, Uehara M, Wu J, Adlercreutz H, Suzuki K, Kanazawa K, Takeda K, Yamada K, Ishimi Y (2004): Equol, a metabolite of daidzein, inhibits bone loss in ovariectomized mice. J Nutr 134(10): 2623-7 
[Gao und Yamaguchi 2000] = Gao YH, Yamaguchi M (2000): Suppressive effect of genistein on rat bone osteoclasts: involvement of protein kinase inhibition and protein tyrosine phosphatase activation. Int J Mol Med $\underline{5(3): ~ 261-7 ~}$

[Garnero und Delmas 2004] = Garnero P, Delmas PD (2004): Contribution of bone mineral density and bone turnover markers to the estimation of risk of osteoporotic fracture in postmenopausal women. J Musculoskelet Neuronal Interact 4(1): 50-63

[Gasser et al. 2005] = Gasser JA, Ingold P, Grosios K, Laib A, Hammerle S, Koller B (2005): Noninvasive monitoring of changes in structural cancellous bone parameters with a novel prototype micro-CT. J Bone Miner Metab 23 Suppl: 90-6

[Genant et al. 1996] = Genant HK, Engelke K, Fuerst T, Gluer CC, Grampp S, Harris ST, Jergas M, Lang T, Lu Y, Majumdar S (1996): Noninvasive assessment of bone mineral and structure: state of the art. J Bone Miner Res 11(6): 707-30

[Gennari et al. 2007] = Gennari L, Merlotti D, Valleggi F, Martini G, Nuti R (2007): Selective estrogen receptor modulators for postmenopausal osteoporosis: current state of development. Drugs Aging 24(5): 361-79

[Glüer et al. 1994] = Glüer CC, Wu CY, Jergas M, Goldstein SA, Genant HK (1994): Three quantitative ultrasound parameters reflect bone structure. Calcif Tissue Int 55(1): $46-52$

[Glüer et al. 2004] = Glüer CC, Eastell R, Reid DM, Felsenberg D, Roux C, Barkmann R, Timm W, Blenk T, Armbrecht G, Stewart A (2004): Association of five quantitative ultrasound devices and bone densitometry with osteoporotic vertebral fractures in a population-based sample: the OPUS Study. J Bone Miner Res 19(5): 782-93

[Grampp et al. 1993] = Grampp S, Jergas M, Gluer CC, Lang P, Brastow P, Genant HK (1993): Radiologic diagnosis of osteoporosis. Current methods and perspectives. Radiol Clin North Am 31(5): 1133-45

[Grampp et al. 2004] = Grampp S, Willvonseder R, Dimai H, Leb G, Dobnig H (2004): Leitlinien zur Anwendung densitometrischer Verfahren in der Postmenopause. J Miner Stoffwechs 11: $7-10$

[Greenspan et al. 2007] = Greenspan SL, Bone HG, Ettinger MP, Hanley DA, Lindsay R, Zanchetta JR, Blosch CM, Mathisen AL, Morris SA, Marriott TB (2007): Effect of recombinant human parathyroid hormone (1-84) on vertebral fracture and bone mineral 
density in postmenopausal women with osteoporosis: a randomized trial. Ann Intern Med 146(5): 326-39

[Grey und Reid 2006] = Grey A, Reid IR (2006): Differences between the bisphosphonates for the prevention and treatment of osteoporosis. Ther Clin Risk Manag 2(1): 77-86

[Guglielmi und Lang 2002] = Guglielmi G, Lang TF (2002): Quantitative computed tomography. Semin Musculoskelet Radiol 6(3): 219-27

[Guralnik et al. 1995] = Guralnik JM, Ferrucci L, Simonsick EM, Salive ME, Wallace RB (1995): Lower-extremity function in persons over the age of 70 years as a predictor of subsequent disability. N Engl J Med 332(9): 556-61

[Häussler et al. 2007] = Häussler B, Gothe H, Gol D, Glaeske G, Pientka L, Felsenberg D (2007): Epidemiology, treatment and costs of osteoporosis in Germany-the BoneEVA Study. Osteoporos Int 18(1): 77-84

[Hans et al. 1996] = Hans D, Dargent-Molina P, Schott AM, Sebert JL, Cormier C, Kotzki PO, Delmas PD, Pouilles JM, Breart G, Meunier PJ (1996): Ultrasonographic heel measurements to predict hip fracture in elderly women: the EPIDOS prospective study. Lancet 348(9026): 511-4

[Harris et al. 1999] = Harris ST, Watts NB, Genant HK, McKeever CD, Hangartner T, Keller M, Chesnut CH, 3rd, Brown J, Eriksen EF, Hoseyni MS (1999): Effects of risedronate treatment on vertebral and nonvertebral fractures in women with postmenopausal osteoporosis: a randomized controlled trial. Vertebral Efficacy With Risedronate Therapy (VERT) Study Group. JAMA 282(14): 1344-52

[Herold 2009] = Herold G; Innere Medizin, Selbstverlag, Köln 2009, 725-728

[Hertrampf et al. 2007] = Hertrampf T, Gruca MJ, Seibel J, Laudenbach U, Fritzemeier KH, Diel P (2007): The bone-protective effect of the phytoestrogen genistein is mediated via ER alpha-dependent mechanisms and strongly enhanced by physical activity. Bone 40(6): 1529-35

[Hirner und Weise 2004] = Hirner A, Weise K; Chirurgie - Schnitt für Schnitt, 1. Auflage; Georg Thieme Verlag, Stuttgart 2004, 228-229 
[Huopio et al. 2004] = Huopio J, Kroger H, Honkanen R, Jurvelin J, Saarikoski S, Alhava E (2004): Calcaneal ultrasound predicts early postmenopausal fractures as well as axial BMD. A prospective study of 422 women. Osteoporos Int 15(3): 190-5

[ISCD 2004] = Writing Group for the ISCD Position Development Conference (2004): Diagnosis of osteoporosis in men, premenopausal women, and children. J Clin Densitom 7(1): $17-26$

[Iwaniec et al. 2007] = Iwaniec UT, Moore K, Rivera MF, Myers SE, Vanegas SM, Wronski TJ (2007): A comparative study of the bone-restorative efficacy of anabolic agents in aged ovariectomized rats. Osteoporos Int 18(3): 351-62

[Jarry et al. 2003] = Jarry H, Metten M, Spengler B, Christoffel V, Wuttke W (2003): In vitro effects of the Cimicifuga racemosa extract BNO 1055. Maturitas 44 Suppl 1: 31-8

[Jergas und Schmid 1999] = Jergas M, Schmid G (1999): [Conventional radiology of osteoporosis and radiographic absorptiometry]. Radiologe 39(3): 174-85

[Jiang et al. 2003] = Jiang Y, Zhao JJ, Mitlak BH, Wang O, Genant HK, Eriksen EF (2003): Recombinant human parathyroid hormone (1-34) [teriparatide] improves both cortical and cancellous bone structure. J Bone Miner Res 18(11): 1932-41

[Johnell und Kanis 2006] = Johnell O, Kanis JA (2006): An estimate of the worldwide prevalence and disability associated with osteoporotic fractures. Osteoporos Int 17(12): $1726-33$

[Johnell et al. 2005] = Johnell O, Kanis JA, Oden A, Johansson H, De Laet C, Delmas P, Eisman JA, Fujiwara S, Kroger H, Mellstrom D (2005): Predictive value of BMD for hip and other fractures. J Bone Miner Res 20(7): 1185-94

[Jones et al. 1994] = Jones G, Nguyen T, Sambrook PN, Kelly PJ, Gilbert C, Eisman JA (1994).: Symptomatic fracture incidence in elderly men and women: the Dubbo Osteoporosis Epidemiology Study (DOES). Osteoporos Int 4(5): 277-82

[Junqueira und Carneiro 2005] = Junqueira LC, Carneiro J: Histologie; 6. Auflage; Springer Medizin Verlag, Heidelberg 2005, 92-104

[Kalu 1991] = Kalu DN (1991): The ovariectomized rat model of postmenopausal bone loss. Bone Miner 15(3): 175-91 
[Kanis und Glüer 2000] = Kanis JA, Glüer CC (2000): An update on the diagnosis and assessment of osteoporosis with densitometry. Committee of Scientific Advisors, International Osteoporosis Foundation. Osteoporos Int 11(3): 192-202

[Kanis und Johnell 2005] = Kanis JA, Johnell O (2005): Requirements for DXA for the management of osteoporosis in Europe. Osteoporos Int 16(3): 229-38

[Kanis et al. 2004] = Kanis JA, Johnell O, De Laet C, Johansson H, Oden A, Delmas P, Eisman J, Fujiwara S, Garnero P, Kroger H (2004): A meta-analysis of previous fracture and subsequent fracture risk. Bone $\underline{35(2): 375-82}$

[Kim und Jahng 1999] = Kim HW, Jahng JS (1999): Effect of intermittent administration of parathyroid hormone on fracture healing in ovariectomized rats. Iowa Orthop J 19: 71-7

[Kolios et al. 2009] = Kolios L, Sehmisch S, Daub F, Rack T, Tezval M, Stuermer KM, Stuermer EK (2009): Equol but not genistein improves early metaphyseal fracture healing in osteoporotic rats. Planta Med 75(5): 459-65

[Komatsubara und Mori 2005] = Komatsubara S, Mori S (2005): [Bone quality in fracture callus]. Clin Calcium 15(6): 977-83 (Abstract)

[Kubo et al. 1999] = Kubo T, Shiga T, Hashimoto J, Yoshioka M, Honjo H, Urabe M, Kitajima I, Semba I, Hirasawa Y (1999): Osteoporosis influences the late period of fracture healing in a rat model prepared by ovariectomy and low calcium diet. J Steroid Biochem Mol Biol 68(5-6): 197-202

[Kuiper et al. 1997] = Kuiper GG, Carlsson B, Grandien K, Enmark E, Haggblad J, Nilsson S, Gustafsson JA (1997): Comparison of the ligand binding specificity and transcript tissue distribution of estrogen receptors alpha and beta. Endocrinology 138(3): 863-70

[Kulling und Watzl 2003] = Kulling SE, Watzl B (2003): Basiswissen aktualisiert: Phytoöstrogene. Ernährungsumschau $\underline{50(6):}$ 234-239

[Lane 2006] = Lane NE (2006): Epidemiology, etiology, and diagnosis of osteoporosis. Am J Obstet Gynecol 194: 3-11

[Lane et al. 1995] = Lane NE, Thompson JM, Strewler GJ, Kinney JH (1995): Intermittent treatment with human parathyroid hormone (hPTH[1-34]) increased trabecular bone volume but not connectivity in osteopenic rats. J Bone Miner Res 10(10): 1470-7 
[Leib et al. 2004] = Leib ES, Lewiecki EM, Binkley N, Hamdy RC (2004): Official positions of the International Society for Clinical Densitometry. South Med J 97(1): 107-10

[Leibson et al. 2002] = Leibson CL, Tosteson AN, Gabriel SE, Ransom JE, Melton LJ (2002): Mortality, disability, and nursing home use for persons with and without hip fracture: a population-based study. J Am Geriatr Soc 50(10): 1644-50

[Li und Yu 2003] = Li B, Yu S (2003): Genistein prevents bone resorption diseases by inhibiting bone resorption and stimulating bone formation. Biol Pharm Bull 26(6): 780-6

[Lill et al. 2002 a] = Lill CA, Fluegel AK, Schneider E (2002): Effect of ovariectomy, malnutrition and glucocorticoid application on bone properties in sheep: a pilot study. Osteoporos Int 13(6): 480-6

[Lill et al. 2002 b] = Lill CA, Gerlach UV, Eckhardt C, Goldhahn J, Schneider E (2002): Bone changes due to glucocorticoid application in an ovariectomized animal model for fracture treatment in osteoporosis. Osteoporos Int 13(5): 407-14

[Löffler und Petrides 2003] = Löffler G, Petrides PE: Biochemie und Pathobiochemie; 7. Auflage; Springer Medizin Verlag, Berlin 2003, 953-957

[Manolagas 2000] = Manolagas SC (2000): Birth and death of bone cells: basic regulatory mechanisms and implications for the pathogenesis and treatment of osteoporosis. Endocr Rev 21(2): 115-37

[Marie et al. 2001] = Marie PJ, Ammann P, Boivin G, Rey C (2001): Mechanisms of action and therapeutic potential of strontium in bone. Calcif Tissue Int 69(3): 121-9

[Marini et al. 2007] = Marini H, Minutoli L, Polito F, Bitto A, Altavilla D, Atteritano M, Gaudio A, Mazzaferro S, Frisina A, Frisina N (2007): Effects of the phytoestrogen genistein on bone metabolism in osteopenic postmenopausal women: a randomized trial. Ann Intern Med 146(12): 839-47

[Marshall et al. 1996] = Marshall D, Johnell O, Wedel H (1996): Meta-analysis of how well measures of bone mineral density predict occurrence of osteoporotic fractures. BMJ 312(7041): 1254-9

[Mathey et al. 2007] = Mathey J, Mardon J, Fokialakis N, Puel C, Kati-Coulibaly S, Mitakou S, Bennetau-Pelissero C, Lamothe V, Davicco MJ, Lebecque P (2007): Modulation 
of soy isoflavones bioavailability and subsequent effects on bone health in ovariectomized rats: the case for equol. Osteoporos Int 18(5): 671-9

[Matkovic et al. 1994] = Matkovic V, Jelic T, Wardlaw GM, Ilich JZ, Goel PK, Wright JK, Andon MB, Smith KT, Heaney RP (1994): Timing of peak bone mass in Caucasian females and its implication for the prevention of osteoporosis. Inference from a crosssectional model. J Clin Invest 93(2): 799-808

[McClung et al. 2001] = McClung MR, Geusens P, Miller PD, Zippel H, Bensen WG, Roux C, Adami S, Fogelman I, Diamond T, Eastell R (2001): Effect of risedronate on the risk of hip fracture in elderly women. Hip Intervention Program Study Group. N Engl J Med $\underline{344(5): 333-40}$

[Melhus et al. 2007] = Melhus G, Solberg LB, Dimmen S, Madsen JE, Nordsletten L, Reinholt FP (2007): Experimental osteoporosis induced by ovariectomy and vitamin D deficiency does not markedly affect fracture healing in rats. Acta Orthop 78(3): 393-403

[Melton et al. 1992] = Melton LJ, 3rd, Chrischilles EA, Cooper C, Lane AW, Riggs BL (1992): Perspective: How many women have osteoporosis? J Bone Miner Res $\underline{7}$ : 1005-10

[Melton et al. 1993] = Melton LJ, 3rd, Atkinson EJ, O'Fallon WM, Wahner HW, Riggs BL (1993): Long-term fracture prediction by bone mineral assessed at different skeletal sites. J Bone Miner Res 8(10): 1227-33

[Meunier et al. 2004] = Meunier PJ, Roux C, Seeman E, Ortolani S, Badurski JE, Spector TD, Cannata J, Balogh A, Lemmel EM, Pors-Nielsen S (2004): The effects of strontium ranelate on the risk of vertebral fracture in women with postmenopausal osteoporosis. $\mathrm{N}$ Engl J Med 350(5): 459-68

[Morabito et al. 2002] = Morabito N, Crisafulli A, Vergara C, Gaudio A, Lasco A, Frisina N, D'Anna R, Corrado F, Pizzoleo MA, Cincotta M (2002): Effects of genistein and hormone-replacement therapy on bone loss in early postmenopausal women: a randomized double-blind placebo-controlled study. J Bone Miner Res 17(10): 1904-12

[Mounach et al. 2008] = Mounach A, Mouinga Abayi DA, Ghazi M, Ghozlani I, Nouijai A, Achemlal L, Bezza A, El Maghraoui A (2008): Discordance Between Hip and Spine Bone Mineral Density Measurement Using DXA: Prevalence and Risk Factors. Semin Arthritis Rheum 38(6): 467-71 
[Nakajima et al. 2002] = Nakajima A, Shimoji N, Shiomi K, Shimizu S, Moriya H, Einhorn TA, Yamazaki M (2002): Mechanisms for the enhancement of fracture healing in rats treated with intermittent low-dose human parathyroid hormone (1-34). J Bone Miner Res 17(11): 2038-47

[Namkung-Matthai et al. 2001] = Namkung-Matthai H, Appleyard R, Jansen J, Hao Lin J, Maastricht S, Swain M, Mason RS, Murrell GA, Diwan AD, Diamond T (2001): Osteoporosis influences the early period of fracture healing in a rat osteoporotic model. Bone 28(1): 80-6

[Neer et al. 2001] = Neer RM, Arnaud CD, Zanchetta JR, Prince R, Gaich GA, Reginster JY, Hodsman AB, Eriksen EF, Ish-Shalom S, Genant HK (2001): Effect of parathyroid hormone (1-34) on fractures and bone mineral density in postmenopausal women with osteoporosis. N Engl J Med 344(19): 1434-41

[Nguyen et al. 2004] = Nguyen TV, Center JR, Eisman JA (2004): Osteoporosis: underrated, underdiagnosed and undertreated. Med J Aust 180(5 Suppl): 18-22

[NIH Consensus Development Panel on Osteoporosis 2001] = NIH Consensus Development Panel on Osteoporosis (2001): Osteoporosis prevention, diagnosis, and therapy. JAMA 285: $785-95$

[O'Gradaigh et al. 2003] = O'Gradaigh D, Debiram I, Love S, Richards HK, Compston JE (2003): A prospective study of discordance in diagnosis of osteoporosis using spine and proximal femur bone densitometry. Osteoporos Int 14(1): 13-8

[Ohtomo et al. 2008] = Ohtomo T, Uehara M, Penalvo JL, Adlercreutz H, Katsumata S, Suzuki K, Takeda K, Masuyama R, Ishimi Y (2008): Comparative activities of daidzein metabolites, equol and O-desmethylangolensin, on bone mineral density and lipid metabolism in ovariectomized mice and in osteoclast cell cultures. Eur J Nutr 47(5): 273-9

[Okimoto et al. 1998] = Okimoto N, Tsurukami H, Okazaki Y, Nishida S, Sakai A, Ohnishi H, Hori M, Yasukawa K, Nakamura T (1998): Effects of a weekly injection of human parathyroid hormone (1-34) and withdrawal on bone mass, strength, and turnover in mature ovariectomized rats. Bone 22(5): 523-31

[Ouyang et al. 2004] = Ouyang H, Sherman PJ, Paschalis EP, Boskey AL, Mendelsohn R (2004): Fourier transform infrared microscopic imaging: effects of estrogen and estrogen deficiency on fracture healing in rat femurs. Appl Spectrosc 58(1): 1-9 
[Pacifici 1998] = Pacifici R (1998): Cytokines, estrogen, and postmenopausal osteoporosisthe second decade. Endocrinology 139(6): 2659-61

[Pallamar und Friedrich 2005] = Pallamar M, Friedrich M (2005): Aktuelle Diagnostik der Osteoporose. J Miner Stoffwechs 12(4): 94-100

[Pfeilschifter 2006] = Pfeilschifter J: Prophylaxe, Diagnostik und Therapie der Osteoporose bei Frauen ab der Menopause, bei Männern ab dem 60. Lebensjahr, S3-Leitlinie des Dachverbands der Deutschsprachigen Wissenschaftlichen Osteologischen Gesellschaften e.V.; 2. Auflage; Dachverband Osteologie e.v.; Essen 2006

[Picherit et al. 2000] = Picherit C, Coxam V, Bennetau-Pelissero C, Kati-Coulibaly S, Davicco MJ, Lebecque P, Barlet JP (2000): Daidzein is more efficient than genistein in preventing ovariectomy-induced bone loss in rats. J Nutr 130(7): 1675-81

[Podsiadlo und Richardson 1991] = Podsiadlo D, Richardson S (1991): The timed "Up \& Go": a test of basic functional mobility for frail elderly persons. J Am Geriatr Soc 39(2): $142-8$

[Pols et al. 1999] = Pols HA, Felsenberg D, Hanley DA, Stepan J, Munoz-Torres M, Wilkin TJ, Qin-sheng G, Galich AM, Vandormael K, Yates AJ (1999): Multinational, placebocontrolled, randomized trial of the effects of alendronate on bone density and fracture risk in postmenopausal women with low bone mass: results of the FOSIT study. Fosamax International Trial Study Group. Osteoporos Int 9(5): 461-8

[Prevrhal und Genant 1999] = Prevrhal S, Genant HK (1999): [Quantitative computer tomography]. Radiologe 39(3): 194-202

[Rachon et al. 2007 a] = Rachon D, Seidlova-Wuttke D, Vortherms T, Wuttke W (2007): Effects of dietary equol administration on ovariectomy induced bone loss in SpragueDawley rats. Maturitas $\underline{58(3):}$ 308-15

[Rachon et al. 2007 b] = Rachon D, Vortherms T, Seidlova-Wuttke D, Menche A, Wuttke W (2007): Uterotropic effects of dietary equol administration in ovariectomized SpragueDawley rats. Climacteric 10(5): 416-26

[Rachon et al. 2008] = Rachon D, Menche A, Vortherms T, Seidlova-Wuttke D, Wuttke W (2008): Effects of dietary equol administration on the mammary gland in ovariectomized Sprague-Dawley rats. Menopause 15(2): 340-5 
[Rahn 1976] = Rahn BA (1976): The fluorochrome sequence labeling of the bone. Nova Acta Leopold 44: 249-255

[Raisz 2005] = Raisz LG (2005): Clinical practice. Screening for osteoporosis. N Engl J Med 353(2): 164-71

[Randell et al. 1995] = Randell A, Sambrook PN, Nguyen TV, Lapsley H, Jones G, Kelly PJ, Eisman JA (1995): Direct clinical and welfare costs of osteoporotic fractures in elderly men and women. Osteoporos Int $\underline{5(6)}$ : 427-32

[Reginster et al. 2003] = Reginster JY, Deroisy R, Jupsin I (2003): Strontium ranelate: a new paradigm in the treatment of osteoporosis. Drugs Today (Barc) 39(2): 89-101

[Reginster et al. 2005] = Reginster JY, Seeman E, De Vernejoul MC, Adami S, Compston J, Phenekos C, Devogelaer JP, Curiel MD, Sawicki A, Goemaere S (2005): Strontium ranelate reduces the risk of nonvertebral fractures in postmenopausal women with osteoporosis: Treatment of Peripheral Osteoporosis (TROPOS) study. J Clin Endocrinol Metab 90(5): $2816-22$

[Roepke 2009] = Roepke TA (2009): Oestrogen modulates hypothalamic control of energy homeostasis through multiple mechanisms. J Neuroendocrinol 21(2): 141-50

[Rossouw et al. 2002] = Rossouw JE, Anderson GL, Prentice RL, LaCroix AZ, Kooperberg C, Stefanick ML, Jackson RD, Beresford SA, Howard BV, Johnson KC (2002): Risks and benefits of estrogen plus progestin in healthy postmenopausal women: principal results From the Women's Health Initiative randomized controlled trial. JAMA 288(3): 321-33

[Rüter et al. 2004] = Rüter A, Trentz O, Wagner M: Unfallchirurgie; 2. Auflage; Urban \& Fischer Verlag, München 2004, 147-153

[Ruhlen et al. 2007] = Ruhlen RL, Haubner J, Tracy JK, Zhu W, Ehya H, Lamberson WR, Rottinghaus GE, Sauter ER (2007): Black cohosh does not exert an estrogenic effect on the breast. Nutr Cancer 59(2): 269-77

[Sathyamoorthy und Wang 1997] = Sathyamoorthy N, Wang TT (1997): Differential effects of dietary phyto-oestrogens daidzein and equol on human breast cancer MCF-7 cells. Eur J Cancer 33(14): 2384-9 
[Schenk und Willenegger 1977] = Schenk RK, Willenegger HR (1977): [Histology of primary bone healing: modifications and limits of recovery of gaps in relation to extent of the defect (author's transl)]. Unfallheilkunde $\underline{80(5): ~ 155-60 ~}$

[Schiebler und Schmidt W 2002] = Schiebler TH, Schmidt W: Anatomie; 8. Auflage; Springer Medizin Verlag, Berlin 2002, 133-137

[Schmidt R et al. 2000] = Schmidt R, Thews G, Lang F: Physiologie des Menschen; 28. Auflage; Springer Medizin Verlag, Berlin 2000, 785-789

[Seeman 2003] = Seeman E (2003): Invited Review: Pathogenesis of osteoporosis. J Appl Physiol 95(5): 2142-51

[Sehmisch et al. 2008] = Sehmisch S, Hammer F, Christoffel J, Seidlova-Wuttke D, Tezval M, Wuttke W, Stuermer KM, Stuermer EK (2008): Comparison of the phytohormones genistein, resveratrol and 8-prenylnaringenin as agents for preventing osteoporosis. Planta Med 74(8): 794-801

[Sehmisch et al. 2009] = Sehmisch S, Erren M, Rack T, Tezval M, Seidlova-Wuttke D, Richter J, Wuttke W, Stuermer KM, Stuermer EK (2009): Short-term effects of parathyroid hormone on rat lumbar vertebrae. Spine (Phila Pa 1976) 34(19): 2014-21

[Seibel 2003] = Seibel MJ (2003): Biochemical markers of bone remodeling. Endocrinol Metab Clin North Am 32(1): 83-113

[Seidlova-Wuttke et al. 2003 a] = Seidlova-Wuttke D, Hesse O, Jarry H, Christoffel V, Spengler B, Becker T, Wuttke W (2003): Evidence for selective estrogen receptor modulator activity in a black cohosh (Cimicifuga racemosa) extract: comparison with estradiol17beta. Eur J Endocrinol 149(4): 351-62

[Seidlova-Wuttke et al. 2003 b] = Seidlova-Wuttke D, Jarry H, Becker T, Christoffel V, Wuttke W (2003): Pharmacology of Cimicifuga racemosa extract BNO 1055 in rats: bone, fat and uterus. Maturitas 44(1): 39-50

[Setchell et al. 2005] = Setchell KD, Clerici C, Lephart ED, Cole SJ, Heenan C, Castellani D, Wolfe BE, Nechemias-Zimmer L, Brown NM, Lund TD (2005): S-equol, a potent ligand for estrogen receptor beta, is the exclusive enantiomeric form of the soy isoflavone metabolite produced by human intestinal bacterial flora. Am J Clin Nutr 81(5): 1072-9 
[Siegenthaler und Blum 2006] = Siegenthaler W, Blum HE: Klinische Pathophysiologie; 9. Auflage; Georg Thieme Verlag, Stuttgart 2006, 316-319

[Siewert 2006] = Siewert R: Chirurgie; 8. Auflage; Springer Medizin Verlag, Heidelberg 2006, 780-784

[Siris et al. 2004] = Siris ES, Brenneman SK, Miller PD, Barrett-Connor E, Chen YT, Sherwood LM, Abbott TA (2004): Predictive value of low BMD for 1-year fracture outcomes is similar for postmenopausal women ages 50-64 and 65 and Older: results from the National Osteoporosis Risk Assessment (NORA). J Bone Miner Res 19(8): 1215-20

[Spelsberg et al. 1999] = Spelsberg TC, Subramaniam M, Riggs BL, Khosla S (1999): The actions and interactions of sex steroids and growth factors/cytokines on the skeleton. Mol Endocrinol 13(6): 819-28

[Steiniche 1995] = Steiniche T (1995): Bone histomorphometry in the pathophysiological evaluation of primary and secondary osteoporosis and various treatment modalities. APMIS 51: 1-44

[Stürmer et al. 2006] = Stürmer EK, Seidlova-Wuttke D, Sehmisch S, Rack T, Wille J, Frosch KH, Wuttke W, Stürmer KM (2006): Standardized bending and breaking test for the normal and osteoporotic metaphyseal tibias of the rat: effect of estradiol, testosterone, and raloxifene. J Bone Miner Res 21(1): 89-96

[Stürmer et al. 2008] = Stürmer EK, Sehmisch S, Rack T, Wenda E, Seidlova-Wuttke D, Tezval M, Wuttke W, Frosch KH, Stürmer KM (2008): Estrogen and raloxifene improve metaphyseal fracture healing in the early phase of osteoporosis. A new fracture-healing model at the tibia in rat. Langenbecks Arch Surg (elektronisch publiziert;

http://www.ncbi.nlm.nih.gov/pubmed/19048282)

[Stürmer et al. 2009] = Stürmer EK, Sehmisch S, Tezval M, Tezval H, Rack T, Boekhoff J, Wuttke W, Herrmann TR, Seidlova-Wuttke D, Stürmer KM (2009): Effect of testosterone, raloxifene and estrogen replacement on the microstructure and biomechanics of metaphyseal osteoporotic bones in orchiectomized male rats. World J Urol 27(4): 547-55

[Tezval et al. 2009 a] = Tezval M, Sehmisch S, Seidlova-Wuttke D, Rack T, Kolios L, Wuttke W, Stuermer KM, Stuermer EK (2009): Changes in the Histomorphometric and Biomechanical Properties of the Proximal Femur of Ovariectomized Rat after Treatment with the Phytoestrogens Genistein and Equol. Planta Med (elektronisch publiziert; http://www.ncbi.nlm.nih.gov/pubmed/19764010) 
[Tezval et al. 2009 b] = Tezval M, Stuermer EK, Sehmisch S, Rack T, Stary A, Stebener M, Konietschke F, Stuermer KM (2009): Improvement of trochanteric bone quality in an osteoporosis model after short-term treatment with parathyroid hormone: a new mechanical test for trochanteric region of rat femur. Osteoporos Int (elektronisch publiziert; http://www.ncbi.nlm.nih.gov/pubmed/19436940)

[Thompson et al. 1995] = Thompson DD, Simmons HA, Pirie CM, Ke HZ (1995): FDA Guidelines and animal models for osteoporosis. Bone 17(4): 125-133

[Thomsen et al. 2002] = Thomsen JS, Ebbesen EN, Mosekilde LI (2002): Age-related differences between thinning of horizontal and vertical trabeculae in human lumbar bone as assessed by a new computerized method. Bone 31, 136-142

[Tian et al. 2006] = Tian Y, Xu KH, Qiao L (2006): [Comparative study of effects of hormonal therapies on the healing of fracture in ovariectomized rats and Rats' endometria]. Sichuan Da Xue Xue Bao Yi Xue Ban 37(3): 416-20 (Abstract)

[Wang et al. 2005 a] = Wang JW, Li W, Xu SW, Yang DS, Wang Y, Lin M, Zhao GF (2005): Osteoporosis influences the middle and late periods of fracture healing in a rat osteoporotic model. Chin J Traumatol 8(2): 111-6

[Wang et al. 2005 b] = Wang XL, Hur HG, Lee JH, Kim KT, Kim SI (2005): Enantioselective synthesis of S-equol from dihydrodaidzein by a newly isolated anaerobic human intestinal bacterium. Appl Environ Microbiol 71(1): 214-9

[Weinstein 2009] = Weinstein JN (2009): Balancing science and informed choice in decisions about vertebroplasty. N Engl J Med 361(6): 619-21

[WHO 1994] = WHO (1994): Assessment of fracture risk and its application to screening for postmenopausal osteoporosis. Report of a WHO Study Group. World Health Organ Tech Rep Ser. $\underline{843}, 1-129$

[Wolff 1892] = Wolff J: Das Gesetz der Transformation der Knochen; Von August Hirschwald Verlag; Berlin 1892

[Woolf und Akesson 2003] = Woolf AD, Akesson K (2003): Preventing fractures in elderly people. BMJ 327(7406): 89-95

[Wronski und Yen 1991] = Wronski TJ, Yen CF (1991): The ovariectomized rat as an animal model for postmenopausal bone loss. Cell Mater (1): 69-74 
[Wronski et al. 1985] = Wronski TJ, Lowry PL, Walsh CC, Ignaszewski LA (1985): Skeletal alterations in ovariectomized rats. Calcif Tissue Int 37(3): 324-8

[Wuttke et al. 2003] = Wuttke W, Jarry H, Becker T, Schultens A, Christoffel V, Gorkow C, Seidlova-Wuttke D (2003): Phytoestrogens: endocrine disrupters or replacement for hormone replacement therapy? Maturitas $\underline{44(1)}$ : 9-20

[Wuttke et al. 2006] = Wuttke W, Gorkow C, Seidlova-Wuttke D (2006): Effects of black cohosh (Cimicifuga racemosa) on bone turnover, vaginal mucosa, and various blood parameters in postmenopausal women: a double-blind, placebo-controlled, and conjugated estrogens-controlled study. Menopause 13(2): 185-96

[Xu et al. 2003] = Xu SW, Yu R, Zhao GF, Wang JW (2003): Early period of fracture healing in ovariectomized rats. Chin J Traumatol 6(3): 160-6 (Abstract)

[Xu et al. 2004] = Xu SW, Wang JW, Li W, Wang Y, Zhao GF (2004): [Osteoporosis impairs fracture healing of tibia in a rat osteoporotic model]. Zhonghua Yi Xue Za Zhi 84(14): 1205-9 (Abstract)

[You et al. 2008] = You L, Temiyasathit S, Lee P, Kim CH, Tummala P, Yao W, Kingery W, Malone AM, Kwon RY, Jacobs CR (2008): Osteocytes as mechanosensors in the inhibition of bone resorption due to mechanical loading. Bone 42(1): 172-9

[Zhang et al. 2002] = Zhang KQ, Chen JW, Li QN, Li GF, Tian XY, Huang LF, Bao LH, Wang ML (2002): Effect of intermittent injection of recombinant human parathyroid hormone on bone histomorphometry of ovariectomized rats. Acta Pharmacol Sin 23(7): 659-62 


\section{Danksagung}

Ein besonderer Dank gilt meiner Doktormutter Frau PD Dr. med. Ewa Klara Stürmer für die Überlassung dieser interessanten Aufgabenstellung und die fachlich sehr gute und nette Betreuung. Mit vielfältigen Anregungen, ihrer steten Diskussionsbereitschaft und konstruktiven Kritik hat sie wesentlich zum Gelingen dieser Arbeit beigetragen.

Des Weiteren danke ich Herrn Prof. Dr. med. Klaus Michael Stürmer. Die ihm unterstellte unfallchirurgische Abteilung des Universitätsklinikums Göttingen bot mir vorbildliche Bedingungen für diese wissenschaftliche Arbeit.

Ich danke Herrn Dr. med. Stephan Sehmisch für seine Ratschläge, seine Hilfsbereitschaft und die gute Zusammenarbeit.

Außerdem danke ich Herrn Friedrich Kauer, Frau Ramona Castro-Machguth und Frau Annette Witt für die fachkundige Hilfe bei der Durchführung aller Laborarbeiten und die vielen netten Gespräche.

Ich danke Frau Dr. med. Dana Seidlová-Wuttke und Herrn Prof. Dr. med. Wolfgang Wuttke für die Bereitstellung der Testsubstanzen und die Unterstützung bei der Durchführung des tierexperimentellen Anteils dieser Arbeit. 